\title{
DEVELOPMENT OF TRANSGENIC LIVESTOCK WITH REDUCED MYOSTATIN EXPRESSION USING RNA INTERFERENCE
}

\author{
A Dissertation \\ by \\ KIMBERLY JEAN TESSANNE
}

\begin{abstract}
Submitted to the Office of Graduate Studies of Texas A\&M University

in partial fulfillment of the requirements for the degree of

DOCTOR OF PHILOSOPHY
\end{abstract}

December 2009

Major Subject: Veterinary Physiology 


\title{
DEVELOPMENT OF TRANSGENIC LIVESTOCK WITH REDUCED MYOSTATIN EXPRESSION USING RNA INTERFERENCE
}

\author{
A Dissertation \\ by \\ KIMBERLY JEAN TESSANNE
}

\begin{abstract}
Submitted to the Office of Graduate Studies of Texas A\&M University

in partial fulfillment of the requirements for the degree of

DOCTOR OF PHILOSOPHY
\end{abstract}

\begin{abstract}
Approved by:
Chair of Committee, Mark Westhusin

Committee Members, Charles Long Thomas Spencer

Nancy Ing

Head of Department, Glen Laine
\end{abstract}

December 2009

Major Subject: Veterinary Physiology 


\author{
ABSTRACT \\ Development of Transgenic Livestock with Reduced Myostatin Expression Using RNA \\ Interference. (December 2009) \\ Kimberly Jean Tessanne, B.S., The Ohio State University; \\ M.S., University of Wisconsin-Madison \\ Chair of Advisory Committee: Dr. Mark Westhusin
}

RNA interference (RNAi) is a means of regulating gene expression by targeting mRNA in a sequence-specific manner for degradation or translational inhibition. Short hairpin RNAs (shRNAs) and short interfering RNAs (siRNAs) have been extensively employed for manipulating gene expression in a wide range of species. The goal for this research was to produce transgenic livestock in which myostatin, a negative regulator of muscle growth, has been targeted for silencing by RNAi. This would demonstrate the utility of RNAi for reducing gene expression in large animal species. To successfully target the myostatin gene for reduction, siRNAs were designed to target the both the bovine and caprine myostatin mRNA sequence. These were then tested for effectiveness in vitro using both an HEK $293 \mathrm{~T}$ cell line expressing caprine myostatin as well as adult bovine muscle cells. The most effective siRNA, GDF8-1026, was cloned into a lentiviral plasmid and used to transduce bovine fetal fibroblasts for somatic cell nuclear transfer cloning as well as perivitelline injection of in vitro produced bovine embryos. To date, seven pregnancies have been established using these two methods. 
Concern over the possibility of off-target effects associated with the expression of shRNAs in vivo prompted investigation into tissue-specific expression. Therefore, investigation into the use of a muscle-specific promoter to drive transgene expression was pursued. The bovine myogenin promoter and muscle creatine kinase (MCK) promoter were cloned into a lentiviral plasmid and evaluated in bovine fetal muscle cells and mouse $\mathrm{C} 2 \mathrm{C} 12$ cells in vitro for their ability to drive GFP expression. Both promoters demonstrated an increase in GFP intensity at day nine of differentiation when compared to the nontransduced control.

The retroviral basis of lentiviral plasmids has raised concern over the possible development of replication competent lentivirus (RCL). Therefore, analysis of tissues from recipients of lentivirus-treated embryos was performed to detect possible RCL. Tissues and blood serum were tested for RCL using p24 ELISA as well as qRT-PCR for the VSV-G gene. To date all tissues tested so far shown no evidence for RCL using these analyses. Analysis of offspring transgenic for an shRNA targeting myostatin will allow confirmation of RNAi as a useful tool for manipulating gene expression in large animal species. 


\section{DEDICATION}

This dissertation is dedicated to my family, without whom I would never have been able to make it to where I am today. My parents unending love and support have been vital throughout my educational career. I will be forever grateful for their encouragement during difficult times. My grandparents have contributed to my growth as a student and as a person and will always be in my heart. Thank you to all who have been the backbone of my growth as a student and as a person. 


\section{ACKNOWLEDGEMENTS}

I would like to thank my committee chair, Dr. Westhusin, and my committee members, Dr. Long, Dr. Spencer, and Dr. Ing, for their guidance and assistance throughout the course of my career here at Texas A\&M. I would also like to thank all of the present and past members of the Reproductive Sciences Lab at Texas A\&M University, who were invaluable in this work. In addition, thanks to all of my family and friends for their support during this research program. 
TABLE OF CONTENTS

Page

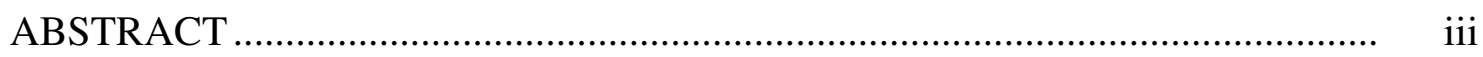

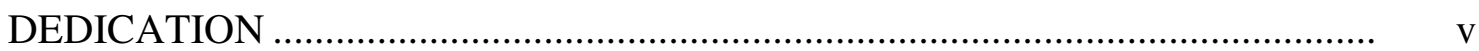

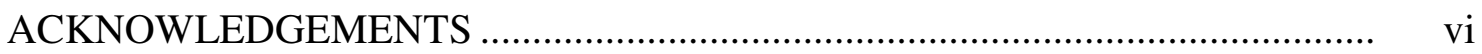

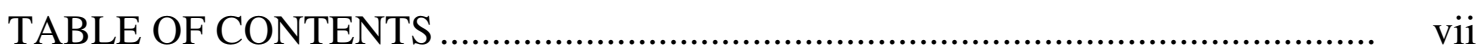

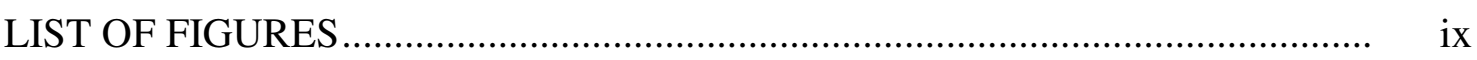

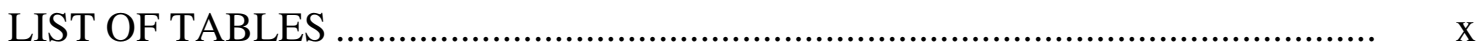

CHAPTER

I INTRODUCTION AND LITERATURE REVIEW ............................ 1

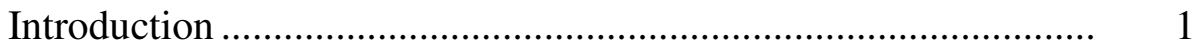

RNA Interference ................................................................... 2

Lentiviral Delivery of shRNAs ................................................... 5

Off-target Effects of RNAi......................................................... 9

Large Animal Research Models ................................................... 12

Development of Transgenic Livestock ………………………..... 15

Myostatin ................................................................................ 18

II IN VITRO SUPPRESSION OF MYOSTATIN ................................... 23

Introduction ....................................................................... 23

Materials and Methods .............................................................. 24

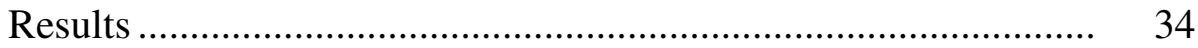

Discussion .......................................................................... 44

Conclusions ........................................................................... 48

III ANALYSIS OF MUSCLE-SPECIFIC PROMOTERS FOR LENTIVIRAL-MEDIATED shRNA EXPRESSION .......................... 50

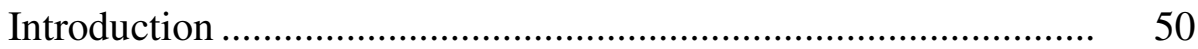

Materials and Methods ................................................................ 51

Results ............................................................................. 54 
CHAPTER Page

Discussion ............................................................................ 59

Conclusions ..................................................................... 61

IV PRODUCTION OF TRANSGENIC ANIMALS WITH REDUCED MYOSTATIN EXPRESSION .................................................. 63

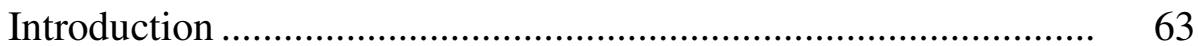

Materials and Methods ....................................................... 65

Results .................................................................... 68

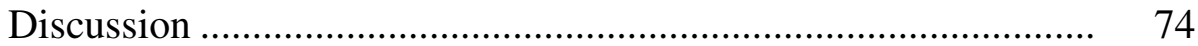

Conclusions ...................................................................... 78

V REPLICATION COMPETENT LENTIVIRUS (RCL) ANALYSIS IN RECIPIENT ANIMALS OF TRANSGENIC EMBRYOS PRODUCED BY LENTIVIRAL TRANSFER ............................... 80

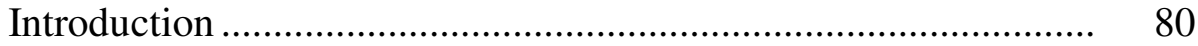

Materials and Methods ........................................................ 82

Results ................................................................. 85

Discussion ..................................................................... 90

Conclusions .................................................................... 92

VI SUMMARY ...................................................................... 93

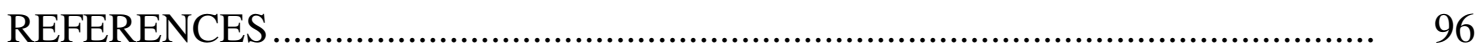

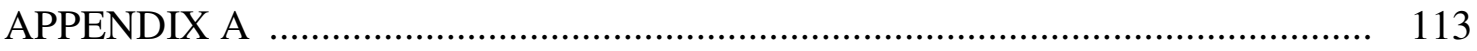

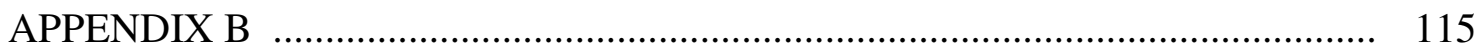

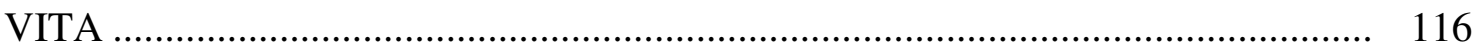




\section{LIST OF FIGURES}

FIGURE

Page

1 HEK 293T cells expressing caprine myostatin as well as an shRNA targeting myostatin.

2 Suppression of myostatin mRNA in vitro

3 Bovine primary muscle cells in culture

38

4 Immunocytochemistry on bovine primary muscle cells.

5 Transduction of primary bovine fetal muscle cells

6 Myotube development in adult bovine muscle cells transfected with siRNAs

7 Expression of bovine myostatin mRNA in primary adult muscle cells .....

8 Map showing insertion of bovine muscle-specific promoters into the G-zeo lentiviral plasmid

9 Expression of GFP in fetal bovine myotubes

10 Mean GFP intensity in fetal bovine and mouse C2C12 cells at day 9 post differentiation

11 Cloned transgenic bovine blastocysts expressing an shRNA targeting the myostatin gene

12 Transgenic bovine cloned fetus and placental tissue.

13 Trangenic in vitro-produced bovine blastocysts produced through perivitelline injection of lentivirus at the zygote stage

14 Transgenic ovine blastocysts and conceptus

15 Immunohistochemistry for GFP at the uterine and placental interface 


\section{LIST OF TABLES}

TABLE Page

1 Sequences of siRNAs designed to target bovine and caprine myostatin ... 34

2 Analysis of bovine fetal tissues for presence of the lentiviral transgene ...

70

3 Production and transfer of transgenic embryos using either somatic cell nuclear transfer or perivitelline injection of in vitro produced zygotes .....

$4 \quad$ Analysis of bovine and ovine recipients and fetuses for RCL using qRT-PCR to detect the VSV-G gene sequence and the p24 ELISA assay

5 Analysis of different tissues collected from bovine and ovine recipients for presence of the lentiviral transgene cassette. 


\section{CHAPTER I}

\section{INTRODUCTION AND LITERATURE REVIEW}

Introduction

Manipulation of gene expression in vivo has become invaluable in furthering our understanding of gene function and the role genes play in development and disease. The majority of this work has been, to date, in mice. This is primarily due to the ability to selectively target genes for silencing using homologous recombination, creating animals in which a gene is "knocked out". However, it has become increasingly evident that larger animal models are also important for studying gene function and disease. Homologous recombination is relatively inefficient in larger species, revealing a need for an alternative tool for altering gene expression. RNA interference (RNAi) may fulfill this need, as it is conserved among all mammalian species and provides a manner of

sequence-specific gene silencing. ${ }^{1,2}$ In addition, recent successes in delivery of shRNAs into livestock species not only demonstrates the utility of this mechanism for studying gene function but also opens up a new realm of transgenic animal development. RNAi, along with the advent of retroviral delivery of shRNAs into mammalian cells, holds promise for the development of large animal transgenics that could contribute both to agriculture and human medicine.

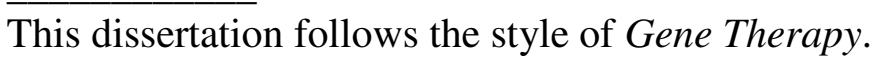


RNA Interference

RNAi is a means of regulating gene expression by targeting mRNA in a sequence-specific manner for degradation or translational inhibition. RNAi was first described in detail by Fire and Mello in C. elegans in $1998 .^{3}$ Since then, the RNAi mechanism has been shown to be highly conserved among drosophila, ${ }^{4}$ fungi, ${ }^{5}$ plants, ${ }^{6}$ and mammals. ${ }^{7}$ Short hairpin RNAs (shRNAs) and short interfering RNAs (siRNAs) have been extensively employed for manipulating gene expression in a wide range of species. Therefore RNAi has become a powerful genetic tool not only for understanding basic gene function but also in developing novel treatments for human disease.

RNA interference was first discovered but not fully understood in work with petunias to improve flower color. Here, additional copies of a pigmentation gene were inserted in order to alter flower color. ${ }^{8}$ The expected outcome of this experiment was for the flowers to be deeper in color, but in fact most flowers were either variegated or white due to "co-suppression" of both the endogenous and added gene copies. The exact mechanism for this suppression was not known. Two years later, work to transform a Neurospora strain with genes for albinism resulted in a silencing of endogenous copies of these genes. This observation was found to be related to the number of exogenous transcripts introduced and was termed "quelling". 5 Still, these examples of endogenous gene silencing were not fully comprehended until work by Fire and colleagues with $C$. elegans utilizing antisense RNAs to reduce gene expression. ${ }^{3}$ It was found that injection of the sense RNA strands, used as a control, also reduced gene expression. What was more surprising was that injection of both the antisense and sense strands together 
resulted in greater gene repression than the use of either alone. Futher investigation into this mechanism led them to describe what is now known as RNA interference.

After its initial description, further investigation into this novel method of gene regulation has identified the general mechanisms behind RNAi. The process is invoked by the presence of double stranded RNA (dsRNA), which triggers the enzyme Dicer to cleave the RNA into short (21-25 nucleotide) pieces termed siRNAs. ${ }^{1}$ The siRNAs are then recognized and loaded into a complex called RISC (RNA-induced silencing complex), which unwinds and preferentially retains one of the strands. This single stranded siRNA strand guides the complex to its complimentary target transcript which, in mammals, triggers silencing by one of two methods. The first induces degradation of the transcript, initiated in part by the protein Argonaute 2. ${ }^{1,9}$ The second is translational inhibition due to physical blockage of translational machinery by the RISC complex. ${ }^{1,10}$

About the same time that siRNA-induced silencing was being discovered, studies of larval development in C. elegans revealed another means of transcriptional gene silencing within the cell. However, unlike siRNAs that are produced within the cytoplasm, this trigger came initially from the nucleus. Found to be encoded by genes throughout the genome, these microRNAs (miRNAs) are transcribed first as long double stranded precursors (pre-miRs). Then, these precursors are processed by the enzyme Drosha to form pri-miRs, which are exported from the nucleus by Exportin-5. ${ }^{10,11}$ The pri-miRs are then recognized by Dicer and processed through the RNAi pathway. However, unlike siRNAs which are identical in sequence to their cognate mRNAs, miRNAs use 5-7 bp seed sequences to target the genes, most often in the ${ }^{\text {' }}$ UTR. ${ }^{12}$ This 
base pairing is usually imperfect and may result in translational inhibition or target instability. ${ }^{10,11}$ This allows one miRNA to control expression of multiple mRNAs in a cell. Hundreds of miRNA genes have been identified since the first, lin-4, was found in C. elegans. ${ }^{13}$ These miRNA genes have been shown to play a role in numerous aspects of physiology, including muscle generation, ${ }^{14,15}$ cardiovascular disease,${ }^{16}$ stem cells, ${ }^{17,18}$ and cancer. $^{19,20}$

Soon after its discovery, the realization that RNAi could be a tool for studying gene expression became apparent. In C. elegans, it was shown that feeding worms bacteria that express siRNAs or simply soaking the worms in a solution containing siRNAs resulted in reduced expression of the target gene. ${ }^{21,22}$ However, in mammals, the use of RNAi to study functional genomics was initially inhibited due to the presence of an endogenous antiviral response induced by the presence of long double-stranded RNA (dsRNA). ${ }^{23}$ It was discovered that these dsRNA molecules activated protein kinase R (PKR) resulting in a general widespread reduction in gene expression through translational repression. Additional induction of RNase L was also found to occur, resulting in nonspecific RNA degradation. ${ }^{24}$

Two methods of introducing siRNAs have been developed to bypass the endogenous interferon response in mammalian cells. The first utilizes chemically synthesized siRNA products $(\sim 21 \mathrm{nt})$ that mimic the siRNAs produced by Dicer. ${ }^{25}$ These induce gene-specific silencing in mammalian cells and have become a useful tool for exploring gene function. However, their effects are usually transient. The second method involves the use of genome integrating vectors to deliver transgenes encoding 19-29 nt 
inverted repeats joined by an intergenic loop sequence. When transcribed in vivo, these repeats anneal to form dsRNA molecules called shRNAs which mimic miRNAs and are processed in a similar manner by Drosha and Dicer to induce gene silencing. ${ }^{25-27}$ In addition, the transgenes are integrated into the genome of the cell, and therefore are replicated and inherited during mitosis. This allows for propagation of shRNA-induced silencing to the resulting daughter cells. Integration of the transgene is especially important when considering in vivo applications, where stable transgene expression is vital for consistent suppression of the target transcript in subsequent generations.

Lentiviral Delivery of shRNAs

The ultimate goal of many in vitro assays for manipulating gene expression is the transition to an in vivo application. In order to make this transition, stable and effective delivery and expression of the transgene is necessary. Multiple methods have been utilized for manipulating gene expression in vivo, including adenoviral and adenoassociated vectors, plasmid DNA, and antisense RNAs. ${ }^{27,28}$ Although effective, expression of a transgene using these systems does not allow for genome integration, resulting ultimately in a localized and transient effect. ${ }^{26,27}$ Without integration, the transgene expression is not maintained throughout cell division, and this limits the usefulness of these methods in long-term experiments. ${ }^{26}$ This has led to the advent of retroviral vectors for transgene expression. Retroviral vectors are designed using elements from a naturally occurring retrovirus, such as human immunodeficiency virus (HIV), feline immunodeficiency virus (FIV), or equine infectious anemia virus (EIAV), 
allowing them to enter the cell as RNA and then reverse transcribe into DNA and integrate into the genome. ${ }^{27}$ This integration, although not targeted, allows for stable transgene expression throughout the life of an animal. In addition, the ability to pseudotype recombinant viral particles using alternative glycoprotein capsids allows for incorporation in a wide range of cell types. ${ }^{27}$ A subclass of retroviruses, called lentiviruses, is of particular interest due to their ability to infect both dividing and nondividing cells. This allows for transgene delivery into a variety of differentiated cells, including neurons, ${ }^{29}$ cardiomycytes, ${ }^{30}$ and hepatocytes. ${ }^{31}$ Moreover, expression of the transgene in the F1 generation from transgenic animals produced using lentiviral vectors suggests a lack of silencing of the transgene in the germline. ${ }^{32}$ This is advantageous over other retroviral systems that have shown a lack of expression both in the F0 and F1 generations. $^{33}$

Lentiviral vectors are designed using exogenous retroviral elements. However, to ensure safe and effective transgene delivery, all of the components that make the virus replication competent are removed, therefore allowing the production of a replicationincompetent viral particle in vitro. ${ }^{34}$ Typically this is accomplished by co-transfection of separate plasmids each encoding the viral genes, the capsid protein, and the lentiviral expression cassette into an immortalized cell line. Lentiviral vectors also contain a selfinactivating 3' long terminal repeat (LTR) region that, when transferred to the 5' LTR during reverse transcription and integration, results in transcriptional inactivation. ${ }^{35,36}$ These precautionary measures are in place to ensure safe, stable, and efficient delivery of transgenes both in vitro and in vivo. Still, there is some trepidation regarding the use of 
lentiviral vectors in both human therapeutics as well as transgenic animal production. Concerns are that recombination with wild-type viruses or endogenous retroviral elements may allow the integrated provirus genome to become a replication competent retrovirus (RCR). Development of RCR has been shown during production of murine retroviral vectors as well as amphotropic vectors. ${ }^{37,38}$ These RCRs were shown to contain sequences from endogenous retroviral elements present in the cell lines used for vector production. In addition, recombination between transfer and packaging plasmids during lentiviral particle production may also result in replication competent lentivirus (RCL). ${ }^{39}$ Therefore, tests to detect these potential RCL are necessary in order to ensure their safety in in vivo applications.

Several different methods currently exist to test for potential RCL from HIVbased lentiviral vectors. The first is a p24 ELISA assay that detects the presence of the p24 HIV antigen. Viral particles that may be produced from an HIV-based vector would be recognized as foreign, and an antigen would then be produced against the p24 viral protein. The p24 assay detects the presence of this antigen in serum. Work by Escarpe et al. (2003) showed that after amplification of potential RCL on a permissive cell line for 6 passages, no p24 was detected. ${ }^{40}$ However, this assay, although effective at detection of p24 antigen, can fail to be sensitive enough when considering the fact that the presence of even one RCL particle must be detected if it is present. PCR-based methods to detect viral gene sequence (ie. gag, pol) integration into the genome as well as and vesicular stomatitis virus glycoprotein (VSV-G) have since been developed. ${ }^{40,41}$ VSV-G 
is often used for pseudotyping recombinant viral particles. ${ }^{27}$ The PCR-based tests are more sensitive, and a combinatorial approach ensures RCL detection if it is present.

One PCR-based test that has been developed detects the potential recombination between the gag gene in the lentiviral packaging vector (used in recombinant lentiviral production in vitro) and the psi packaging signal present in the lentiviral transfer cassette. $^{41}$ Recombination between these two genes could potentially provide the integrated transfer cassette the ability to become replication competent. Sastry et al. developed PCR-based methods to detect any potential RCL from in vitro culture of cells three weeks post-transduction. Cells containing evidence of recombination between the gag gene in the lentiviral packaging vector and the psi signal present in the lentiviral cassette were found in 20 out of 21 tests, indicating transfer of gene sequence from the packaging plasmid to the transfer cassette. However, no evidence of RCL transfer was found when media from cells three weeks post-transduction was added to a naive permissive cell line, establishing that no replication-competent particles were made. A second PCR-based test, designed to detect the presence of the VSV-G gene in the host genome, indicates transfer to the host and evidence of replication, as this gene is only expressed during in vitro production of recombinant lentivirus. ${ }^{42}$ Of these same 21 samples, one was found to be positive for VSV-G by comparison to positive and negative control samples. Again, no RCL transfer was detected on naive cells. The FDA is now recommending the use of these tests in order to monitor RCL in in vitro and in vivo applications that employ lentiviral vectors for transgene delivery. 
Delivery of RNAi using retroviral vectors represents a safe and stable system for expressing shRNAs in vivo. However, RNAi both in vitro and in vivo has also been shown to exhibit silencing not related to the target gene. This off-target silencing can interfere with cell survival and confound experimental gene expression data. In addition, off-target effects can have negative impacts in vivo.

\section{Off-target Effects of RNAi}

The use of RNAi as a means of gene manipulation has provided a valuable tool for research of mammalian gene expression in vitro and in vivo. However, the use of siRNAs and shRNAs has revealed that there can also be unintended off-target gene suppression. Such off-target silencing can confound gene expression data and in vivo has

resulted in cytotoxic effects. ${ }^{43-45}$ According to a review by Svoboda et al., there are three main ways in which these off-target effects can occur in mammalian cells. ${ }^{24}$ These include 1) activation of endogenous antiviral response (interferon response), 2) seed sequence complimentarity, and 3) saturation of enzymes required for the RNAi pathway. All three are important to consider when designing an experiment involving the use of RNAi for gene silencing.

Probably the most well-known means of off-target gene silencing in mammalian systems is activation of the interferon response. The interferon response is a mammalian cellular defense mechanism present to guard against invasion by foreign material, often viral RNA that is reverse transcribed into DNA prior to insertion into the host genome. The primary enzyme activated is PKR, which blocks cellular protein translation by 
phosphorylating the translation initiation factor eIF2 $\alpha$. This results in a genomewide downregulation of gene expression. ${ }^{23,24}$ In addition, lack of a two nucleotide 3' overhang on siRNAs introduced through transfection has been shown to trigger the interferon response through induction of the RNA helicase RIG-1. ${ }^{24}$ Activation of the interferon pathway can be avoided to an extent by the use of short (19-29 nt) double stranded RNAs with 3' overhangs. However, induction of this response is not always eliminated, as interferon-stimulated gene expression, including PKR, has been shown after transfection of short siRNAs. ${ }^{23}$

Another potential source of off-target silencing is through imperfect sequence homology with nontarget genes, resulting in suppression through the microRNA pathway. This pathway utilizes short regions of homology called seed sequences, often in the 3'UTR of mammalian genes. ${ }^{12}$ The siRNAs present in the cytoplasm of the cell and loaded into the RISC complex may also guide it to these unintended genes, annealing to them and causing translational repression of the mRNA. Examples of this kind of off-target gene suppression are numerous. Transfection of an siRNA designed to target the firefly luciferase gene upregulated expression of 1154 genes and downregulated 689 when measured using an Affymetrix genechip array. ${ }^{46}$ However, the concentration of siRNA transfected affected what genes were altered. Similarly, an siRNA targeting GFP was also shown to decrease expression of endogenous genes in vitro using both microarray and quantitative real-time PCR analysis (qRT-PCR). ${ }^{47}$ Additionally, work using siRNAs targeting the MEN1 gene, a tumor suppressor gene, also reduced the expression of p21 and p53 protein levels in multiple cell lines. ${ }^{43}$ The 
mRNA levels of the repressed genes were minimally altered, suggesting a translational inhibition indicative of the miRNA pathway.

Saturation of the enzyme Dicer and proteins the compose the RISC complex can also lead to unintended gene silencing. ${ }^{24}$ The presence of excess siRNAs in the cell would alter endogenous miRNA processing and therefore control of gene expression. Yi et al. (2005) demonstrated that transfection of a construct expressing the exportin-5 protein, which aid in the export of pre-miRs and expressed shRNAs out of the nucleus, increased processing of mir30a as well as in vitro transcribed shRNAs. ${ }^{48}$ This suggests that shRNA mediated RNAi-induced silencing may saturate the Exportin-5 gene, a key step in endogenous miRNA pathway.

Off-target effects have also been reported with in vivo RNAi experiments using mice. Work evaluating sustained expression of shRNAs targeting the luciferase firefly gene in the livers of mice induced toxicity. ${ }^{49}$ Morbidity was associated with downregulation of miRNAs, suggesting inhibition of this pathway in the liver. Moreover, work to inhibit the Huntington's disease (HD) gene in the mouse brain through expression of shRNAs was effective at reducing HD gene expression in vivo but also induced toxicity. ${ }^{50}$ The control shRNA, while resulting in no measurable decrease in HD, also induced toxicity. Interestingly, when the shRNAs targeting HD were instead expressed as an artifical microRNA, toxicity was greatly reduced. These reports suggest it is important it is important to consider methods to reduce off-target effects of shRNA expression in vivo as well as in vitro. 
Although the majority of in vivo experiments like those discussed above have been to date in mice, it is becoming increasingly apparent that larger models may be necessary for some disorders. Demand for the development of larger animal models is growing, and these models may provide valuable insight into animal and human disease.

\section{Large Animal Research Models}

Mouse knockout models have provided valuable information to study a plethora of human disorders such as asthma, ${ }^{51}$ cardiovascular disease, ${ }^{52,53}$ fertility, ${ }^{54,55}$ and diabetes. ${ }^{56}$ Although mouse knockout models have provided insight into human genetic disorders, they often do not mimic the human form of the disease, making inferences difficult. In addition, mouse models are short lived and do not allow for longevity studies. Their inbred background is also not congruent with the heterogeneity of humans, and therefore effects that are seen in mouse models may not translate to human medicine. ${ }^{57}$ Work in breast cancer research has revealed the creation of a rat knockout model for breast cancer in which the BRCA1 and BRCA2 genes were silenced through random mutation followed by mutational screening. ${ }^{58}$ This is significant because rats can more closely model human cancers, and rat knockout models have been largely unsuccessful using more conventional methods. However, both homologous recombination and mutational screening techniques are inefficient and costly in larger animal models. Therefore there is a growing need of alternative methods for suppressing genes in species other than rodents. 
Larger animal models have for the most part been discouraged due to the difficulty of genetic manipulations and increased maintenance costs. However, recent research is demonstrating the importance of these larger models. ${ }^{59}$ Body and organ size as well as blood volume more closely match humans than mouse models. ${ }^{59}$ Studies of retinal degeneration, ${ }^{60,61}$ hemophelia, ${ }^{60,62}$ and muscular dystrophy ${ }^{60,63}$ in dogs has become invaluable for human medicine. The canine model has become increasingly useful in modeling human genetic disorders, with more than $58 \%$ of genetic diseases in dogs having a human orthologue. ${ }^{57}$ Swine have also become a valuable large animal model for cardiovascular disease, as their coronary anatomy and cardiac conduction are similar to humans. ${ }^{64}$ Additionally, their heart size to body weight ratio is identical to that of humans. ${ }^{64}$ A swine model of cystic fibrosis has also been developed, allowing a more in depth investigation of this disease. ${ }^{65}$ Sheep models of intrauterine growth restriction (IUGR) have been developed, and their larger size has allowed for repeated samplings of uterine and fetal vasculature. ${ }^{66}$ The sheep IUGR model mimics many of the characteristics of the human form of this disorder, allowing for a greater understanding of its role during human pregnancy.

In addition to creating animal models for studying human disease, large animal transgenics also have applications in gene therapy and xenotransplantation. Successful production of human therapeutics in the milk of transgenic cattle, ${ }^{67}$ goats, ${ }^{68,69}$ and sheep ${ }^{70}$ has paved the way for new pharmaceutical production. The approval for the first recombinant human protein for treatment of a clotting disease isolated from the milk of transgenic goats has been reported this year. ${ }^{71}$ Additionally, work to inactivate genes 
involved with human rejection of porcine transplants is ongoing as swine most closely match humans in the size and physiology of the heart and other organs. ${ }^{64,72}$ Successful production of transgenic pigs with a deletion of the alpha $(1,3)$ galactosyl transferase (GalT) gene involved in organ rejection has now been reported. ${ }^{73}$ This may allow the production of organs for xenotransplantation without rejection.

In addition to contributing to human disease, these models can also extend to agricultural species. Animals in which the prion protein $(\mathrm{PrP})$ gene has been suppressed or deleted have been produced, providing potential resistance to scrapie and bovine spongiform encephalitis. ${ }^{74,75}$ The development of disease resistant animals could have a dramatic impact on agriculture, especially in developing countries. Moreover, transgenic dairy cattle have been created which produce the bacterial enzyme lysostaphin in their milk, protecting them from mastitis. ${ }^{76}$ Mastitis costs American dairy producers approximately two billion dollars annually. ${ }^{77}$ Therefore animals resistant to this disease would have a great impact in the US.

Although there is an increasing demand for large animal transgenics, production of these animals is more difficult. Longer generation intervals mean higher maintenance and housing costs and more time waiting for evaluation of genetic manipulations. Traditional gene knockout strategies are very inefficient due to heterogeneity. However, in some agricultural species, reproductive techniques such as in vitro fertilization (IVF), embryo culture, somatic cell nuclear transfer, and micromanipulation have been extensively developed. ${ }^{78}$ These have allowed for the development of embryonic transgene delivery techniques such as lentiviral delivery and cloning of transgenic cell 
lines to effectively create transgenics. Since gene knockout techniques fail to work efficiently in larger species, RNAi provides an opportunity for manipulation of gene expression. The universal nature of RNAi suggests an adaptability of this technique to larger organisms where traditional methods such as gene knockouts have been relatively unsuccessful.

Development of Transgenic Livestock

In order to incorporate a transgene into a large animal species, several methods have been employed, including pronuclear injection, ${ }^{79}$ somatic cell nuclear transfer, ${ }^{73,80-}$ ${ }^{86}$ and retroviral transfer. ${ }^{75,87-93}$ Until recently, pronuclear injection was the method of choice for livestock species, where recombinant DNA was injected into the pronuclei of zygotes in order to incorporate the transgene into the genome of the developing embryo. ${ }^{79,94}$ However, the relatively low efficiency and requirement for breeding in order to obtain homozygous founders have prompted development of alternative methods for producing transgenic livestock. In addition, isolation and transformation of embryonic stem (ES) cells through homologous recombination have been used extensively for the production of transgenic mice. ${ }^{95,96}$ However, to date there have been no reports of ES cell isolation in livestock species, limiting its use to rodents at this time.

The creation of "Dolly" and the advent of somatic cell nuclear transfer cloning provided an alternative means of transgenic animal production. ${ }^{97}$ With this method, adult-derived somatic cells, often skin fibroblasts, are first transformed to create a transgenic cell line which in turn is recombined with an enucleated oocyte. ${ }^{78}$ This 
recombination produces a zygote in which all of the nuclear DNA is contributed by the transgenic cell. Therefore, embryos produced from this method are transgenic. A variety of cell types (ie. embryonic, fetal and adult) and methods of introducing the transgene have been used to date, the most recent of these being a retroviral vector. This method has been used successively to produce a variety of transgenic animals, including dog, ${ }^{91}$ cat, ${ }^{92,93}$ pig, ${ }^{98,99}$ and cow. ${ }^{100}$ However, although these animals carry the transgene in all cells of their body and are capable of germline transmission, the drawbacks associated with SCNT also can complicate the creation of transgenic animals using this method.

One obstacle in creating transgenic livestock using SCNT cloning is the low survival rate of cloned animals. Efficiencies of clone production in livestock range from only $1-5 \%{ }^{101,102}$ Most embryonic loss is early in gestation and in large part is believed to be due to the epigenetic misregulation of genes expressed in the fetus or placenta. ${ }^{103}$ In cattle, commonly seen defects include the complete absence or severe lack of placentome formation, with malformed caruncules and cotyledons often seen when they do develop to term as well as reduced vascularization. ${ }^{104}$ In addition, the phenomenon referred to commonly as large offpring syndrome is seen frequently in clones, most often with cattle. This results in increased fetal weight and can be accompanied by edema, hepatocephaly, and hydrocephalus. ${ }^{103,104}$

Another method of creating transgenic livestock is retroviral gene transfer into oocytes and embryos prior to transfer. This method utilizes retroviral vectors, most often lentiviral vectors, in order to incorporate the transgene into the genome prior to cell division and subsequent development of the embryo. Infective recombinant lentivirus 
can be injected into an oocyte or zygote prior to embryo transfer in order to get complete incorporation of the transgene into the embryo genome by the first cell division. This method was first reported in the production of transgenic swine by Hoffman et al. (2003) using lentiviral injection into in vivo derived one-cell embryos. ${ }^{88}$ The transfer of transduced zygotes resulted in six pregnancies and the birth of 46 offspring, $70 \%$ of which were confirmed transgenic. Analysis of tissues by fluorescence microscopy revealed transgene expression in all tissues. Further work with bovine oocytes and embryos demonstrated successful transduction of both and production of transgenic bovine offspring. ${ }^{100}$

Lentiviral injection of oocytes or embryos, although successful at bypassing issues associated with cloning, requires a high titer of recombinant lentivirus $\left(\geq 10^{9}\right.$ infectious units (IU)/mL) in order to obtain incorporation. Extremely small volumes of virus are injected, therefore the chance of a recombinant lentiviral particle actually entering the embryo is very small. However, analysis of integration site and number by Hofmann et al. showed that multiple integrations occurred, ranging from 1-20 copies of the transgene. ${ }^{88}$ This could be problematic in that integration into the genome is not targeted and could therefore potentially interrupt endogenous gene function. Additionally, incorporation of the lentiviral cassette after the first cell division may result in mosaic expression of the transgene, which would then require additional breeding to obtain germline transmission and complete transgenesis. Therefore timing of lentiviral infection is also important to producing a transgenic animal with this method. 
However, this method, along with SCNT, provides a means of producing transgenic animals that may prove important additions to the agricultural and medical fields.

Myostatin

Myostatin, or Growth Differentiation Factor 8 (GDF8), is a negative regulator of muscle growth. In a mouse knockout model of myostatin, mice display a distinct increase in muscle mass and differentiation. ${ }^{105}$ Furthermore, breeds of cattle such as the Belgian Blue and Piedmontese, which display dramatically increased muscle mass, have been shown to possess mutations in the myostatin gene. ${ }^{106-108}$ Myostatin has been shown to be involved in the growth and differentiation of muscle and bone in humans, ${ }^{109}$ and has important implications for human health in developing therapeutics for muscle wasting diseases such as muscular dystrophy. This protein's most notable effect is on the hypertrophy and hyperplasia of muscle fibers, both pre- and postnatally.

Myostatin is a member of the TGF $\beta$ superfamily. It is first translated as a precursor protein consisting of a propeptide and a mature peptide joined by an RXRR cleavage site. Post-translational cleavage of this protein into the latent associated peptide (LAP) and mature forms followed by dimerization of both the LAP and the mature peptide and non-covalent binding of the two, forms the latent complex. This complex is then secreted by the cell. Proteolytic cleavage from the propeptide is required for the dimer to bind to its receptor, activin receptor type II $\beta$ (and to a lesser extent II $\alpha$ ), and act through the Smad 2/3 pathway. ${ }^{110}$ Regulation of action can occur through different binding proteins that in turn can inactivate myostatin. These include follistatin and 
follistatin related gene (FRG) as well as metalloproteinases such as those in the BMP1/Tolliod family. ${ }^{111}$ In fact, the use of myostatin binding proteins has been employed to develop therapeutics for such muscle wasting disorders as muscular dystrophy (MD) and amyotrophic lateral sclerosis (ALS). ${ }^{112,113}$

Myostatin is primarily expressed in skeletal muscle, and has been found to be expressed not only during development but throughout an animal's adult life. In 1997, McPherron and colleagues reported the production of a myostatin knockout mouse. ${ }^{105}$ This mouse displayed a similar phenotype to that seen with double muscled cattle breeds, which included a 200\% increase in muscle hypertrophy and hyperplasia of muscle fibers. Soon after, mutations in the myostatin gene were found to be the cause of double muscling in Belgian Blue and Piedmontese cattle. Belgian Blue cattle were found to possess an 11 nucleotide deletion in the third exon which causes a frameshift and a mutant protein. ${ }^{106,108}$ Similarly, Piedmontese have also been found to have a mutation in the third exon, substituting a tyrosine for an invariant cysteine. ${ }^{106,107}$ To date, naturally occurring mutations causing inactivation of the myostatin gene have also been documented in sheep, ${ }^{114-116}$ dogs, ${ }^{117,118}$ and humans. ${ }^{109}$ In all cases, an extreme increase in muscle mass is observed. The double muscling phenotype in cattle, unlike the knockout mouse, has since been shown to result primarily from hyperplasia.

Additionally, tissue-specific and postnatal knockouts of this gene in mice have shown that the underlying causes of this increase can vary. In a mouse overexpressing a dominant negative form of myostatin with the muscle creatine kinase (MCK) promoter, a increase in muscle mass of $35 \%$ was found, all due to hypertrophy. ${ }^{119}$ However, in a 
Cre/lox knockout in which myostatin was inactivated postnatally, a similar increase in muscle was seen, but the source (hypertrophy vs. hyperplasia) was dependent on the muscle examined. ${ }^{120}$ In addition, it has been demonstrated in both mice and cattle that the effects of inactivating myostatin exhibit hemizygosity, with an approximate $50 \%$ increase in muscle mass with those carrying one inactivated copy of the gene.

The cellular actions of myostatin have not been unequivocally established, but many in vitro studies have revealed insight into its action in the cell. Myostatin has been shown to have a negative effect on myoblast growth and differentiation in culture. When exogenous recombinant myostatin was added to $\mathrm{C} 2 \mathrm{C} 12$ mouse muscle cells in culture, proliferation was inhibited in a dose-dependent fashion. ${ }^{121-123}$ Further analysis revealed that myostatin prevented the transition from the G1 to $\mathrm{S}$ phase of the cell cycle by upregulating p21, a cyclin-dependent kinase inhibitor, as well as inhibiting Cdk2. This inhibition was also shown to occur in fetal bovine myoblasts. However, once C2C12 cells were switched to a low-serum media to induce differentiation, exogenous myostatin inhibited upregulation of myogenic factors such as MyoD and Myf5 as well as p21, delaying differentiation. ${ }^{123,124}$ This delay was shown to be reversible in culture. This suggests a role for myostatin in myoblast growth as well as muscle fiber formation.

Experimental suppression of myostatin in vitro and in vivo also lends support to its role in muscle development. An antisense approach to inhibit endogenous myostatin in $\mathrm{C} 2 \mathrm{C} 12$ cells also demonstrated a decrease in $\mathrm{p} 21$, leading to increased proliferation and a protection from apoptosis. ${ }^{123}$ In addition, overexpression of myostatin decreased MyoD as well as myogenin protein expression, whereas antisense reduction of myostatin 
increased transcription of both genes. In vivo work expressing an shRNA targeting the myostatin gene in mice resulted in increased tibialis anterior weight when injected or electroporated into the muscle. ${ }^{125}$ Muscle fiber size was increased by $34 \%$, and satellite cell number doubled.

Myostatin has been found to regulate muscle development in part by the inhibition of muscle satellite cell recruitment during development as well as after injury. Satellite cells are myogenic progenitor cells, capable of both self-renewal and activation. Myostatin has been found to localize to Pax-7 positive satellite cells both in culture and alongside isolated muscle fibers. ${ }^{126,127}$ In a study of satellite cell activation in myostatin null mice versus wild type, a higher number of satellite cells from the knockout mice were activated to enter $S$ phase of the cell cycle. ${ }^{126}$ In addition, steady state numbers of satellite cells in muscle fibers isolated from myostatin null mice were higher as assessed by migration in vitro and CD34 staining. Satellite cells isolated from mature wild type and myostatin null mice were also evaluated for their potential to withdraw from the cell cycle when induced to differentiate in culture. ${ }^{128}$ Addition of differentiation medium stimulated over two-thirds of wild type cells to withdraw from the cell cycle after 6 hours, as measured by pulsing with BrdU. In contrast, over $50 \%$ of myostatin null cells still remained in S phase. Although their withdrawal was delayed, eventually these cells did enter differentiation within 48 hours. Increasing amounts of myostatin added to myostatin null satellite cells in culture also reduced proliferation to a rate consistent with wild type satellite cells, suggesting that myostatin helps to maintain satellite cell quiescence. 
In order to demonstrate the effectiveness of RNAi as a means for gene suppression in animals other than mice, a gene with an established phenotype is desirable. Due to the effects of myostatin suppression in vitro and inactivation in vivo, it is reasonable to consider this gene as a model for this demonstration. If suppression of myostatin expression through RNAi is effective, the phenotype would be expected to be visual and similar to that of naturally occurring mutations. In addition, the effect of this reduction would not be expected to be lethal due to the viability of knockout animals. Therefore, this research focused on two aims. The first was the production of genetically modified cattle expressing an shRNA targeting the myostatin gene. In addition, the use of a lentiviral vector for delivering shRNAs led to the second aim of this research. In order to establish the safety of lentiviral vectors in production of transgenic livestock, animals serving as recipients of transgenic embryos were analyzed for evidence of RCL. Lack of RCL detection would reinforce the safety of using a lentiviral system to deliver transgenes for expression in vivo. 


\section{CHAPTER II}

\section{IN VITRO SUPPRESSION OF MYOSTATIN}

Introduction

RNAi has proved useful as a tool for manipulating gene expression in vitro as well as in vivo. ${ }^{11}$ In order to demonstrate the utility of RNAi in large animal species, the myostatin gene was chosen as a target. Myostatin mutations occur naturally in a number of species and result in a visible increase in muscle mass. ${ }^{109,114-118}$ In addition, a mouse knockout of the myostatin gene results in a similar phenotype. ${ }^{105}$ Therefore, targeting this gene in vivo through RNAi should not be lethal, and, if successful, the phenotype should be readily quantifiable.

Myostatin is primarily expressed in skeletal muscle, and is expressed during development and throughout an animal's adult life. ${ }^{110}$ In vitro studies using exogenous myostatin have shown that myostatin works in part by inhibiting myoblast proliferation through an increase in p21 levels. ${ }^{121}$ Additionally, a delay in myotube formation was seen when the same recombinant protein was added to $\mathrm{C} 2 \mathrm{C} 12$ mouse cells in a low serum media designed to induce differentiation. ${ }^{124}$

The bovine species was chosen because the phenotype of myostatin null mutations has already been well characterized. ${ }^{106}$ Therefore the effect of shRNAmediated suppression should be easy to evaluate. In addition, since the length of gestation in cows is long (270-290 days), the caprine model was also considered. Goats have a shorter gestation length (150 days) and are cheaper to maintain. In order to 
effectively target the myostatin gene in vivo, siRNAs were designed against bovine and caprine coding sequences for myostatin. Resulting siRNA sequences were designed as 97 bp oligonucleotides and cloned into a lentiviral plasmid. These shRNA cassettes were then tested for their ability to reduce myostatin expression in an HEK 293T cell line (an immortalized human cell line) transformed to express recombinant caprine myostatin.

Four siRNA sequences were cloned into a lentiviral plasmid as shRNAs, and all four were found to effectively suppress caprine myostatin mRNA expressed in HEK 293T cells. To further test the most effective siRNA at targeting bovine myostatin mRNA, fetal and adult bovine muscle cells were isolated and characterized. Adult satellite cells were utilized for siRNA analysis using the most effective sequence, and an 80-95\% reduction of bovine myostatin mRNA was achieved in primary bovine muscle cells.

Materials and Methods siRNA design and cloning of shRNAs into the PEF-green lentiviral plasmid

The bovine and caprine myostatin coding sequences were aligned using the ClustalW alignment program (www.clustalw.genome.ad.jp) and regions of sequence identity were identified. These regions were loaded into an siRNA design program at www.biopredsi.org. Resulting sequences were then checked for nonspecific targets using BLAST. Unique siRNA sequences were modified for cloning into the PEF-green lentiviral plasmid (Appendix A) by adding mir30 sequence on either side (http://katahdin.cshl.org:9331/homepage/siRNA/RNAi.cgi?type=shRNA). 
Oligonucleotides were ordered (Integrated DNA Technologies) and amplified through PCR with primers (Appendix B) to add the remaining mir30 sequence as well as XhoI and EcoRI restriction enzyme recognition sites on the 5' and 3' ends, respectively. Amplifications were performed with $10 \mathrm{X}$ Pfx 50 buffer, $2.5 \mathrm{mM}$ dNTPs, $25 \mu \mathrm{M}$ each forward and reverse primer, 0.5 units Pfx50 polymerase (Invitrogen), and 100ng oligo in a $50 \mu 1$ reaction. Cycling conditions consisted of an initial denaturing step at $95^{\circ} \mathrm{C}$ for 3 minutes, followed by 25 cycles of $95^{\circ} \mathrm{C}$ for 30 seconds, $58^{\circ} \mathrm{C}$ for 30 seconds, and $68^{\circ} \mathrm{C}$ for 30 seconds. After a final extension of $68^{\circ} \mathrm{C}$ for 5 minutes, products were run on a $2 \%$ agarose gel to check amplification and gel extracted using a gel extraction kit (QIAGEN). Restriction digests were set up with either 15.8 $\mu 1$ purified PCR product or $5 \mu \mathrm{g}$ of PEF-green plasmid, 10X NEB EcoR1 buffer, $1 \mu \mathrm{l}$ each EcoR1 and Xho1 enzyme (NEB), and bovine serum albumin (BSA) in a $20 \mu 1$ reaction. Digestions were carried out at $37^{\circ} \mathrm{C}$ for 1 hour. After 45 minutes, $1 \mu 1$ of calf intestinal phosphatase (CIP) was added to the plasmid digestion to prevent recircularization of the plasmid. Digested plasmid was run on a $1.2 \%$ agarose gel and extracted using the QIAGEN gel extraction kit. Digested PCR products were purified using a gel extraction kit (QIAGEN) with the following alterations: $3 \mathrm{X}$ volume of QG buffer and $1 \mathrm{X}$ volume of isopropanol was added to the reaction before the entire volume was applied to the column. Products were quantified using a spectrophotometer. Ligations were performed using a 3:1 molar ratio of insert to vector with Quick ligase (NEB) in a $20 \mu 1$ reaction. Ligations were carried out at room temperature for 5 minutes and then put on ice. Ligated plasmids were transformed into Stbl2 chemically competent E. coli (Invitrogen) and plated onto agar 
plates containing $25 \mu \mathrm{g} / \mathrm{mL}$ zeocin and $50 \mu \mathrm{g} / \mathrm{mL}$ ampicillin. Plates were incubated overnight at $30^{\circ} \mathrm{C}$. Colonies were plucked the following day and grown overnight in $5 \mathrm{~mL} \mathrm{LB}$ broth with $25 \mu \mathrm{g}$ zeocin and $50 \mu \mathrm{g}$ ampicillin at $30^{\circ} \mathrm{C}$. Plasmids were purified using the QIAGEN Miniprep kit and eluted in 50 $\mu 1$ water. Plasmids were digested as above with EcoR1 and Xho1 to check for insert, and positive preps were sent for sequencing. Plasmids confirmed through sequencing were labeled as PG (for the PEFgreen lentiviral plasmid) and the corresponding number of the siRNA that was cloned into it as an shRNA (ie. PG57 contains GDF8-57 expressed as an shRNA). Positive clones were grown in $50 \mathrm{~mL}$ LB broth with $25 \mu \mathrm{g}$ zeocin and $50 \mu \mathrm{g}$ ampicillin overnight at $30^{\circ} \mathrm{C}$. Stocks were made in $15 \%$ glycerol and frozen at $-80^{\circ} \mathrm{C}$. Plasmids were purified using the QIAGEN Midiprep kit, resuspended in $100 \mu 1$ water and stored at $-20^{\circ} \mathrm{C}$.

Cloning of caprine myostatin and production of HEK 2937 cells expressing recombinant myostatin

The caprine myostatin coding sequence was previously isolated from goat muscle cDNA and cloned into the pcDNA3.1 plasmid (Invitrogen). This coding sequence was then PCR amplified using primers designed to add EcoR1 and BamH1 restriction sites on each end. PCR was performed using 10X PCR buffer, 10mM dNTPs, $25 \mu \mathrm{M}$ each forward and reverse primer, $0.5 \mu \mathrm{g}$ plasmid, and 0.5 units PlatinumTaq $\mathrm{HiFi}$ polymerase (Invitrogen) in a $25 \mu 1$ reaction. PCR was carried out with an initial denaturing step of $95^{\circ} \mathrm{C}$ for 3 minutes followed by 30 cycles of $95^{\circ} \mathrm{C}$ for 30 seconds, $55^{\circ} \mathrm{C}$ for 30 seconds, and $72^{\circ} \mathrm{C}$ for 1 minute. After a final extension at $72^{\circ} \mathrm{C}$ for 10 minutes, amplified product was run on a $2 \%$ agarose gel and gel extracted using the 
QIAGEN gel extraction kit. The purified PCR product $(5 \mu 1)$ and the pEIT lentiviral

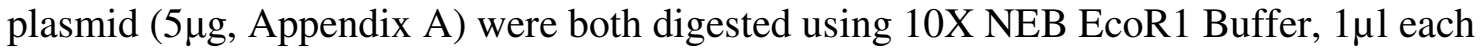
EcoR1 and BamH1 and BSA in a $20 \mu \mathrm{l}$ volume for 1 hour at $37^{\circ} \mathrm{C}$. Digested products ran on a $2 \%$ agarose gel, the appropriately sized bands were excised, and products were purified using the QIAGEN gel extraction kit. Products were eluted in $30 \mu 1$ water and quantified using a spectrophotometer. Ligations were performed using a 3:1 molar ratio of insert to vector with Quick ligase (NEB) in a $20 \mu 1$ reaction for 5 minutes at room temperature. Ligations were then put on ice and transformed into TOP10 chemically competent cells (Invitrogen). Transformed cells were plated on agar plates containing $50 \mu \mathrm{g}$ ampicillin and incubated overnight at $37^{\circ} \mathrm{C}$. The following day colonies were plucked and grown in $5 \mathrm{~mL}$ LB broth with $50 \mu \mathrm{g}$ ampicillin overnight at $37^{\circ} \mathrm{C}$. Plasmids were purified using the QIAGEN Miniprep kit and eluted in 50 $\mu 1$ water. Plasmids were digested with EcoR1 and BamH1 to confirm insert.

Recombinant lentivirus was produced as described by Miyoshi et al. (1998) using the pEIT lentiviral plasmid containing the caprine myostatin coding sequence. ${ }^{35}$ Lentiviral plasmid $(10 \mu \mathrm{g})$ was co-transfected into HEK 293T cells along with $10 \mu \mathrm{g}$ pCMV R8.91 (packaging plasmid) and $1 \mu \mathrm{g}$ pMDG (plasmid expressing the VSV-G gene) in order to make recombinant lentivirus. Transfections were carried out in $100 \mathrm{~mm}$ dishes that were $80-90 \%$ confluent. Plasmid DNA was combined with $36 \mu 12 \mathrm{M} \mathrm{CaCl}_{2}$ in a $300 \mu 1$ volume, and then $300 \mu 12 X$ Hepes Buffered Saline (HBS), pH 7.05 with $0.6 \%$ Dextran was added. Mixtures were vortexed and added dropwise to cells. Media was refreshed 18 hours later with DMEM/F12 with $10 \%$ fetal bovine serum and gentamicin 
plus $10 \mathrm{mM}$ sodium butyrate. Supernatant was collected 48 hours later, centrifuged for 5 minutes at $300 \mathrm{X} \mathrm{g}$ to pellet cellular debris, and filtered through a $0.45 \mu \mathrm{m}$ syringe filter. HEK 293 T cells were transduced using media containing lentivirus plus $8 \mu \mathrm{g} / \mathrm{mL}$ polybrene (hexadimethrine bromide) for 16-20 hours. Transgenic cells were confirmed using fluorescence microscopy to detect expression of the red fluorescent protein present in the pEIT plasmid (Appendix A). Transgenic cells were harvested for RNA using the RNeasy kit (QIAGEN)., and the Superscript III one-step kit (Invitrogen) was used to confirm myostatin mRNA expression.

Transient transfection of PEF-green lentiviral plasmid constructs into HEK 2937 cells expressing recombinant caprine myostatin

HEK 293T cells expressing recombinant caprine myostatin were plated into 6well plates at $90 \%$ confluence on the day of transfection. PEF-green lentiviral plasmid containing either an shRNA targeting myostatin or a nontargeting control shRNA $(5 \mu \mathrm{g})$ was combined with $6.3 \mu 12 \mathrm{M} \mathrm{CaCl}_{2}$ in a $50 \mu 1$ volume, and then an equal volume of $2 \mathrm{X}$ HBS was added. Complexes were vortexed for 15 seconds prior to being added dropwise to cells. Media was refreshed 18 hours later. Transfection efficiencies were estimated using fluorescence microscopy to detect expression of GFP present in the PEF-green plasmid. Cells were maintained in culture for four days before being harvested for RNA isolation.

Isolation and culture of primary bovine muscle cells

Fetal cells were isolated from approximately 60-90 day bovine fetuses as previously described with modifications. ${ }^{129}$ The muscles in the fore- and hindlimbs were 
isolated using a scalpel, cut into 5-8mm pieces, and rinsed in PBS. Tissue sections were incubated in $0.25 \%$ Trypsin-EDTA in $\mathrm{PBS}$ at $37^{\circ} \mathrm{C}$ with shaking for $40 \mathrm{~min}$ to 1 hour. The cells were then pelleted by centrifugation ( 5 minutes at $300 \mathrm{xg}$ ), supernatant was removed and cells were resuspended in DMEM/F12 supplemented with 15\% FBS, 50 $\mu \mathrm{g} / \mathrm{mL}$ gentamicin and $2.5 \mathrm{mg} / \mathrm{L}$ amphotericin prior to transfer to $75 \mathrm{~mm}^{2}$ flasks. During the initial myoblast isolation, recovered cells were preplated for 20 minutes at $37^{\circ} \mathrm{C}$ to enrich for myoblast cells, and this enrichment was repeated at each subsequent passage. To induce fusion into myotubes, cells were switched to a low serum media to induce differentiation containing $2 \%$ horse serum.

Satellite cells were isolated from adult muscle tissue explants as previously described with modifications. ${ }^{130}$ Skeletal muscle was obtained from a local slaughterhouse and trimmed to remove connective tissue. Pieces were rinsed briefly in chlorhexidene and then twice in DMEM/F12 with 15\% FBS plus gentamicin and amphitericin. Tissue was plated in collagen-coated $25 \mathrm{~mm}^{2}$ flasks, 3-4 pieces per flask. Media was refreshed one day later, and then flasks were maintained at $37^{\circ} \mathrm{C}$ with $5 \%$ CO2. Satellite cells began migrating out of the explants 7-10 days later. At the first passage, cells were preplated for 20 minutes at $37^{\circ} \mathrm{C}$ to enrich for myoblast cells, and this enrichment was repeated at each subsequent passage. Cells were cultured in DMEM/F12 with 15\% FBS and gentamicin. To induce fusion into myotubes, cells first plated in fibronectin-coated wells and then switched to a low serum media containing $2 \%$ horse serum. An alternative protocol was also used in which muscle fibers were isolated in DMEM/F12 with 15\% FBS under a dissecting microscope using fine-tipped 
forceps. Media with fibers was then pipetted several times through a $10 \mathrm{~mL}$ serological pipette, pelleted by centrifugation ( 5 minutes at $300 \mathrm{xg}$ ), resuspended in fresh media, and plated on collagen-coated flasks. This also resulted in isolation of adult muscle satellite cells.

Immunocytochemistry to characterize primary bovine muscle cells

Muscle cells were plated on glass cover slips at a density of 50,000 cells/slip in a 24-well plate. Cover slips were first treated with concentrated (8M) $\mathrm{HCl}$ for 15 seconds and rinsed twice in distilled water in order to remove oils on the slide. Cells were cultured one day for labeling of proliferating cells, or grown to confluence and then differentiated for three days prior to labeling of myotubes. Cells were rinsed with PBS and fixed using cold methanol for 10 minutes. Then cells were permeabilized with $0.2 \%$ Triton X-100 in PBS for 30 minutes at $37^{\circ} \mathrm{C}$ and then blocked overnight at $4^{\circ} \mathrm{C}$ with blocking buffer. Blocking buffer consisted of $0.1 \%$ Triton X-100, $1 \%$ BSA, and $1 \%$ goat serum in PBS. Cells were labeled with the appropriate dilution of primary antibody in blocking buffer for 30 minutes at $37^{\circ} \mathrm{C}$ : desmin (ab6322-100, 1:200). After three washes in blocking buffer for 10 minutes with rocking, the appropriate secondary antibody was diluted in $0.1 \%$ Tween-20 in PBS and added for 30 minutes at $37^{\circ} \mathrm{C}$. For desmin labeling an anti-mouse Alexa fluor antibody (either 568 or 488) was used at a dilution of 1:200. Coverslips were washed 3 times for 10 minutes each with rocking in $0.1 \%$ Tween-20 in PBS, then mounted on slides with DABCO and 20\% glycerol plus Hoechst in PBS and sealed with clear nailpolish. Fluorescence intensity was compared to samples with no primary antibody added to control for background fluorescence. 
Production of lentivirus with PEF-green lentiviral plasmid constructs and transduction of primary bovine muscle cells

Recombinant lentivirus was produced as described by Miyoshi et al. (1998) using the PG1026 construct or a nontargeting construct. ${ }^{35}$ Lentiviral plasmid $(10 \mu \mathrm{g})$ was co-

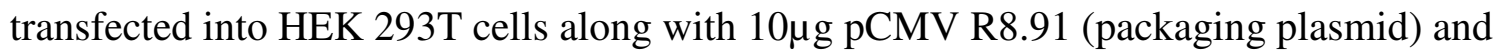
$1 \mu \mathrm{g}$ pMDG (plasmid expressing the VSV-G gene) in order to make recombinant lentivirus. Transfections were carried out in $100 \mathrm{~mm}$ dishes that were $80-90 \%$ confluent. Plasmid DNA was combined with $36 \mu 12 \mathrm{M} \mathrm{CaCl}_{2}$ in a $300 \mu \mathrm{l}$ volume, and then $300 \mu \mathrm{l} 2 \mathrm{X}$ Hepes Buffered Saline (HBS), pH 7.05 with 0.6\% Dextran was added. Mixtures were vortexed and added dropwise to cells. Media was refreshed 18 hours later with DMEM/F12 with $10 \%$ fetal bovine serum and gentamicin plus $10 \mathrm{mM}$ sodium butyrate. Supernatant was collected 48 hours later, centrifuged for 5 minutes at $300 \mathrm{xg}$ to pellet cellular debris, and filtered through a $0.45 \mu \mathrm{m}$ syringe filter. Filtered supernatant was either used for transduction or aliquoted and frozen at $-80^{\circ} \mathrm{C}$ until needed. Concentrated lentivirus was produced by ultracentrifugation using a Beckman Model L8M80 ultracentrifuge with an SW-28 rotor. Centrifugation was performed at 50,000 $\mathrm{xg}$ for 1.5 hours at $4^{\circ} \mathrm{C}$, and recombinant lentivirus was resuspended in phophate buffered saline (PBS). Primary muscle cells were transduced using media containing lentivirus combined with $8 \mu \mathrm{g} / \mathrm{mL}$ hexadimethrine bromide (polybrene). For transductions with concentrated lentivirus, a 10-fold dilution was first performed prior to media being added to muscle cells. Transductions were performed for either 6-8 hours or 16-20 hours, and media was then refreshed. Transgenic cells were visualized using 
fluorescence microscopy to detect expression of GFP present in the PEF-green plasmid. Transgenic cells were selected using puromycin $(0.5 \mu \mathrm{g} / \mathrm{mL})$ for three days prior to being harvested for mRNA isolation using the RNeasy kit (QIAGEN).

Transient transfection of siRNAs into bovine adult satellite cells

One day prior to transfection, early passage bovine adult satellite cells were plated at a density of either 40,000 (for proliferation) or 80,000 (for differentiation) cells/on fibronectin-coated 12-well plates. On the day of transfection, either 20nM or 50nM of siRNA (GDF8-1026 or Cy3 control) was combined with $3.5 \mu 12 \mathrm{M} \mathrm{CaCl}_{2}$ in a $30 \mu \mathrm{l}$ volume, and then an equal volume of $2 \mathrm{X}$ HBS was added. Complexes were vortexed for 15 seconds prior to being added dropwise to cells. Media was refreshed 18 hours later. For differentiation, DMEM/F12 plus $2 \%$ horse serum was added.

Transfection efficiencies were based on $\mathrm{Cy} 3$ control fluorescence. Cells were maintained in culture for four days before being harvested for RNA isolation.

RNA isolation and real-time quantitative PCR analysis

RNA was isolated from transient transfections and transductions mentioned above using the RNeasy kit (QIAGEN). Cells were lysed in 350 $\mu 1$ RLT buffer with $1 \%$ betamercaptoethanol. The lysed cells were homogenized either by vortexing for 1 minute or being drawn through a 20 gauge needle five times. After precipitation with $70 \%$ ethanol, binding to the column by centrifugation and washing with RW buffer, an on-column DNase digestion was performed. After two washes with RPE buffer, RNA was eluted with $20 \mu 1$ DEPC-treated water. RNA was quantified using a spectrophotometer, and $0.5 \mu \mathrm{g}$ RNA was added to a $20 \mu 1$ reaction to synthesize cDNA 
using either the qScript kit (Quanta Bio) or Superscript III cDNA Synthesis kit (Invitrogen). Quantitative real-time PCR (qRT-PCR) reactions were set up in triplicate using $10 \mu 1$ either Perfecta (Quanta Bio) or Power Sybr Green mastermix (Applied Biosystems), $5 \mu 1$ cDNA diluted first 10 -fold, and $5 \mu 1$ primer mix $(2 \mu \mathrm{M})$. Cycling conditions were as follows: $95^{\circ} \mathrm{C}$ for 10 minutes, 40 cycles of $95^{\circ} \mathrm{C}$ for 10 seconds, $60^{\circ} \mathrm{C}$ for 30 seconds, and $72^{\circ} \mathrm{C}$ for 30 seconds. A melt curve analysis followed, with temperature increments of $0.3^{\circ} \mathrm{C}$ from $65^{\circ} \mathrm{C}$ to $95^{\circ} \mathrm{C}$. Primers for qRT-PCR were either taken from the literature or designed using Applied Biosystems Primer Express software. To determine primer efficiency, a relative standard curve was analyzed using a dilution series of the appropriate cDNA.

Real-time PCR data analysis

qRT-PCR data was analyzed using the $\Delta \Delta \mathrm{Ct}$ method with comparison to GAPDH as an internal control. The difference between the average $\mathrm{Ct}$ value for GAPDH and the $\mathrm{Ct}$ values for each myostatin replicate was calculated, and then the difference between this and the maximum $\Delta \mathrm{Ct}$ was calculated to obtain the $\Delta \Delta \mathrm{Ct}$ for each replicate. These were then compared to the $\Delta \Delta \mathrm{Ct}$ for the transgenic control replicate to determine fold change in mRNA levels. Mean fold change values were tested using one-way ANOVA with a Tukey test for differences between means. 
Results

Design and testing of shRNAs targeting bovine and caprine myostatin

Four shRNAs targeting both the bovine and caprine myostatin coding sequences were designed using the Biopredsi program, three of which align to the propeptide portion of the mRNA (bases 1-828) and one that aligns to the mature portion (bases 8291147). The sequences of the siRNAs are listed in Table 1. Each siRNA sequence was named for the gene they target (GDF8) and the position within the coding sequence that they begin (ie. GDF8-57 begins at base 57). These siRNAs were then analyzed using the BLAST program (NCBI) to check for specificity. All four were confirmed to target the myostatin gene in Bos taurus and Capra hircus. In addition these siRNAs were found to align to this gene in other species as well. These siRNA sequences were used to create shRNAs which were then amplified and cloned into the PEF-green lentiviral plasmid (Appendix A). This plasmid contains a GFP reporter to confirm expression as well as a puromycin gene for antibiotic selection of transgenic cells.

Table 1 Sequences of siRNAs designed to target bovine and caprine myostatin SiRNA Sense Strand

\begin{tabular}{|c|l|}
\hline GDF8-57 & caguggaucugaaugagaatt \\
\hline GDF8-181 & caguaaacuucgccuggaatt \\
\hline GDF8-545 & gguacaagguauacuggaatt \\
\hline GDF8-1026 & caaagaugucuccaauuaatt \\
\hline
\end{tabular}


Myostatin suppression in HEK293T-myo cells

In order to test the effectiveness of the shRNAs targeting the myostatin gene, an immortalized human cell line (HEK 293T) was engineered to express the caprine myostatin gene. This cell line was then named 293T-myo. The four lentiviral plasmids encoding the siRNAs listed in Table 1 (PG57, PG181, PG545, and PG1026) as well as a transgenic control shRNA targeting the firefly luciferase gene (PGLUC) were transfected into the HEK 293T cells expressing recombinant caprine myostatin.

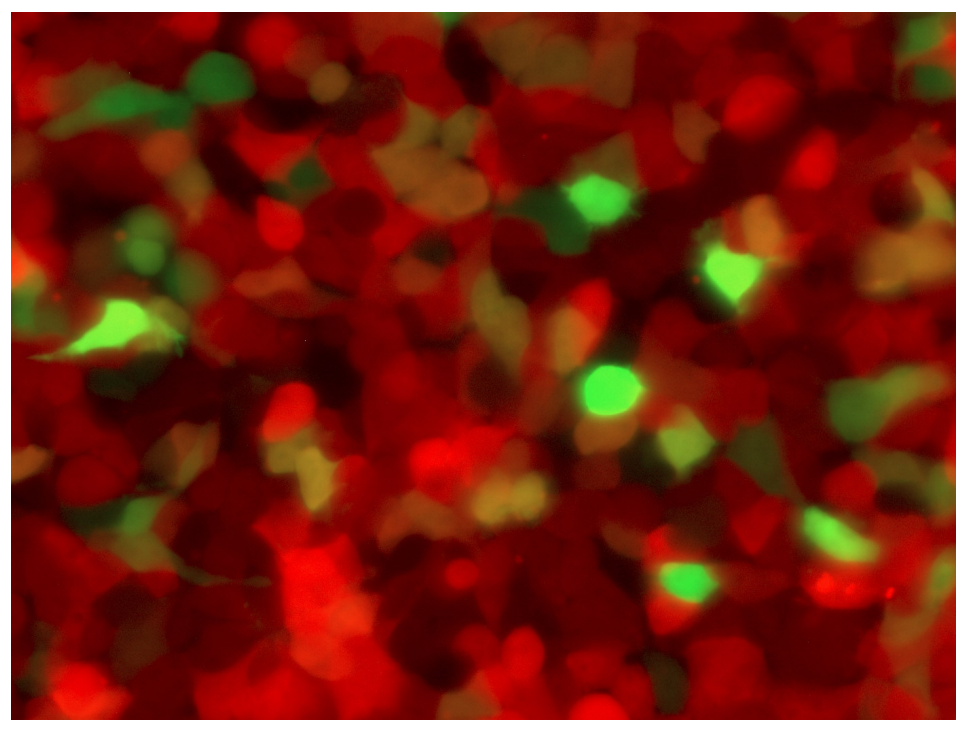

Figure 1 HEK 293T cells expressing caprine myostatin as well as an shRNA targeting myostatin. Cells were first transduced with a lentivirus containing the caprine myostatin gene, then transfected with lentiviral plasmids containing shRNAs targeting either myostatin or a nonsense control shRNA. red $=$ expression of caprine myostatin, green $=$ PEF-green plasmid containing an shRNA targeting myostatin. 


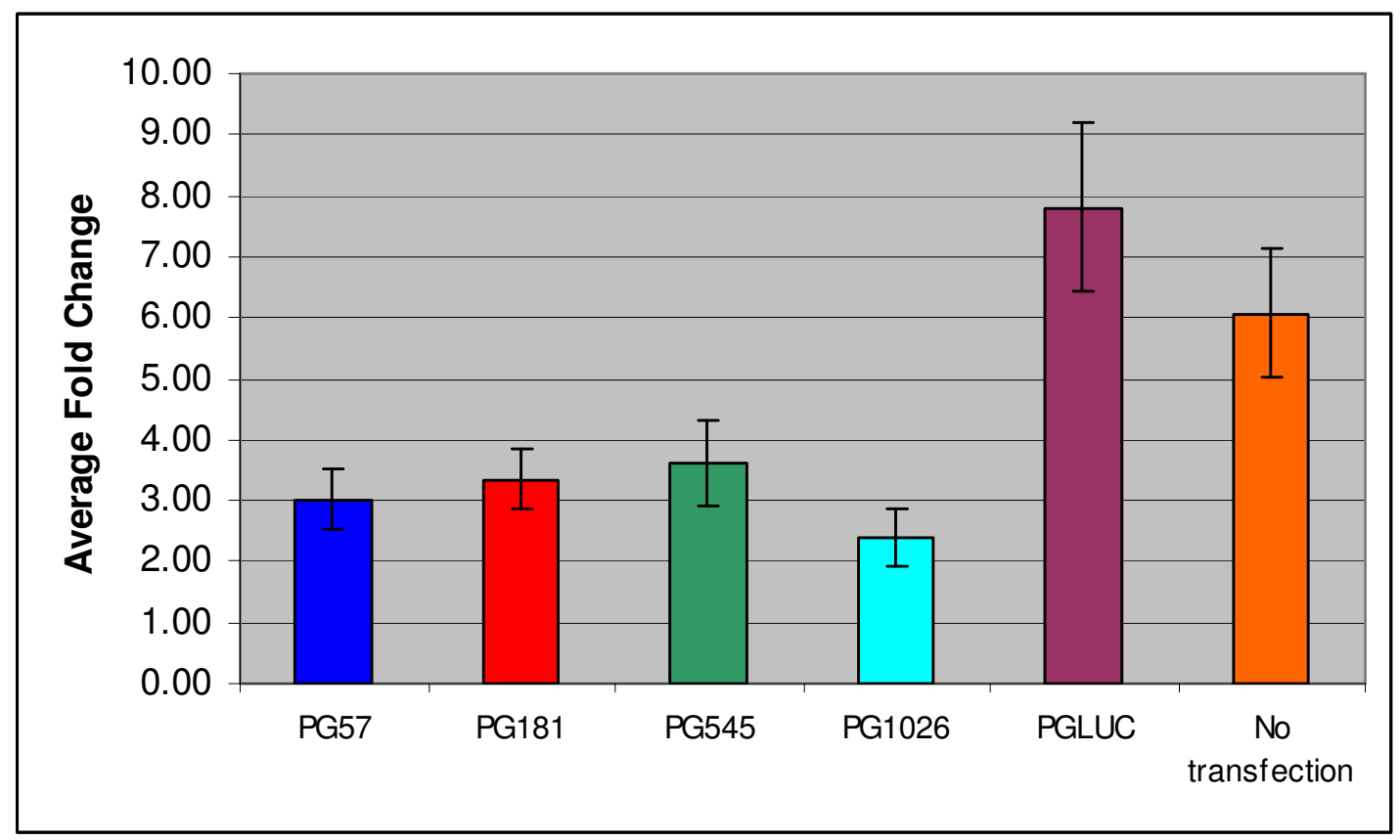

Figure 2 Suppression of myostatin mRNA in vitro. Average fold change in caprine myostatin mRNA as compared to GAPDH as an internal control after transfection with PEF-green plasmids. PG57, PG181, PG545, and PG1026: plasmids containing shRNAs targeting myostatin, PGLUC: plasmid containing a nonsense shRNA targeting luciferase, no transfection: baseline expression of myostatin in the HEK 293T cell line.

Transfection efficiencies among wells and replicates were consistent and averaged 50$60 \%$ as assessed by GFP fluorescence (Figure 1). Transfections were replicated twice and qRT-PCR analysis was performed on each experiment. All four shRNAs targeting the myostatin gene showed effective suppression of myostatin mRNA levels when compared to the transgenic control PGLUC (Figure 2). The amount of myostatin mRNA in 293T-myo cells with no transfection was not significantly different from cells transfected with PGLUC, confirming that the reduction was not due to transfection 
alone. One-way ANOVA revealed expression of myostatin mRNA in cells transfected with each shRNA targeting myostatin was significantly different from the transgenic control $(\mathrm{P}<0.05)$. Due to the fact that the level of myostatin expression in the 293T-myo cell line does not reflect physiological levels expressed in muscle, the most effective shRNA construct from this experiment, PG1026, was chosen for evaluation in primary muscle cells.

Isolation and culture of primary bovine muscle cells

In order to test the effectiveness of the PG1026 construct against endogenous expression of myostatin, primary bovine muscle cell cultures were established. Fetal bovine muscle cells were isolated from bovine fetal muscle tissue excised from 60-90 day fetuses. Cells tended to be spindle-shaped but could not be visually distinguished from fibroblasts in culture (Figure 3). Since fibroblasts are always present in enzyme digestions of muscle due to connective tissue, cultures needed to be enriched for myoblasts versus fibroblasts. A technique termed preplating was utilized to enrich myoblast cultures, taking advantage of the fact that fibroblast cells attach more quickly than myoblasts. ${ }^{131}$ However, when cells that had adhered during the preplating treatment were cultured to confluence, myotube formation was seen. Therefore myoblasts were also present in these cultures. In addition to myotube formation, desmin labeling was also used to characterize these cells. Immunocytochemistry was performed in order to determine the extent of desmin positive cells. Desmin is a type III intermediate filament protein expressed in fetal myoblasts as well as adult myogenic precursors. ${ }^{126,132}$ Desmin labeling on primary bovine muscle cells cultures after preplating were $>90 \%$ desmin 
positive, indicative that this is in fact a fetal bovine myoblast population of cells (Figure 4).

A)

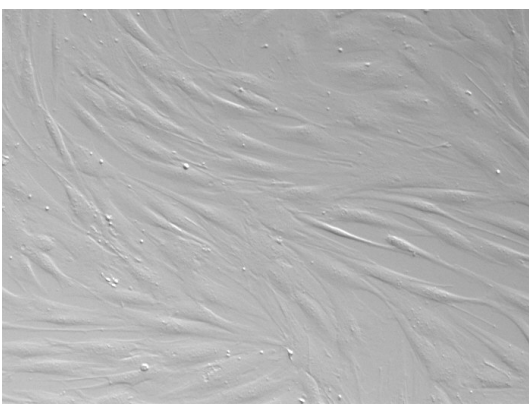

C)

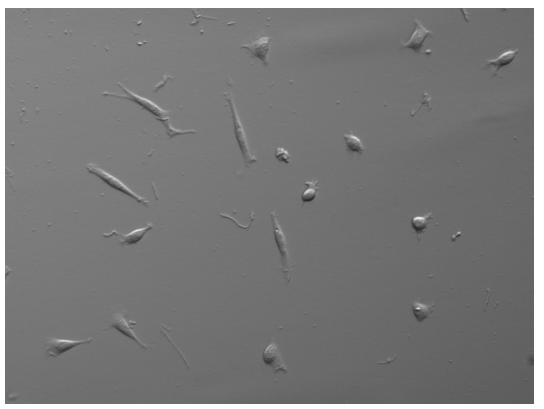

B)

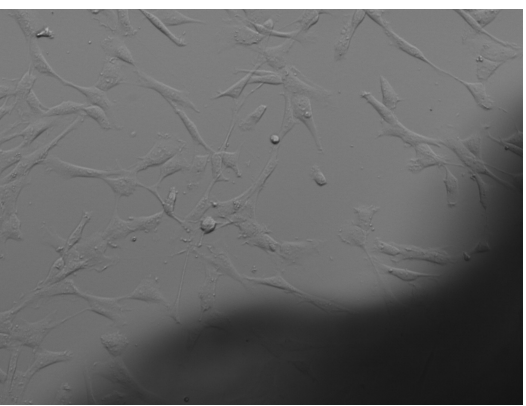

Figure 3 Bovine primary muscle cells in culture. Primary cells isolated from either fetal bovine muscle (A), bovine adult muscle using the explant method (B), or from adult bovine muscle using the fiber isolation methods.

Primary adult muscle cells were isolated from mature bovine muscle both through muscle fiber isolation and from explants cultured in vitro. Both methods resulted in a large proportion of muscle cells, however cells could be repeatedly harvested from explant cultures for up to two weeks after initial growth was seen. Muscle cells began migrating out of explant cultures and plating down after 7-10 days in culture. These cells grew more slowly than fibroblasts and were round to spindle shaped in appearance 
(Figure 3B). When these cells were induced to differentiate in vitro, extensive myotube formation was seen, indicative that these were indeed myogenic cells. However, in order to characterize these cells, immunocytochemistry was utilized. Adult myogenic

A)

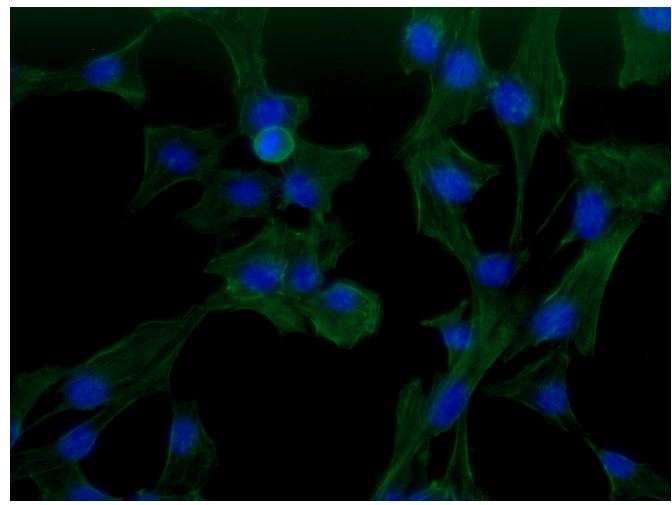

B)

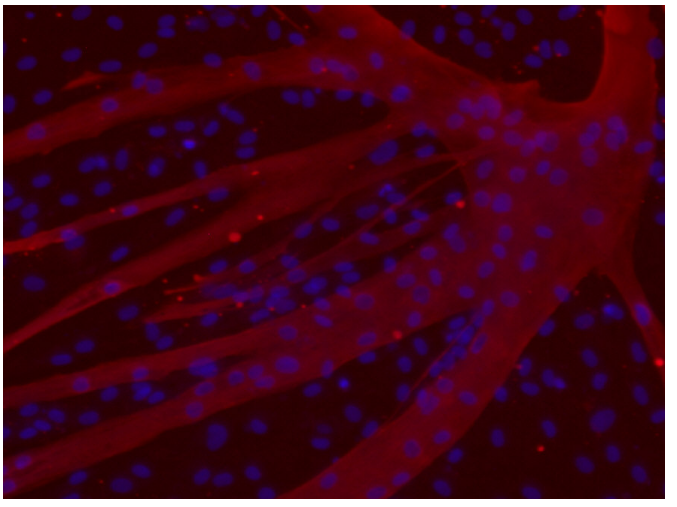

Figure 4 Immunocytochemistry on bovine primary muscle cells. A)

Immunofluorescence labeling for desmin in bovine fetal muscle cells, B) labeling for desmin in adult bovine myotubes. red $=$ desmin, blue $=$ Hoescht nuclear counterstain .

precursor cells express desmin as mononuclear cells, whereas satellite cells do not express desmin until they are fused into myotubes. ${ }^{126}$ Desmin labeling was negative in mononuclear cultures of these cells. However, when induced to differentiate, desmin labeling was strong and localized specifically to multinucleated myotubes, indicating that these cells are most likely satellite cells. Further attempts to label these cells with antibodies to myostatin and the differentiation factor Myf-5 were unsuccessful due to lack of an effective antibody for either bovine protein. 


\section{Transduction of primary bovine myoblasts}

In order to test shRNA expression once it is stably integrated into the cell, recombinant lentivirus was produced (titer $\sim 1 \mathrm{X} 10^{6}$ infectious units $[\mathrm{IU}] / \mathrm{mL}$ ) and used to transduce bovine fetal myoblasts in culture. This transgene expression is more reflective of expression in vivo, providing a more complete picture of the myostatin suppression expected in a transgenic animals expressing the shRNA construct. The highest percentage of GFP positive cells $(\sim 60 \%)$ was achieved with a 16-20 hour transduction with $8 \mu \mathrm{g} / \mathrm{mL}$ polybrene. However, this also induced a large amount of cell death. Cells that did survive this manner of transduction had a high proportion of large, flat, senescent cells that ceased to proliferate. In order to improve cell survival and maintain the proliferative state of these cells, the transduction time was reduced to 6-8 hours. Since the majority of retroviral infection should occur by this time point, a major reduction in efficiency was not expected based on previous experiments. As expected, transduction rates remained at 50-60\%. In addition, cell survival and morphology improved, and myoblasts continued to proliferate after transduction. Addition of

$0.5 \mu \mathrm{g} / \mathrm{mL}$ puromycin for three days resulted in cultures that were greater than or equal to 90\% GFP positive (Figure 5). GFP positive cells were cultured to confluence and induced to differentiate by addition of a low-serum media. As expected, myotube formation was seen in cultures of lentivirally transduced myoblasts, and some of these myotubes expressed GFP.

In order to improve transduction efficiency further, lentiviral particles were concentrated prior to addition to myoblast cultures. Concentration resulted in titers $\geq 10^{9}$ 
IU/mL. As expected, a 16-20 hour transduction time resulted in a proportion of cells either dying or becoming senescent. However, transduction for 6-8 hours was successful at reducing this occurrence. In addition, initial transduction rates improved to $70-80 \%$ as determined by GFP expression. Cell morphology was also maintained, and when cells were grown to confluence and induced to differentiate, myotube formation was seen. However, multiple attempts to characterize myostatin expression in these cells after transduction using qRT-PCR failed, with Ct values $>35$ for all transduced samples regardless of the shRNA being expressed. The efficiency of transduction for adult

A)

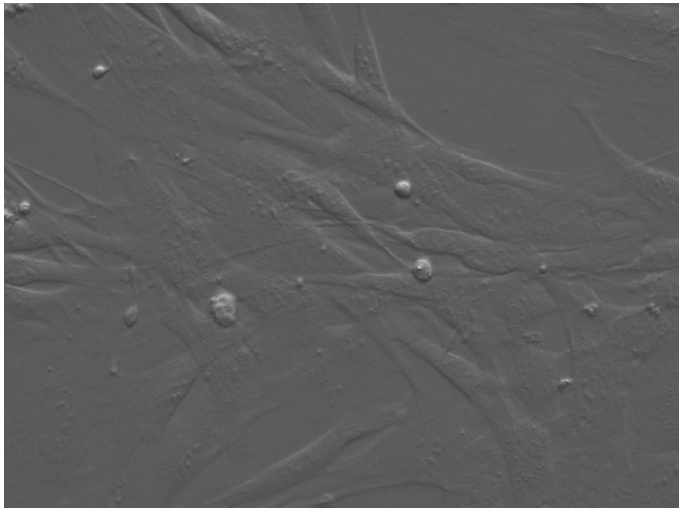

B)

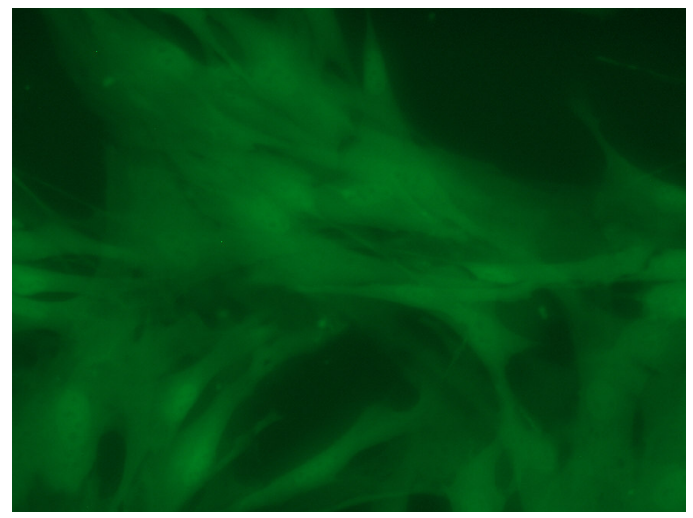

Figure 5 Transduction of primary bovine fetal muscle cells. Cells were transduced with lentivirus made using the PG1026 lentiviral plasmid, then selected with puromycin for 3 days. A) brightfield image, B) fluorescent image.

muscle cells was also investigated. Unlike the fetal myoblasts, cell death and senescence were seen after transduction for both 16-20 hours as well as 6-8 hours. Proliferation ceased and cells did not differentiate after being switched to low serum media. Due to 
the negative impact of transduction on these cells and the inability to evaluate mRNA levels afterwards, transfection experiments utilizing siRNAs were pursued instead. Evaluation of myostatin suppression in adult bovine muscle cells using siRNAs

Due to the inability to successfully detect myostatin suppression after transduction of primary muscle cells, an siRNA approach was investigated. The GDF81026 siRNA or a nontargeting control Cy3-labeled siRNA was transfected into adult bovine muscle cells using the calcium phosphate transfection method. This resulted in a transfection efficiency of $>90 \%$ as assessed by Cy3 fluorescence. Furthermore, little to no cell death or senescence was seen with this method. When switched to the low serum media, cells differentiated into multinucleated myotubes, with notable accumulation of the Cy3 label within these myotubes. Although not quantified, there appeared to be more

A)

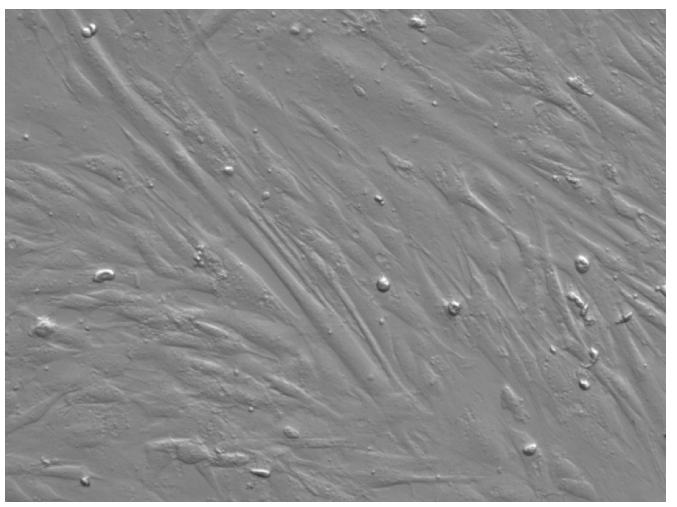

B)

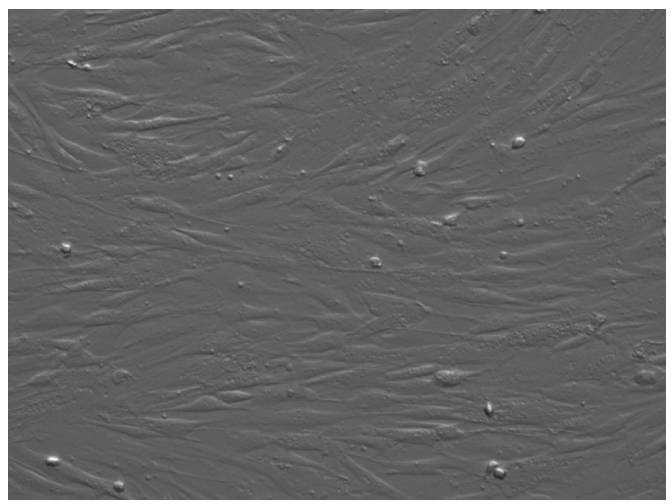

Figure 6 Myotube development in adult bovine muscle cells transfected with siRNAs. Cells were transfected with 50nM siRNA, then allowed to proliferate and differentiate in culture for 4 days. A) GDF8-1026 siRNA, B) nontargeting control Cy3 siRNA. 
abundant myotube development observed in wells transfected with the GDF8-1026 siRNA versus those with the $\mathrm{Cy} 3$ control (Figure 6). Analysis by qRT-PCR revealed a dramatic decrease in myostatin expression in adult muscle cells transfected with the GDF8-1026 siRNA versus the Cy3 control for both the $20 \mathrm{nM}$ and 50nM concentrations, with suppression ranging from 80-95\% (Figure 7). However, the level of myostatin mRNA in cells that were not transfected was significantly lower than that of the Cy3 control.

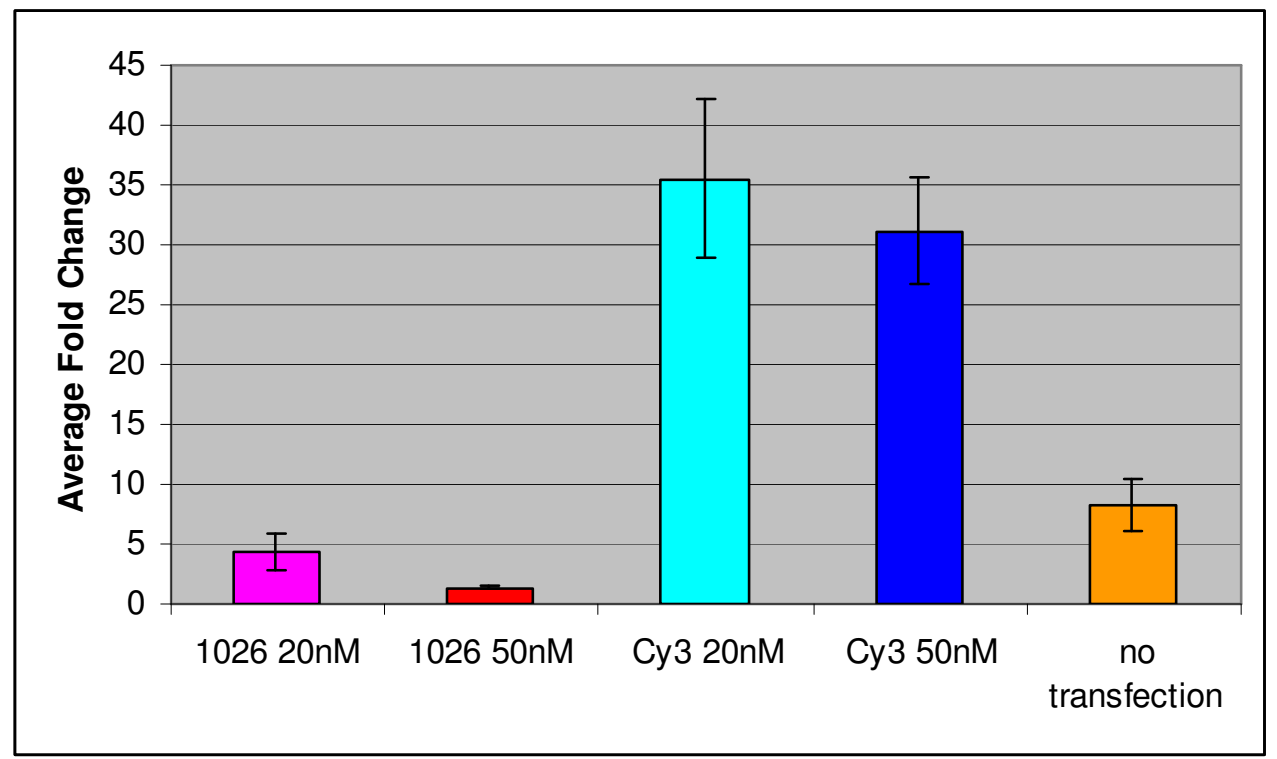

Figure 7 Expression of bovine myostatin mRNA in primary adult muscle cells. Average fold change in bovine myostatin mRNA as compared to GAPDH as an internal control after transfection with either the GDF8-1026 siRNA (20nM or 50nM) or the nontargeting control Cy3 siRNA (20nM or 50nM). 


\section{Discussion}

In order to demonstrate the utility of RNAi in a large animal species, the myostatin gene was chosen. However, due to the similarity of gene sequence between different species, the siRNAs designed to target the bovine and caprine myostatin gene sequences were found to also target this gene in a wide variety of animals. This further emphasizes the value of RNAi as a tool for manipulating gene expression. RNAi can potentially provide the ability to suppress the same gene across multiple species. In the case of the myostatin gene, suppression could prove to be a valuable agricultural tool, resulting in more meat production per animal. Additionally, siRNAs that also match human sequence may become valuable therapeutically for investigation into antimyostatin drug development to treat such disorders as muscular dystrophy and muscle wasting. Therefore once an effective siRNA is found in one species, it may also be effective in suppressing gene expression in other species if the siRNA sequence matches.

The HEK 293T cells expressing recombinant myostatin provided a means of evaluating the effectiveness of the designed shRNAs without the need for manipulation of a difficult to transfect primary cell line. In addition, it demonstrated effectiveness across species. However, the level of myostatin expression in these cells, while stable, was likely not physiological. In addition, the amount of plasmid DNA transfected was also not reflective of the normal cellular transcription level of shRNAs integrated using a lentiviral system. Therefore, there was still a need to demonstrate this same suppression in a primary cell line. This necessitated isolation and culture of primary muscle cells. 
Both fetal and adult muscle cells were successfully isolated from bovine muscle by modifying previously described protocols. ${ }^{129,130}$ Fetal myoblasts were confirmed through positive staining for the desmin protein with immunocytochemistry as well as myotube formation. A preplating protocol was used to enrich for myoblasts versus fibroblasts, as fibroblasts are expected to plate onto the flask quickly. However, it was found that this was only marginally effective as myotube formation was also seen in cultures derived from cells that had plated down onto the flask during the preplating treatment. This demonstrates the need for a more effective protocol for bovine myoblast enrichment. Fetal myoblasts were able to be maintained in culture up to passage five, when they tended to cease proliferation and spontaneously differentiate. Fetal myoblasts were also successfully cryopreserved, and these cells maintained their ability to proliferate and differentiate once thawed.

Adult muscle cells were also successfully isolated from tissue explants as previously described. ${ }^{130}$ These muscle cells were postulated to be satellite cells through their lack of desmin staining in the proliferative state, but positive staining when differentiated into multinucleated myotubes. However, further attempts to characterize these cells failed. This was due to the difficulty in finding antibodies that react well with bovine proteins. Manipulation of adult satellite cells proved more difficult, as they would spontaneously differentiate in culture and did not cryopreserve well. Adult muscle cells also did not transduce efficiently and often became senescent when transduced. Various agents have been previously shown to be effective in transfecting primary muscle cells. ${ }^{133,134}$ When transfected using the calcium phosphate method, little to no 
cell death or senescence was seen in adult satellite cell cultures. Cells continued to proliferate and differentiate after treatment. This allowed for evaluation of mRNA expression in bovine primary muscle cells.

Fetal myoblasts were effectively transduced using both raw and concentrated lentiviral particles using the 6-8 hour transduction. Longer transduction times resulted in visible cell death as well as the presence of senescent cells that would not proliferate or differentiate. Additionally, transduction of adult muscle cells gave a similar result regardless of the transduction time. Lentiviral transduction of primary muscle cells has been shown previously in mice ${ }^{135,136}$ and pigs. ${ }^{137}$ Work in mice to express a minidystrophin via lentiviral-mediated delivery resulted in greater than $90 \%$ transduction of both myoblasts as well as differentiated myotubes. ${ }^{136}$ However, somewhat lower transduction rates were found using porcine muscle cells. ${ }^{137}$ The supernatant that is harvested from lentivirus-producing cells is lower in nutrient content and has a notable acidic $\mathrm{pH}$ as indicated by media appearance. Since withdrawal of serum induces differentiation in confluent cultures of these cells, it is possible that the lentivirus containing media itself may be in part responsible for these effects. However, the addition of serum to raw supernatant lentivirus did not improve cell survival or morphology. In addition, concentrated lentivirus resuspended in fresh media also produced some cell death, albeit not as severe. Due to the high concentration of lentiviral particles, a higher rate of integration is possible and this could have interfered with cellular function. However, GFP fluorescence in these cells did not appear to be stronger 
than those transduced with unconcentrated supernatant. Therefore, a higher rate of integration did not appear to be a factor.

Due to the difficulties in transducing both bovine fetal and adult myoblasts with lentivirus, an alternative method was pursued. Transfection of siRNAs had been previously shown to be effective in reducing myostatin expression in primary chicken myoblasts as well as mouse $\mathrm{C} 2 \mathrm{C} 12$ cells. ${ }^{125,138}$ Transfection of adult muscle cells with siRNAs not only resulted in a high transfection efficiency, but cells also continued to proliferate and when induced, differentiate into multinucleated myotubes. Furthermore, analysis of myostatin mRNA concentrations in these cells by qRT-PCR revealed a 8095\% reduction by GDF8-1026 when compared to the Cy3 control at both the $20 \mathrm{nM}$ and 50nM concentrations. Thus, transfection with a myostatin specific siRNA effectively demonstrated depletion of myostatin mRNA in primary muscle cells. However, cells with no transfection had a significantly lower level of myostatin mRNA than those transfected with the $\mathrm{Cy} 3$ control $(\mathrm{p}<0.05)$. This discrepancy between the transfected and nontransfected control cannot be explained. However, if another control was performed in which no siRNA is added, this may help to determine whether this was an effect of transfection alone or possibly the $\mathrm{Cy} 3$ control siRNA.

Although the siRNA sequences tested showed a reduction of myostatin mRNA, protein expression could not be analyzed. This was due to a lack of a reactive and bovine specific myostatin antibody for protein analysis. If an effective antibody is found, protein measurement based on either immunocytochemistry or Western blot would become an option. Due to its therapeutic value in human medicine, myostatin antibodies 
have been purchased by various drug companies and withheld from use in academic research. In this project, four different antibodies (ab37254-50, ab996-50 [Abcam], MAB788 [R\&D Systems], and sc-6884 [Santa Cruz Biotechnologies]) were tested using a Western blot. All of these were shown to be either nonreactive or nonspecific to bovine myostatin protein in skeletal muscle extracts. One of these (ab996-50) was also tested using immunocytochemistry on desmin-positive bovine fetal myoblasts, and labeling failed. However, the significant reduction in myostatin mRNA using siRNA GDF8-1026 in the adult muscle cells was sufficient to demonstrate effective mRNA depletion using RNAi in vitro.

Conclusions

The experiments described effectively demonstrated reduction of bovine and goat myostatin mRNA using siRNAs designed against regions of homology between these two species. These siRNA sequences were successful in suppressing mRNA expression both when introduced in vitro as an siRNA or when expressed from a lentiviral plasmid as an shRNA. A similar approach has been previously reported in mice, where an siRNA targeting the mouse myostatin gene was then incorporated as an shRNA into a lentiviral system for in vivo transgene delivery. ${ }^{125}$ Therefore this approach should be effective when transitioning from in vitro testing to an in vivo application in livestock.

Isolation of both fetal myoblasts and adult satellite cells from bovine skeletal muscle was successful as shown by immunocytochemistry and myotube development. Additionally, transduction of fetal myoblasts with recombinant lentivirus was 
demonstrated. However, reduction of myostatin mRNA expression in transduced fetal myoblasts was unable to be measured using qRT-PCR. Improved primer design or increased sensitivity of detection through a Taqman assay may allow for evaluation of myostatin expression in these cells. It has previously been shown that myostatin mRNA levels are upregulated at the onset of differentiation in adult satellite cells. ${ }^{129}$ Efficient transduction of isolated satellite cells was unsuccessful. Transfection of an siRNA into these satellite cells, however, was effective and resulted in reduction of endogenous bovine myostatin mRNA.

The siRNA sequence shown to be the most effective at suppressing myostatin mRNA in vitro, GDF8-1026, was chosen for evaluation in an in vivo setting using a recombinant lentiviral plasmid (PG1026). This will facilitate the transition of lentiviralmediated shRNA expression from in vitro testing to an in vivo application, allowing production of animals transgenic for reduced myostatin expression. 


\section{CHAPTER III}

\section{ANALYSIS OF MUSCLE-SPECIFIC PROMOTERS FOR LENTIVIRAL-MEDIATED shRNA EXPRESSION}

Introduction

The ultimate goal of our in vitro experiments using RNAi was the translation to an in vivo application. However, expression of shRNAs in vivo has been shown to produce off-target effects. In work by Grimm et al. (2006), tissue-expression of shRNAs targeting the firefly luciferase gene in a mouse produced liver toxicity. ${ }^{49}$ Since these shRNAs did not target an endogenous gene, this was an unexpected result. Additionally, various microarray and qRT-PCR studies have shown silencing of off-target genes using RNAi. $^{43,45-47}$ This has led to the investigation of methods to control shRNA expression so as to avoid these effects in vivo. One of these methods is tissue-specific expression. This is most useful when the target gene is expressed mainly in one tissue or organ. In the case of the myostatin gene, expression is localized primarily to skeletal muscle. Therefore, it presents an attractive target for application of this method. Tissue-specific expression of shRNAs may also increase the effectiveness of the transgenes in suppressing gene expression, and it may also be useful in therapeutic delivery.

Muscle-specific expression has already been utilized in mice for delivering therapeutic agents. Expression of a mini-dystrophin protein using the muscle creatine kinase (MCK) promoter demonstrated an effective decrease in muscle atrophy in the mdx mouse model of muscular dystrophy. ${ }^{139}$ This promoter has been found to have 
different expression patterns and quantitative expression levels depending on the size of the promoter sequence utilized when analyzed in vitro. In mice, progressive deletion of the MCK promoter from -3300 to -723 reduced quantitative expression in vivo but not specificity. ${ }^{140}$ However, when tested in myogenic cells, no difference was found in expression levels when analyzed using chloramphenicol acetyltransferase (CAT) fusion genes. ${ }^{141}$ Another example of muscle-specific expression of a transgene is the use of the myogenin promoter. When inserted into a lentiviral transfer vector that included a GFP reporter gene and used to generate transgenic mice, skeletal-muscle specific expression of GFP was found. ${ }^{32}$ In addition, myogenin expression is thought to be influenced by myostatin. ${ }^{123}$ Other muscle specific promoters have also been demonstrated to be effective, including the $\alpha$-actin and myosin light chain. ${ }^{142,143}$ To this end, the bovine muscle-specific promoters driving MCK and myogenin were cloned from genomic DNA and tested for their ability to drive transgene expression in muscle cells in vitro. Both genes should be upregulated in differentiated skeletal muscle, ensuring transgene expression not only during development but throughout the animal's life in a restricted, tissue specific manner.

Materials and Methods

Isolation and cloning of bovine muscle promoters

Promoter sequences were amplified from bovine genomic DNA using PCR. Reactions were performed using $2.5 \mu 110 \mathrm{X}$ amplification buffer, $10 \mathrm{mM} \mathrm{dNTP}$ mix, 0.5 units Taq polymerase, $0.5 \mu 1$ each $50 \mu \mathrm{M}$ forward and reverse primer, and 50-100ng 
genomic DNA in a total volume of $25 \mu 1$. Primer sequences for each promoter are listed in Appendix A. Cycling conditions were as follows: $95^{\circ} \mathrm{C}$ for 5 minutes, 30 cycles of $95^{\circ} \mathrm{C}$ for 30 seconds, $57^{\circ} \mathrm{C}$ for 30 seconds, and $72^{\circ} \mathrm{C}$ for 45 seconds, and a final extension of $72^{\circ} \mathrm{C}$ for 10 minutes. Products were run on a $1.8 \%$ agarose gel to confirm amplification, and bands of expected sizes for each promoter were excised and purified using the QiaQuick gel extraction kit (QIAGEN). Products were cloned into either the pGEM T-easy vector (Promega) or TOPO TA sequencing vector (Invitrogen) according to kit instructions and sequenced to confirm inserts. Once promoter sequences were verified, PCR was used to amplify and add Xba1 and Age1 restriction enzyme sites on the 5' and 3' ends for cloning into the G-Zeo lentiviral plasmid (Appendix A). Reaction and cycling conditions were as above. Restriction digestions were performed in order to remove the constitutive CMV promoter from the G-Zeo plasmid as well as to cut the 5' and 3' ends of each PCR product for cloning. Restriction digests were carried out with $2 \mu 1$ NEB Buffer 4, $1 \mu 1$ each Xba1 and Age1 enzymes, BSA and either $10 \mu l$ of purified PCR product or $5 \mu \mathrm{g}$ of plasmid in a $20 \mu \mathrm{l}$ reaction for 1.5 hours at $37^{\circ} \mathrm{C}$. Digested plasmid was run on a $1.2 \%$ agarose gel to separate the two bands, and the plasmid band was excised and purified as above. Digested PCR products were cleaned using the QiaQuick gel extraction kit with the recommended modifications for cleaning enzyme digestions (addition of 3X volume Buffer QG plus 1X volume isopropanol prior to loading onto the spin column). Ligation of the bovine myogenin promoter into G-Zeo was performed using the Quick ligase kit (NEB). Briefly, $50 \mathrm{ng}$ digested plasmid was combined with insert in a 3:1 molar ratio (insert:vector) along with 2X Quick ligase 
buffer and $1 \mu 1$ Quick ligase in a $20 \mu 1$ total volume. The ligation proceeded for 5 minutes at room temperature before being put on ice. The MCK promoter was ligated using 100ng plasmid in a 6:1 molar ratio of insert to vector with Quick ligase. Ligated products, $5 \mu 1$ each, were then transformed into Stbl3 chemically competent cells and clones were isolated and confirmed as described in Chapter II. Confirmed constructs were labeled as G-Zeo Bmyog and G-Zeo BMCK (bovine myogenin and bovine muscle creatine kinase, respectively).

Testing of bovine promoter activity in vitro

Recombinant lentivirus was produced as in Chapter II (Materials and Methods) using the G-Zeo Bmyog and G-Zeo BMCK plasmids. Medium containing lentiviral particles was aliquoted and either used fresh or frozen at $-80^{\circ} \mathrm{C}$ for future use. For this experiment, bovine fetal myoblasts (cultured in DMEM/F12 plus 15\% FBS and gentamicin) and mouse C2C12 cells (cultured in DMEM-Glutamax plus 15\% FBS and gentamicin) were utilized. Cells were plated in either 12- or 48- well plates at approximately $50 \%$ confluence the day of transduction. Muscle cells were transduced with recombinant lentivirus for each new muscle specific construct. Transductions were performed for either 6-8 hours or 16-20 hours as described in Chapter II. The transformed cells were allowed to proliferate for one day before being induced to differentiate using DMEM/F12 or DMEM-Glutamax plus 2\% horse serum. Differentiation media was refreshed each day.

The new promoters were cloned into G-Zeo so that they would drive GFP expression. Therefore, in order to test the effectiveness of the new construsts, primary 
muscle cells were evaluated for timing and localization of GFP fluorescence beginning on day 1 post-differentiation using fluorescence microscopy. In addition, transduced muscle cells were evaluated for mean intensity of GFP fluorescence using a fluorometer. Medium was refreshed with PBS plus $2 \%$ FBS prior to being evaluated. Transductions were performed in either duplicate or triplicate, and wells were evaluated on days $1,3,5$, 7, and 9 post-differentiation for overall GFP fluorescence.

\section{Data analysis}

Average fluorescence intensity was calculated for each sample and day of measurement. Means were tested using one-way ANOVA with a Tukey test for comparison between means.

Results

Isolation and cloning of bovine muscle-specific promoters

The bovine myogenin promoter (bases -7 to -1410) and muscle creatine kinase (MCK) promoter (bases -183 to -1764 ), in relation to the translational start site, were amplified from genomic DNA and cloned. The myogenin promoter sequence matched NCBI entry (AY882581) as well as upstream sequence as determined by comparison to bovine genomic sequence (BTA4). The MCK promoter was confirmed to match bovine genomic sequence upstream from the MCK gene (BTA18). These sequences were then cloned into the G-Zeo plasmid in place of the constitutive CMV promoter (Figure 8). Recombinant lentivirus was produced using the new constructs and used to transduce 
bovine fetal myoblasts as well as $\mathrm{C} 2 \mathrm{C} 12$ mouse myoblasts, an immortalized mouse muscle cell line.

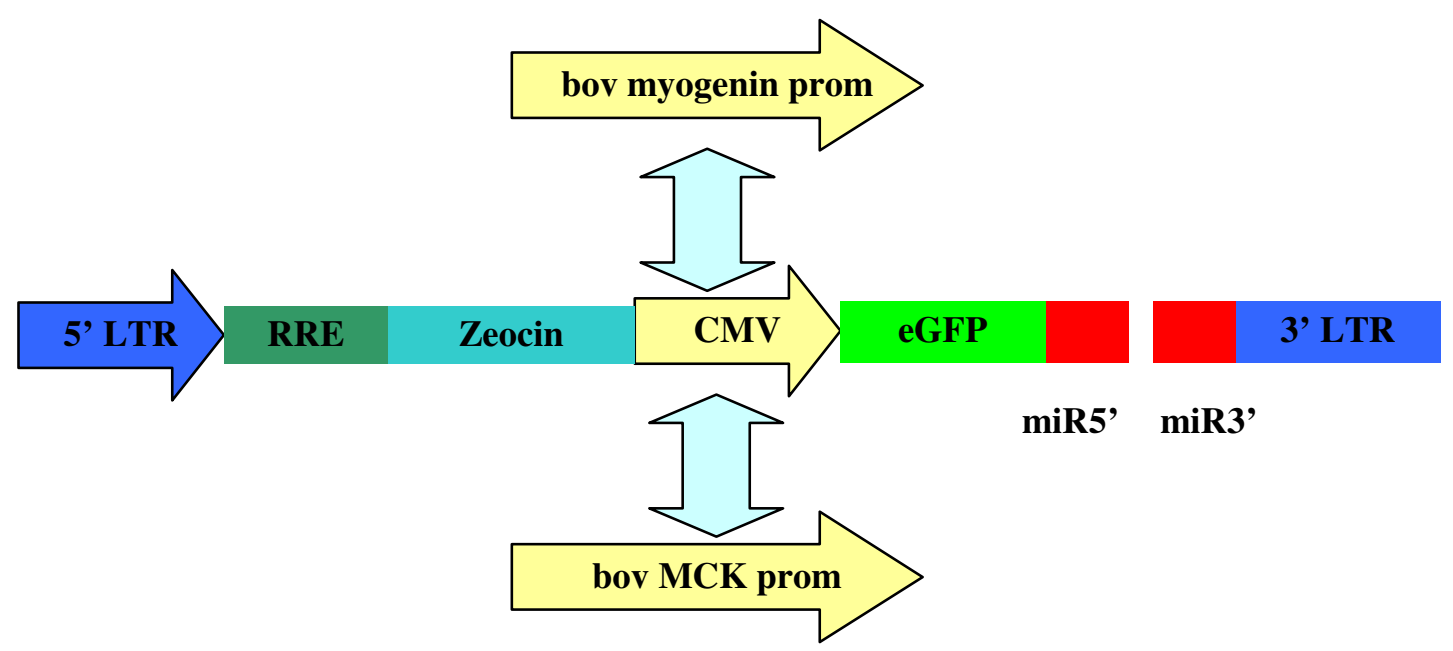

Figure 8 Map showing insertion of bovine muscle-specific promoters into the G-zeo lentiviral plasmid. Vector map showing the insertion site of the bovine myogenin and MCK promoters.

\section{Evaluation of promoter expression}

The myogenin gene is a differentiation factor induced at the time of cell cycle withdrawal. ${ }^{144}$ Therefore, expression of the transgene, GFP, should be induced at this time as well in muscle cells. To test this, cells were transduced with a lentivirus containing a GFP marker driven by the myogenin promoter. Images demonstrating timing of GFP expression are provided in Figure 9. One day post-differentiation, both bovine fetal muscle and $\mathrm{C} 2 \mathrm{C} 12$ cells began to express GFP. These were presumably myoblasts that had been induced to differentiate. On day 3, myotube formation was seen 
in bovine fetal muscle cells, and GFP expression was localized to these myotubes. C2C12 cells continued to fluoresce but had not yet completed differentiation. By day 5 post-differentiation, long myotubes were visible in both cell types that expressed GFP. However, C2C12 cells that had not fused also displayed fluorescence. Analysis of fluorescence intensity using a plate reader revealed no difference between cells expressing GFP driven by the myogenin promoter or those without the transgene until

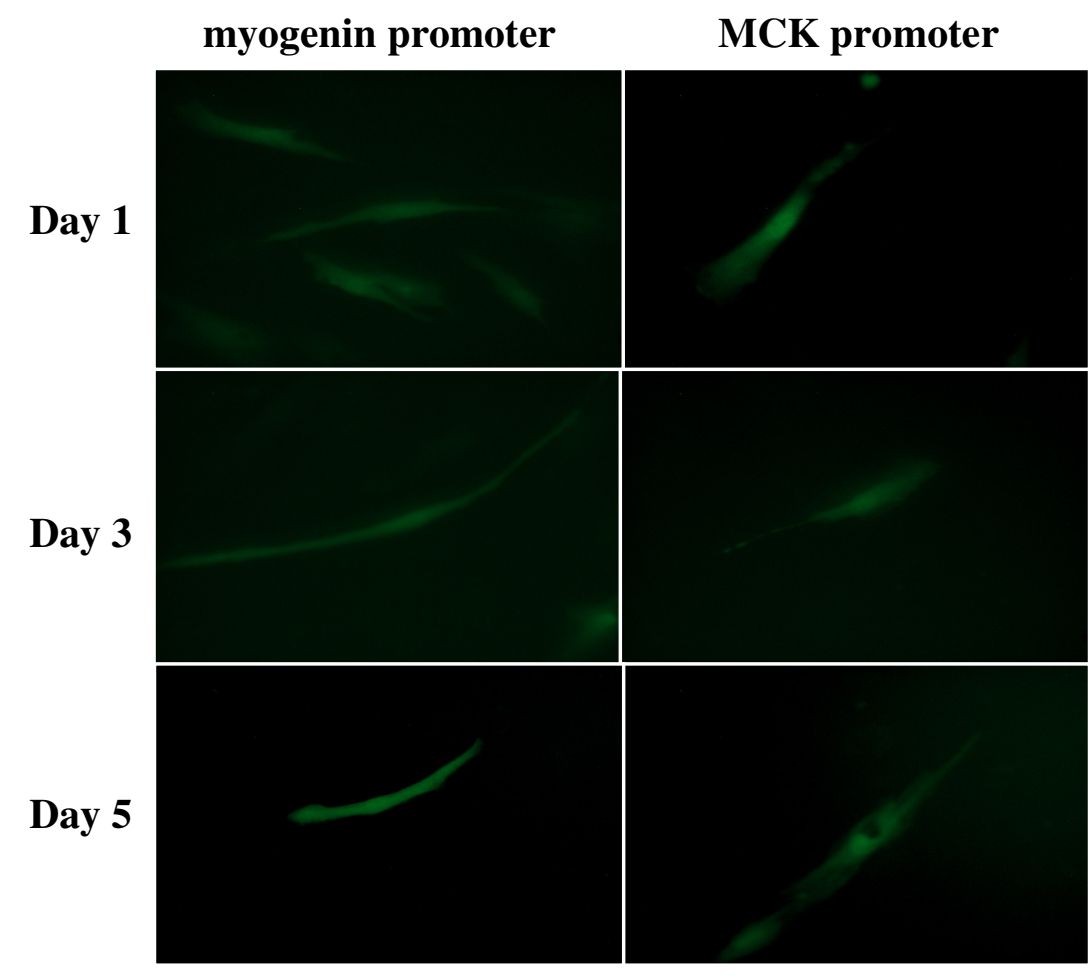

Figure 9 Expression of GFP in fetal bovine myotubes. Cells were first transduced with lentivirus containing either the bovine myogenin promoter or the bovine MCK promoter driving GFP expression. Transduced cells were then differentiated in low serum media for 5 days. Images were taken on days 1, 3, and 5 post-differentiation. 
day 9 post-differentiation (Figure 10). On day 9, mean intensity in both bovine fetal muscle and $\mathrm{C} 2 \mathrm{C} 12$ cells was significantly greater than that of the nontransgenic control $(\mathrm{p}<0.05)$ for both constructs.

The MCK gene is a muscle-specific variant of creatine kinase upregulated in mature skeletal muscle cells. ${ }^{140}$ Although it was expected that this gene would also be upregulated at differentiation, this was not the case. GFP expression in bovine fetal muscle cells transduced with the lentivirus containing the MCK promoter began to be detected in cells as early as day 1 post-differentiation. However, intensity of GFP expression was lower at this timpoint than in cells expressing GFP from the myogenin promoter. In addition, although some myotubes became GFP positive as differentiation progressed, a large proportion of mononuclear GFP positive cells were seen throughout the time course (Figure 9). GFP expression was seen in myotubes as they developed but was not restricted to them. In $\mathrm{C} 2 \mathrm{C} 12$ cells, a similar expression pattern to that of the bovine myogenin promoter was seen. Analysis of mean fluorescence intensity revealed a significant difference between transgenic and nontransgenic bovine fetal muscle and $\mathrm{C} 2 \mathrm{C} 12$ cells at day 9 post-differentiation $(\mathrm{p}<0.05)$ (Figure 10). 

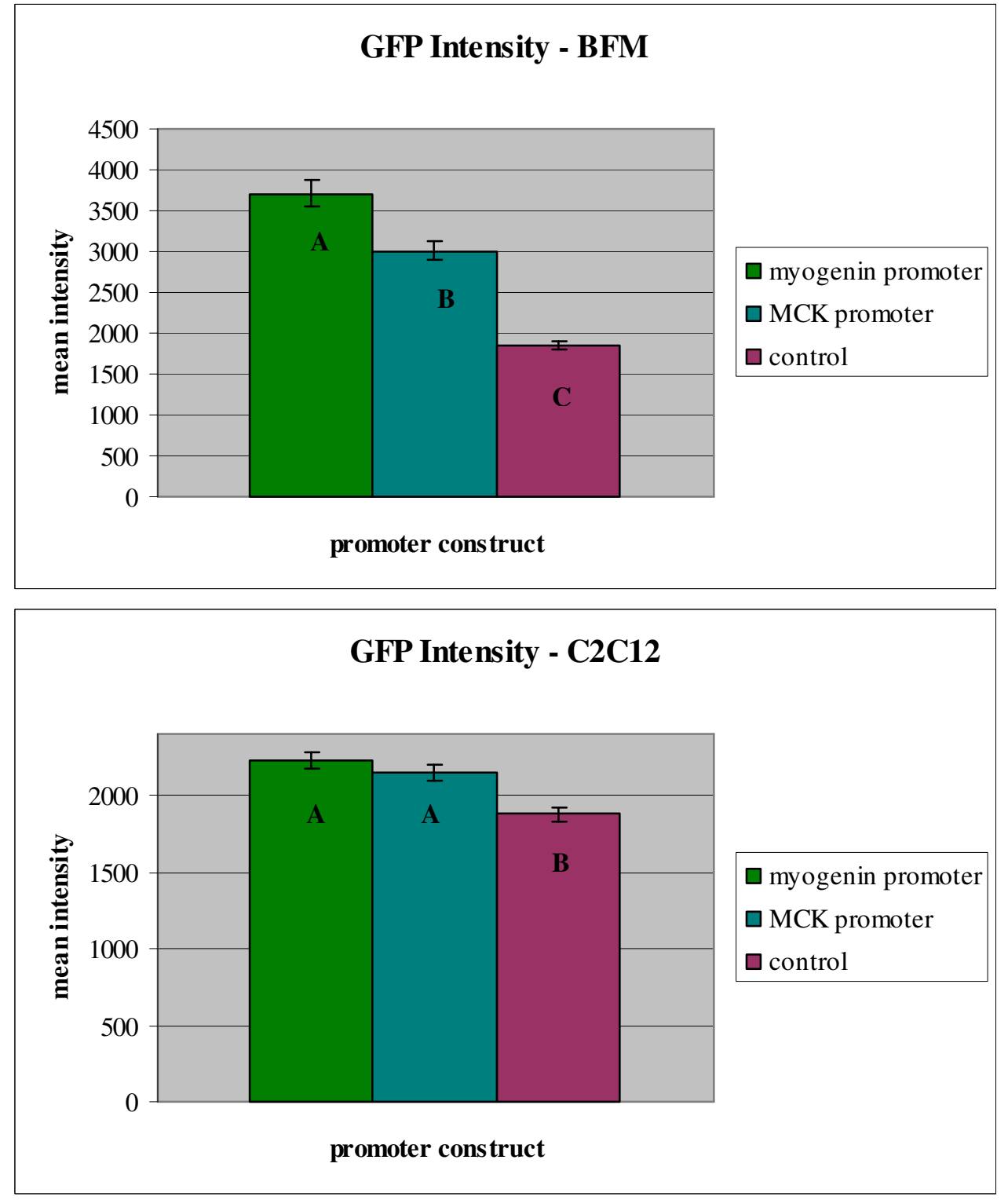

Figure 10 Mean GFP intensity in fetal bovine and mouse $\mathrm{C} 2 \mathrm{C} 12$ cells at day 9 postdifferentiation. Letters that are different from each other are significantly different $(\mathrm{p}<0.05)$ 


\section{Discussion}

Expression of shRNAs for suppressing gene expression in vivo has been effectively demonstrated in a wide variety of species, including worms, ${ }^{3}$ plants, ${ }^{6}$ and mice. ${ }^{7}$ However, instances of off-target effects have been found in some cases. ${ }^{43,45-47,49}$ When working with livestock species, it is important that any manipulation does not have a negative impact on the health or production of the animal. Therefore, in order to attempt to control for possible off-target effects, tissue-specific expression of the transgene was explored. Myostatin is almost exclusively produced in skeletal muscle. ${ }^{129}$ Therefore, limiting shRNA expression to skeletal muscle should help prevent any potential toxicity or other effects of the transgene. In addition, effectiveness of the targeting shRNA expression may be increased as well.

The two promoters analyzed here were chosen for their specificity as well as their ability to drive muscle-specific expression in mice. The myogenin promoter has been shown previously to localize GFP expression to the skeletal muscle of mice when used in a lentiviral system. ${ }^{32}$ In addition, myogenin is predicted to be a target of the myostatin protein. ${ }^{123}$ In vitro experiments showing an inhibition of differentiation by myostatin also showed an inhibition of differentiation factors, including myogenin protein. ${ }^{123}$ Inversely, inhibition of myostatin using antisense RNAs resulted in a 450-fold increase in myogenin transcript levels. ${ }^{123}$ Therefore, it is plausible that targeting myostatin through RNAi driven by this promoter may create a positive feedback loop. Decreased myostatin should in theory increase transcription of myogenin, and therefore a higher rate of promoter activation would be expected. The second promoter chosen 
was the MCK promoter. This promoter has been well-documented in mouse experiments limiting transgene expression to skeletal muscle, even postnatal expression. ${ }^{120,139,140,145,146}$ Therefore, this promoter was expected to also be efficient in driving muscle-specific expression in bovine cells.

A portion of the bovine myogenin promoter was found in GenBank (AY882581). However, initial testing with this portion revealed extremely weak expression of GFP. Therefore a larger portion was isolated, containing sequence upstream of the myogenin gene as compared to assembled bovine genomic sequence (BTA4). This bovine myogenin promoter localized GFP expression to myotubes effectively in bovine fetal myoblasts. Expression of GFP was first seen in presumptive differentiating cells on day 1 post-induction, and this expression was then localized to multinucleated myotubes by day 3. Expression seemed to increase by day 5 post-differentiation. In C2C12 cells, GFP expression appeared fainter, which may be indicative that this promoter is less effective in mouse cells than bovine cells. No detectable increase in overall fluorescence was seen in either cell type when evaluated using the fluorometer until day 9 post-differentiation. However, a lack of sensitivity is thought to be partially responsible for this observation. Additionally, given that not all cells that are transduced express the myogenin gene (ie. nondifferentiating myoblasts, contaminating fibroblasts), this may not be an accurate measurement for induction of promoter expression. Therefore, more characterization of this promoter may be needed prior to its use in vivo.

The bovine MCK promoter had not been previously characterized, and so bovine genomic sequence (BTA18) was used to isolate it from bovine genomic DNA. After 
several attempts, anchoring the 5' primer in the first exon prior to the translation start site allowed successful amplification of a $1.6 \mathrm{~kb}$ portion upstream. This promoter sequence was able to drive GFP expression. However, it did not appear to be limited to myotubes in either fetal myoblasts or $\mathrm{C} 2 \mathrm{C} 12$ cells. This may be due to a lack of musclespecific or differentiation-specific elements or binding motifs. Johnson et al. (1989) characterized a $3.3 \mathrm{~kb}$ piece of the mouse MCK promoter, which has since been used to

localize transgene expression to skeletal muscle. ${ }^{140}$ Progressive deletions from the 5' end of the promoter sequence reduced expression of the transgene, indicating that perhaps a larger portion of this promoter may be needed. However, several reports using this promoter in mice show that a $1.35 \mathrm{~kb}$ portion is sufficient for muscle-specific expression. ${ }^{139,145}$ The majority of C2C12 cells that expressed GFP were also mononuclear, indicating that this gene may not be upregulated at differentiation as myogenin in vitro. Analysis of GFP intensity using a plate reader revealed a significant difference from the mean intensity of nontransgenic cells in bovine myoblasts at day 9 of differentiation. However, this difference was not as pronounced in $\mathrm{C} 2 \mathrm{C} 12$ cells, as only one of the two constructs showed a significant difference. Further analysis of this promoter sequence is needed prior to use in in vivo applications.

\section{Conclusions}

Both the bovine myogenin and MCK promoter sequences isolated and analyzed were successful in driving GFP expression in both bovine fetal muscle and C2C12 mouse cell lines. However, similarities among treatment groups in mean intensity until 
day 9 of differentiation demonstrates a need for further analysis of the promoter sequences utilized. In addition, the lack of GFP localization to differentiated cells using the MCK promoter supports this need. The development of a lentiviral vector using a muscle-specific promoter to drive transgene expression will aid in reducing possible offtarget effects when applying shRNA-mediated suppression of myostatin to a large animal model. 


\section{CHAPTER IV}

\section{PRODUCTION OF TRANSGENIC ANIMALS WITH REDUCED MYOSTATIN EXPRESSION}

Introduction

In Chapter II, it was demonstrated that shRNAs targeting the bovine myostatin gene were effective at suppressing both bovine and caprine myostatin mRNA expression in vitro. The most effective shRNA construct, PG1026, was chosen for further experiments. In order to demonstrate the effectiveness of gene suppression in vivo in a large animal model using RNAi, this construct was utilized for transgenic animal production. To ensure the transgene cassette was inserted into the genomic DNA using lentiviral-mediated transfer, two methods of transgenic embryo production were explored. The first utilized somatic cell nuclear transfer (SCNT) cloning with a bovine cell line transduced with a recombinant lentivirus prior to nuclear transfer. The second involved microinjection of concentrated recombinant lentivirus into the perivitelline space of bovine zygotes.

Cloning using somatic cells as the nuclear donor has been used previously to produce a large number and variety of animals. Wilmut et al. produced the first sheep clone using a somatic cell, demonstrating that somatic cells are indeed capable of reprogramming back to a totipotent state. ${ }^{97}$ Since then, this method, combined with retroviral gene transfer, has been used successively to produce a variety of transgenic large animals, including dog, ${ }^{91} \mathrm{cat}^{93} \mathrm{cow}^{100}$ and pig. ${ }^{84,99}$ Although inherently inefficient, 
SCNT with a transduced cell line should therefore result in transgenic embryos for transfer and the production of a live transgenic offspring.

The second method involves the production of high-titer lentivirus that is microinjected into a zygote to transduce it directly. Although the use of a retrovirus to infect an embryo directly was initially described by Jaenisch et al. in 1975, it was abandoned for a number of years due to germline silencing. ${ }^{147}$ However, the development of vectors based on a lentivirus allowed germline transmission and expression of the transgene. ${ }^{32}$ This same method was used by Hofmann et al. (2003) to produce transgenic pigs. ${ }^{88}$ Tranduction of in vivo produced porcine zygotes with a lentiviral plasmid expressing eGFP resulted in $70 \%$ transgenic offspring as indicated by PCR analysis. ${ }^{88}$ Additional work by this lab revealed production of transgenic bovine embryos through transduction of both in vitro produced zygotes as well as denuded oocytes prior to IVF. Although a lower rate of transgenesis was found (45\% vs. $92 \%$ ) in bovine blastocysts produced through microinjection of zygotes versus that of oocytes, the necessary step of cumulus cell removal prior to injection of oocytes has been shown previously to lower fertilization rates. ${ }^{148,149}$ Therefore, production of transgenic animals through lentiviral transduction in this experiment was performed using microinjection of zygotes rather than mature oocytes, followed by IVF and in vitro culture. 
Materials and Methods

Production of transgenic embryos through SCNT

Recombinant lentivirus was produced as previously described (see Materials and Methods, Chapter II) using constructs PG1026 as well as a transgenic control PG5529. The shRNA in PG5529 targets the foot and mouth disease virus. Medium containing recombinant lentiviral particles was used to transduce a bovine fetal fibroblast cell line. This cell line had been previously utilized for SCNT cloning and shown to result in high pregnancy rates (personal communication, David Faber, TransOva Genetics). Cells were plated at $70-80 \%$ confluence in 6-well plates for transduction. One milliliter of lentivirus containing medium was combined with $8 \mu \mathrm{g} / \mathrm{mL}$ polybrene and added to the cells for 16 20 hours. Cells were cultured for two days, and once fluorescence was visualized cells were put under selection with puromycin. Cells were selected with $1 \mu \mathrm{g} / \mathrm{mL}$ puromycin, and a $100 \%$ GFP positive population of cells was obtained after 3-4 days. Cells were then cryopreserved for future use. Transgenic cell lines were sent to ViaGen, Inc. in Austin, Texas to produce cloned blastocysts by somatic cell nuclear transfer. Blastocysts were either vitrified prior to transfer or transferred fresh into synchronized recipient cattle on day 7 of culture. Prior to transfer embryos were visualized for GFP fluorescence. Cows were ultrasounded after 35 days gestation to confirm pregnancy. Pregnant animals were then monitored every two weeks by ultrasound until day 120 of gestation, then checked every month by palpation. 
Production of transgenic embryos by microinjection of zygotes with recombinant lentivirus

$\underline{\text { Recombinant lentivirus concentration }}$

Recombinant lentivirus was produced as described (Materials and Methods, Chapter II) but with modifications for production and concentration of a large volume. For each lentiviral construct, HEK $293 \mathrm{~T}$ cells were plated in six $100 \mathrm{~mm}$ plates at $90 \%$ confluency on the day of transfection. Cells were transfected as in Chapter II, and 18 hours later media was refreshed with 6mL OptiMEM media (Invitrogen) plus 10mM sodium butyrate per plate. Media was collected 48 hours later and harvested as described in Chapter II (Materials and Methods). Approximately 33mL lentiviral media was added to a Beckman thin-walled ultracentrifuge tube (part no. 344058 ), and $5 \mathrm{~mL}$ of a $15 \%$ sucrose solution in PBS was layered on the bottom of each tube using a Pasteur pipette. Tubes were balanced using a scale and centrifuged in a Beckman Model L8M80 ultracentrifuge using an SW28 rotor. Ultracentrifugation was done at $4^{\circ} \mathrm{C}$ for 1.5 hours at a speed of 50,000 xg. Supernatant was removed and viral pellets were resuspended in $35 \mu 1$ sterile $\mathrm{PBS}$ overnight at $4^{\circ} \mathrm{C}$. Concentrated virus was frozen at $-80^{\circ} \mathrm{C}$ in $5 \mu 1$ aliquots until needed.

\section{$\underline{\text { Determining lentiviral titer }}$}

Recombinant virus was titered prior to use in order to ensure successful embryo transduction. HEK293T cells were plated at a density of 25,000 cells/well in a 48-well plate in the morning the day of transduction. That afternoon, cells were transduced with serial dilutions of concentrated lentivirus. Due to limited volumes of concentrated virus, 
serial dilutions of $0.1,0.01,0.001$, and 0.0001 were used. All transductions were done with $8 \mu \mathrm{g} / \mathrm{mL}$ polybrene. Media was refreshed 18 hours later and cells were maintained in culture for 3 days before evaluation. Titer was calculated as follows:

$\{[(\#$ cells plated $) X(\%$ GFP positive cells $)] /(\mathrm{mL}$ viral media $)\} X$ dilution factor

Only concentrated virus with a titer at or above $1 \mathrm{X} 10^{9} \mathrm{IU} / \mathrm{mL}$ was used for microinjection of embryos.

$\underline{\text { In vitro production of bovine embryos }}$

Bovine embryos were produced using in vitro fertilization as previously described with modifications. ${ }^{150}$ Mature oocytes were washed out of maturation media and twice through TL Hepes media before being washed in groups of up to 50 into $400 \mu 1$ of equilibrated fertilization media (Tyrode's medium with $25 \mathrm{mM}$ bicarbonate, $22 \mathrm{mM}$ sodium lactate, $1 \mathrm{mM}$ sodium pyruvate and $6 \mathrm{mg} / \mathrm{mL}$ fatty acid-free BSA). Semen was thawed and sorted using a Percoll density gradient $(2 \mathrm{~mL} 45 \%$ v/v over $2 \mathrm{~mL} 90 \% \mathrm{v} / \mathrm{v}$ Percoll). Semen was spun at $2000 \mathrm{rpm}$ (need $\mathrm{xg}$ ) for 20 minutes. Live motile sperm collected at the bottom of the gradient were washed once through $1 \mathrm{~mL}$ fertilization media and concentrated by centrifugation at $2000 \mathrm{rpm}$ for 5 minutes. Sperm was counted using a hemocytometer and diluted to the appropriate concentration in fertilization media. Fertilization was performed at a concentration of $1.5-2$ million sperm $/ \mathrm{mL}$ in a total of $500 \mu 1$ per well. To aid capacitation of the sperm, $20 \mu$ l each of heparin $(6 \mu \mathrm{g} / \mathrm{mL})$, and $\mathrm{PH}$ (penicillamine, $2 \mathrm{mM}$ and hypotaurine, $1 \mathrm{mM}$ ) were added per well. Fertilized zygotes were removed from fertilization media 7.5 hours post-fertilization and vortexed 
in TL Hepes with $5 \mu \mathrm{g} / \mathrm{mL}$ hyaluronidase to remove cumulus cells. Embryos were washed into and injected in a 100mM sucrose solution in M199 Hanks Hepes media (Invitrogen). Perivitelline injections were performed with a micropipette using a steady flow into the perivitelline space for 10-20 seconds per embryo. Embryos were then cultured in groups of up to 50 embryos in $500 \mu 1$ Evolve bovine formulated culture media (Zenith Biotech) plus $4 \mathrm{mg} / \mathrm{mL}$ probumin and $100 \mu \mathrm{g} / \mathrm{mL}$ gentamicin. At day 7 of culture, blastocysts were evaluated for GFP fluorescence and either transferred into synchronized recipients or cryopreserved. Recipients were monitored for establishment of pregnancy after 35 days gestation to confirm pregnancy, and then monitored by ultrasound every 30 days throughout gestation.

\section{Detection of incorporation of the transgene}

In vitro produced embryos, recovered fetuses and placental tissue were analyzed for GFP expression using fluorescence microscopy. In addition, tissue samples were sent to Dr. Kenneth Cornetta's laboratory at the University of Indiana Medical School, Indianapolis, Indiana. Genomic DNA was isolated using the QIAamp DNA mini kit (QIAGEN), and the DNA was analyzed for integration of the lentiviral cassette using qRT-PCR to amplify a portion of the 5' LTR and psi packaging signal (Appendix B). ${ }^{41}$

Results

Production of transgenic embryos by somatic cell nuclear transfer

Cloning was performed by ViaGen, Inc., and 22 blastocysts were produced for each transgenic cell line. For each cell line, 10 blastocysts were cryopreserved through 
vitrification by ViaGen (Austin, TX). The rest were transferred fresh into sychronized recipient cattle on day 7 of culture. These embryos were first visualized using a fluorescent microscope to confirm GFP expression. For the PG1026 cell line, all 12 embryos were confirmed to be transgenic (Figure 11), whereas for the PG5529 line only 9 of 11 (one was lost prior to transfer) were overtly GFP positive. A total of 8 recipients were used, with each animal receiving 2-3 embryos. Ultrasounds were performed on day 42 of gestation, and 4 animals were confirmed pregnant, all with embryos produced from the PG1026 cell line. Three out of the four animals were found to be carrying multiple fetuses. At 60 days gestation, two of these animals were discovered to be reabsorbing the fetuses. One of these recipients was sacrificed at day 66, and three fetuses were recovered. At day 87, one of the remaining pregnancies was discovered to have aborted. However, one pregnancy is ongoing as of 230 days gestation. A second round of transfers with warmed vitrified embryos was performed, with 8/10 embryos expressing GFP for each cell line. At day 42 of gestation three animals were confirmed pregnant by ultrasound. However, two of the three appeared to be failing at that time. By 72 days gestation, all three pregnancies had reabsorbed.

Samples of fetal and placental tissue were collected from the recipient that was sacrificed at day 66 of gestation and analyzed using fluorescence microscopy. Of the three fetuses recovered at day 66 of gestation, one was dark in color and assumed to be dead. The other two were GFP positive, indicating their viability (Figure 12). Placental 
A)

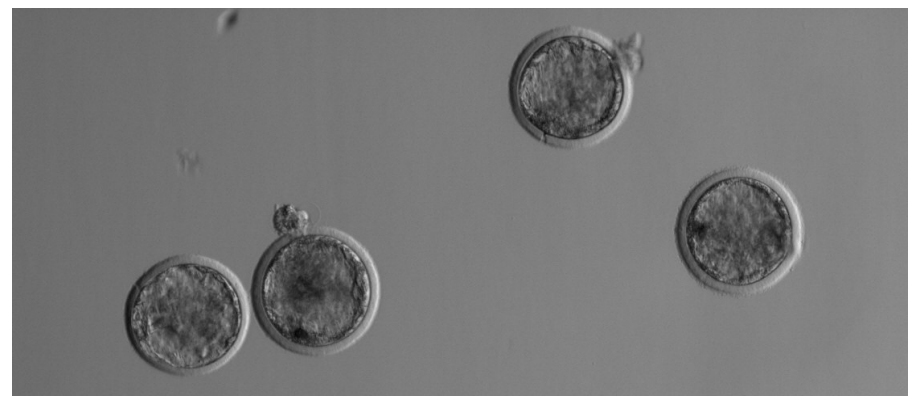

B)

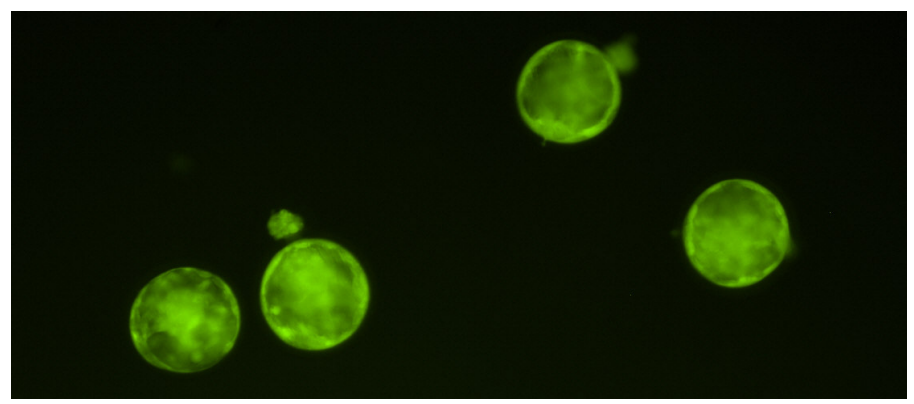

Figure 11 Cloned transgenic bovine blastocysts expressing an shRNA targeting the myostatin gene. Blastocysts were produced through SCNT using a bovine fetal fibroblast cell line transduced with lentivirus expressing the PG1026 construct. A) brightfield image, B) fluorescent image.

tissue from this pregnancy was also GFP positive. All three fetuses were size restricted for the day of gestation. Still, all of these fetuses were shown to be positive for the transgene cassette through qRT-PCR (Table 2). The placental tissue from each of these fetuses was also positive for the transgene cassette using qRT-PCR.

Table 2 Analysis of bovine fetal tissues for presence of the lentiviral transgene

\begin{tabular}{llll} 
& Placenta & Amnion & Fetus \\
\hline \# analyzed & 5 & 2 & 5 \\
\hline \# positive & 4 & 1 & 3 \\
\hline
\end{tabular}




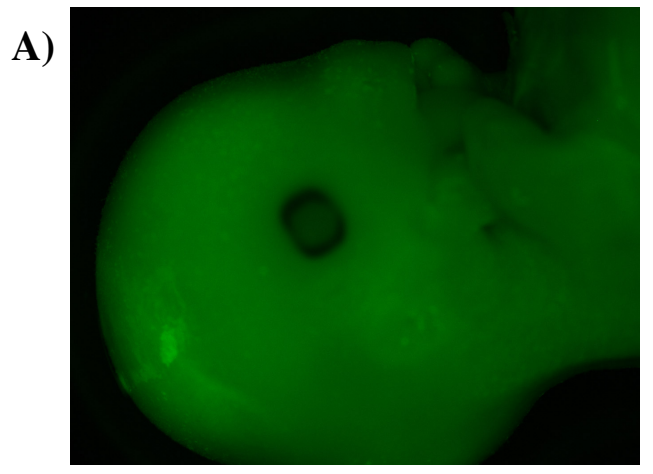

B)

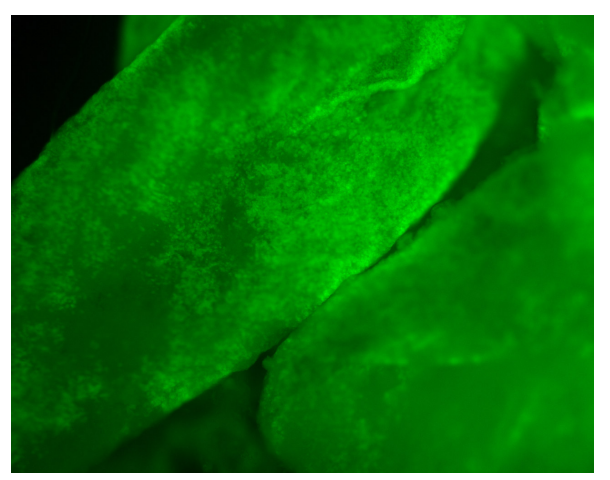

Figure 12 Transgenic bovine cloned fetus and placental tissue. Fetus and tissue were collected at day 66 of gestation from a bovine recipient that received SCNT produced blastocysts. GFP expression is evident throughout the fetus (A) as well as placental tissue (B).

\section{Production of transgenic embryos through perivitelline lentiviral injection}

In order to obtain high enough lentiviral titers for injection of bovine zygotes, the PGK-puromycin cassette was removed from the PEF-green lentiviral plasmid prior to recombinant lentivirus production (Appendix A). Antibiotic resistance genes are only needed for in vitro work and removal allowed for higher transcription rates and increased viral titer. Additionally, alteration of the viral culture media from $1 \mathrm{mM}$ to $10 \mathrm{mM}$ sodium butyrate also improved viral titer. Sodium butyrate has been previously shown to increase recombinant viral titer. ${ }^{151}$ These two modifications allowed for consistent production of lentiviral titers $>1 \times 10^{9} \mathrm{IU} / \mathrm{mL}$ after ultracentrifugation.

Presumptive zygotes were removed from culture media 7.5 hours postfertilization. Microinjection of lentivirus was performed between 8 and 10 hours postfertilization. The microinjection was performed early to attempt lentiviral integration 
prior to the replication and division of DNA required for the first cellular division of the embryo. This would ensure that all cells produced would carry the transgene. However, almost all embryos produced through this method were found to have mosaic GFP expression at day 7 of culture when analyzed by fluorescent microscopy. As seen in Table 3, a total of 181 blastocysts were produced. Of these, 70 were transferred into synchronized recipient cows on day 7-8 of culture. GFP positive embryos were first chosen based on fluorescence, and then embryos were chosen for transfer out of this pool (Figure 13). Since GFP expression was sometimes weak at day 7 of culture, it is possible that some embryos transferred were not transgenic. When synchronized recipients were unavailable for transfer, embryos were instead cryopreserved. Since embryos must be of high quality in order to maintain viability after cryopreservation, only grade 1 and 2 embryos were chosen from those that were microinjected. GFP fluorescence was visualized prior to cryopreservation to ensure that the majority of embryos frozen were expressing the transgene. However, not all embryos cryopreserved were transgenic. A total of 88 embryos were cryopreserved, with 2-4 embryos were per straw. Of these, 32 frozen embryos were thawed and transferred into synchronized recipient cattle, 2-4 embryos per recipient. To date, a total of nine pregnancies have been established with embryos microinjected with concentrated lentivirus. Of these, four are still ongoing, only one of which was established with frozen thawed embryos.

Two fetuses produced through lentiviral microinjection with recombinant lentivirus were recovered at day 78 of gestation from a pregnancy found to be failing via ultrasound. Both of these fetuses were small for gestational age, and one of the fetuses 
showed obvious hemorrhaging. Neither fetus was positive for GFP expression using fluorescent microscopy, and both were found to be negative for incorporation of the transgene cassette through qRT-PCR (Table 2). However, the placental tissue from one of these fetuses was positive for transgene incorporation by qRT-PCR, as was the amionic tissue from this fetus (Table 2).

A)

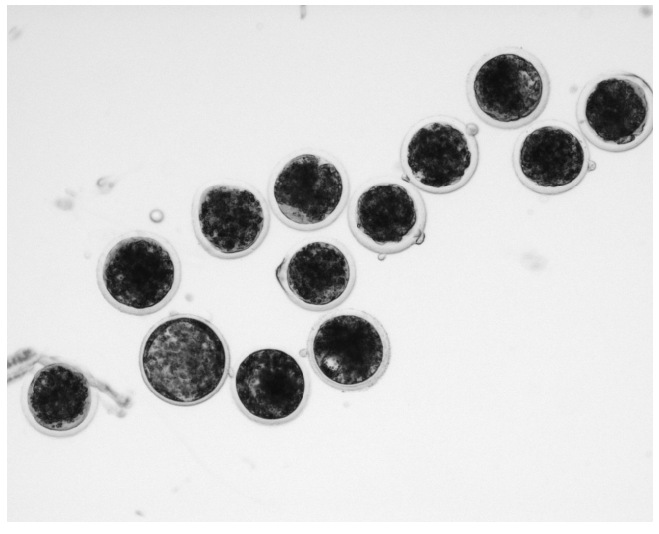

B)

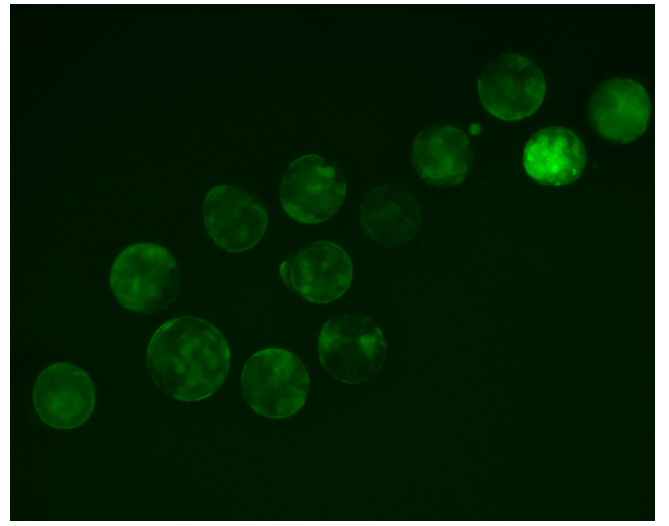

Figure 13 Trangenic in vitro-produced bovine blastocysts produced through perivitelline injection of lentivirus at the zygote stage. Zygotes were produced through IVF. Concentrated lentivirus ( $\geq 1 \mathrm{X} 10^{9} \mathrm{IU} / \mathrm{mL}$ ) was injected into the perivitelline space 810 hours post-fertilization. Embryos were then cultured to the blastocyst stage in vitro. A) brightfield image, B) fluorescent image. 
Table 3 Production and transfer of transgenic embryos using either somatic cell nuclear transfer or perivitelline injection of in vitro produced zygotes

\begin{tabular}{|c|c|c|c|c|c|}
\multicolumn{1}{c}{ Method of production } & $\begin{array}{c}\text { No. } \\
\text { Blastocysts } \\
\text { Produced }\end{array}$ & $\begin{array}{c}\text { No. } \\
\text { Recipients }\end{array}$ & $\begin{array}{c}\text { No. } \\
\text { Pregnant } \\
\text { at Day 35 }\end{array}$ & $\begin{array}{c}\text { Day 35 } \\
\text { Pregnancy } \\
\text { Rate }\end{array}$ & $\begin{array}{c}\text { Day 90 } \\
\text { Pregnancy } \\
\text { Rate }\end{array}$ \\
\hline cloning & 44 & 14 & 7 & $50 \%$ & $7 \%$ \\
\hline transferred fresh & 23 & 8 & 4 & $50 \%$ & $12.5 \%$ \\
transferred frozen & 20 & 6 & 3 & $50 \%$ & $0 \%$ \\
\hline PV injection & 181 & 21 & 9 & $43 \%$ & $19 \%$ \\
\hline transferred fresh & 38 & 10 & 5 & $50 \%$ & $30 \%$ \\
transferred frozen & 32 & 11 & 4 & $36 \%$ & $9 \%$ \\
\hline
\end{tabular}

Discussion

A total of 5 pregnancies are currently ongoing with embryos produced using the two methods outlined for production of transgenic embryos. One of these was produced through SCNT cloning. Although this fetus has progressed to over 240 days gestation, pregnancy failure has been shown throughout gestation in recipients carrying cloned offspring. ${ }^{102}$ Efficiencies in the production of cloned livestock range from only 1$5 \% .^{101,102}$ Therefore the pregnancy loss seen in this experiment was not unexpected. Most embryonic loss associated with cloned pregnancies is early in gestation and in large part is believed to be due to the epigenetic misregulation of genes expressed in the fetus or placenta. ${ }^{103}$ Commonly seen defects include the complete absence or severe lack of placentome formation, with malformed caruncules and cotyledons often seen when they do develop to term as well as reduced vascularization. ${ }^{104}$ Indeed, the lack of placentome formation seen in the placenta recovered at day 66 of gestation demonstrates this result. In addition, the phenomenon referred to commonly as large offpring 
syndrome is seen frequently in clones, most often with cattle. This results in increased

fetal weight and can be accompanied by edema, hepatocephaly, and hydrocephalus. ${ }^{103,104}$ Another complication present in these pregnancies was the fact that the embryos, and therefore resulting fetuses expressed a transgene. It is possible that the lentiviral expression cassette integrated at a location in the genome of the cell that interrupted an essential gene or function. This could also have had a negative impact on pregnancy establishment and maintenance. In addition, the micromanipulation skills required (oocyte enucleation, cell injection, and fusion) and the number of fused oocytes needed in order to produce the desired number of blastocysts demonstrates the inefficiency of embryo production with this method. ${ }^{101,102}$

Only 37of the 43 blastocysts transferred were positive for GFP expression. Four of the embryos not expressing GFP were produced using a cell line transduced with recombinant lentivirus containing an shRNA targeting the foot and mouth disease virus (PG5529). Although this cell line underwent selection using puromycin to establish a population of cells that was completely transgenic, it was later discovered that this cell line had not been completely transgenic prior to being used for SCNT. Therefore, this most likely resulted in the nontransgenic embryos. In addition, two of the warmed vitrified embryos produced using the cell line expressing the construct PG1026 were also negative for GFP. However, both of these embryos were of poor quality after thawing, which may have affected their GFP expression.

The main advantage of this method, however, is that any animal produced should express the transgene in every cell of the body, including the germline. This is because 
the initial DNA used for production of the embryo carried the transgene inserted through lentiviral-mediated gene transfer. This was confirmed in part through analysis of the placental and fetal tissues from fetuses that were recovered and analyzed using qRTPCR. Analysis of three fetuses by fluorescence microscopy revealed that two of these were positive for GFP expression (Figure 13). One of the fetuses not exhibiting fluorescence was thought to be dead at the time of collection and therefore not surprising. All three were found to contain the transgene cassette using qRT-PCR analysis, as was the placental tissue from each fetus (Table 2).

Four pregnancies established were through transfer of day 7 IVF-produced embryos microinjected with a recombinant lentivirus produced with the construct PG1026 or the control construct PG5529. The transgenic status of these conceptuses was uncertain since GFP fluorescence was sometimes weak when visualized with a microscope. In addition, some of embryos produced by this method were thought to be mosiac in GFP expression using fluorescence microscopy. Therefore the animals produced by this method may not be completely transgenic. Still, the injections can be performed without an extreme amount of skill, requiring only a simple micromanipulation, unlike the complicated process of SCNT.

In addition, pregnancies produced through IVF and lentiviral injection would not expected to suffer from those issues that cause early fetal losses in SCNT. Expected calving rates from cloned embryos is only $5-20 \%$ compared to $40-60 \%$ for fresh IVFproduced embryos. ${ }^{152,153}$ Bovine IVF has an expected blastocyst production rate of $30 \%$, and with an average of $77 \%$ of these expressing GFP (observed in this work), this would 
still result in 69 transgenic blastocysts produced from 300 oocytes. Transfer of these into recipient cattle ( 3 embryos per recipient) would then result in an average of 12 offspring versus only 1-5 offspring with the same number of SCNT embryos.

Although a higher number of pregnancies were established with transgenic embryos produced using lentiviral microinjection, there was a higher than expected amount of pregnancy loss in this experiment. However, half of the pregnancies that were lost were established with frozen thawed embryos, and a lower pregnancy rate has been associated with transfer of frozen thawed bovine embryos. ${ }^{152}$ Additionally, the fact that these embryos were transgenic may also play a role in this pregnancy loss. Integration of the transgene cassette is random, and the location and number of integrations may negatively affect fetal survival. Although minimal integrations are desirable, Hofmann et al. (2006) demonstrated up to 20 integrations using lentiviral microinjection in porcine embryos. $^{154}$

A possible problem with this method is the possibility that embryos produced could be mosaic for expression of the transgene. Currently the majority of the embryos produced to date have been observed to be mosaic in GFP expression using fluorescent microscopy. Additionally, the two fetuses recovered using this method were negative for GFP expression by fluorescence microscopy. Mosaic incorporation of the transgene could limit expression in the fetal cells or even isolate it to the placental tissue. Additionally, it has been shown that fetuses produced through lentiviral microinjection can exhibit some silencing of the transgene in the F1 generation. ${ }^{154}$ This would result in lack of transgene expression. However, since the transgene was not found to be 
incorporated into the fetal tissue by qRT-PCR, the first explanation is more plausible. Also, the placental as well as one of the amnionic samples was positive for the transgene through qRT-PCR, demonstrating transgene incorporation into extraembryonic fetal tissues. Perhaps if embryos are removed from fertilization media at an earlier timepoint, lentiviral transduction could occur sooner, allowing for incorporation of the transgene prior to DNA replication. Therefore, although cleavage rates might be reduced, the frequency of mosaic embryos should decrease.

Conclusions

Both SCNT with transgenic cell line as well as lentiviral microinjection into the perivitelline space of zygotes were successful methods of transgenic embryo production. Cloning with a transgenic cell line resulted in a total of 37/43 transgenic blastocysts which were transferred into 14 recipients. Seven pregnancies were established by transfer of embryos produced through SCNT. One of these pregnancies was analyzed at 66 days gestation, and both of the live fetuses recovered were transgenic. Another pregnancy is still ongoing. Lentiviral microinjection of zygotes produced a total of 181 blastocysts, the majority of were confirmed to be transgenic through expression of GFP fluorescence. Transfer of 70 embryos into 21 synchronized recipients resulted in a total of nine pregnancies, four of which are still ongoing. Analysis of two fetuses recovered at 78 days revealed a lack of GFP expression by fluorescence microscopy and absence of the transgene cassette by qRT-PCR. However, placental and amnionic tissue from one of these fetuses did contain the transgene cassette. Therefore this fetus could have been 
mosaic for the transgene, with incorporation only into the cells that contribute to extraembryonic fetal tissues. Continued transfer of transgenic embryos using these methods should ensure production of animals transgenic for reduced myostatin expression through RNAi. 


\section{CHAPTER V}

\section{REPLICATION COMPETENT LENTIVIRUS (RCL) ANALYSIS IN RECIPIENT ANIMALS OF TRANSGENIC EMBRYOS PRODUCED BY LENTIVIRAL} TRANSFER

Introduction

Lentiviral-mediated transgene delivery provides a valuable tool for manipulating gene expression in vivo, as it allows the integration of transgenes into the genome for stable expression. ${ }^{27}$ However, the retroviral basis for these vectors has raised concern that recombination with wild-type viruses or endogenous retroviral elements may allow the integrated provirus genome to become replication competent. ${ }^{37,38}$ Safety measures that are currently used to ensure a replication-incompetent recombinant lentiviral particle is produced include a self-inactivating 3' LTR and separation of viral genes (gag, pol) from the transfer cassette during in vitro production. ${ }^{35,36}$ However, low levels of recombination between the transfer and packaging plasmids during lentiviral particle production have been detected. ${ }^{41,42}$ Although this recombination was insufficient to produce a replication competent lentivirus (RCL), additional validation of lentiviral vectors is clearly needed. ${ }^{41}$ Therefore, a crucial step in implementing the use of these vectors in transgenic animal production as well as human therapeutics is confirming the lack of RCL production by lentiviral vectors.

There are various methods for detecting potential RCL. One is the use of the p24 ELISA assay. This detects the presence of antigen to the p24 HIV capsid protein. This 
can be used to test the serum isolated from blood, and a positive result would indicate the presence of an RCL in the animal's system. ${ }^{40}$ In addition, any potential RCL present in either serum or in vitro cell culture media can be amplified using a permissive cell line to aid in detection. ${ }^{40}$ Other methods are PCR-based, which require strictly sterile conditions to prevent any false positive amplification. However, they can be much more sensitive in detection than an ELISA. One PCR target is amplification of VSV-G, which would indicate aberrant recombination during lentivirus production resulting in the ability of the lentiviral cassette to replicate and produce infective particles. Additionally, amplification of sequences such as gag or pol, which are normally not present in the transferred cassette, would indicate recombination between the packaging and transfer vectors during recombinant viral production. This recombination may indicate the ability of the transferred cassette to again become replication competent.

In order to evaluate the lentivirus in this experiment for possible RCL, animals that served as recipients for transgenic embryos were analyzed. This included both bovine and ovine recipients. Tissues and blood were collected from animals that were sacrificed and these were analyzed for RCL using both the p24 ELISA and qRT-PCR to detect VSV-G. In addition, when possible fetal and placental samples were also analyzed for the presence of RCL. A lack of detection in recipient animals will build confidence in the safety of using lentiviral-mediated transgene delivery in both transgenic animal production and human medicine. 
Materials and Methods

Production and transfer of transgenic embryos

Three methods were used for producing transgenic embryos for transfer. The first two were somatic cell nuclear transfer cloning with a transduced bovine fetal fibroblast cell line and microinjection of in vitro produced bovine zygotes with concentrated lentivirus (Chapter IV, Materials and Methods). The third was incubation of in vivoproduced hatched ovine blastocysts in culture media containing infectious recombinant lentiviral particles. For ovine blastocyst infection, lentivirus was produced and concentrated in Dr. Thomas Spencer's laboratory by Dr. Joanne Fleming using the pEIZ lentiviral plasmid. Concentrated lentiviral particles were resuspended in $20 \mu 1 \mathrm{G} 2$ v.5 culture media (Vitrolife) and frozen until needed. In vivo produced ovine hatched blastocysts were flushed on day 8 from donor animals and incubated either 6 hours or overnight in $100 \mu \mathrm{l}$ drops of lentiviral media supplemented with $8 \mu \mathrm{g} / \mathrm{mL}$ polybreen and overlayed with mineral oil. Following incubation, embryos were washed through G2 v.5 culture media before being transferred into synchronized sheep recipients.

\section{Collection of tissues}

Sheep that received transgenic blastocysts were euthanized at various stages of gestation (day 15-day 60) with Buthanasia (10cc) intravenously. Cow recipients were first anesthetized, then stunned with a captive bolt and insanguinated. Depending on day of gestation, either elongated conceptuses or fetuses were recovered when possible. In addition, placental tissue including both placentomal and interplacentomal regions were collected. Placental tissue was matched to the corresponding fetus when possible in the 
case of multiple fetuses. Recipient tissues collected included blood, lung, lymph node, kidney, liver, mammary gland, ovary, skeletal muscle, spleen and uterus. Samples to be used for isolation of genomic DNA were cut into approximately 3-5mm pieces and one piece of tissue per sample was submerged in 0.5mL QIAGEN AllProtect reagent in a $1.5 \mathrm{~mL}$ centrifuge tube. Two tubes were collected for each sample, and one was sent to Dr. Kenneth Cornetta's laboratory at the University of Indiana Medical School in Indianapolis, Indiana. The other was kept at $-80^{\circ} \mathrm{C}$ at the Reproductive Sciences Laboratory at Texas A\&M University. Samples to be collected for RNA and protein analysis, two per tissue, were snap frozen in liquid nitrogen in a $1.2 \mathrm{~mL}$ cryotube and then stored at $-80^{\circ} \mathrm{C}$. Muscle and skin tissue were collected for cell culture and cryopreserved in DMEM/F12 media supplemented with FBS, gentamicin, and 10\% dimethylsulfoxide. Blood samples were taken intravenously prior to sacrifice and collected in both serum and heparinized or EDTA-treated collection tubes. Additionally, cross-sectional samples were taken of both uterine and placental tissue and were preserved for future immunohistochemistry analysis by two methods. The first involved embedding the tissue in OCT reagent and floating on liquid nitrogen to harden. These samples were then kept at $-80^{\circ} \mathrm{C}$ until needed. The other was preservation in a $4 \%$ paraformaldehyde solution. Analysis of tissues for RCL

Blood and tissue samples collected in QIAGEN AllProtect reagent were sent on the day of collection overnight to Dr. Kenneth Cornetta's laboratory. There, genomic DNA was isolated from both blood and tissues for PCR using the QIAmp DNA mini kit 
(QIAGEN), and serum was isolated from whole blood for p24 ELISA analysis.

Quantitative real-time PCR (qRT-PCR) was performed on genomic DNA to detect VSV-

$\mathrm{G}$ and the lentiviral cassette. Results were analyzed as previously described. ${ }^{41}$

\section{Immunohistochemistry}

Uterine tissue cross-sections embedded in OCT reagent were cut on a cryostat to a thickness of $8 \mu \mathrm{m}$. Slides were fixed with cold methanol for 10 minutes and then allowed to air dry. Sections were circled with a PAP pen and then rinsed 4-5 times in PBS with $0.3 \%$ Tween-20. Slides were shook dry and then incubated in $60 \mu \mathrm{l}$ blocking buffer (1:10 dilution of goat serum in PBS-Tween with 1\% BSA plus glycerol) for one hour. Slides were rinsed in PBS-Tween and shaken dry before addition of the primary antibody. A primary antibody against GFP (mouse anti-GFP, catalog no.11814460001, 1:200) or blocking buffer (no primary control) was added in a $60 \mu \mathrm{l}$ volume, and slides were incubated overnight at $4^{\circ} \mathrm{C}$. The next day, slides were rinsed in PBS-Tween 3 times for 10 minutes each. Secondary antibody, fluorescein-conjugated goat anti-rabbit IgG, was added in a $60 \mu \mathrm{l}$ volume (1:250, AlexaFluor 488 goat anti-rabbit IgG, Invitrogen), and slides were incubated for one hour. After rinsing 3 times in PBS-Tween and then in distilled water, a drop of Prolong Gold Antifade with DAPI (company) was added to each section before covering with a coverslip. Slides were sealed with clear nailpolish and stored overnight in the dark before imaging. Digital photomicrographs of immunofluorescence staining were evaluated by Dr. Kathrin Dunlap using an Axioplan 2 microscope (Carl Zeiss, Thornwood, NY) interfaced with an Axiocam HR digital camera and Axiovision 4.1 software (Carl Zeiss). 
Results

Analysis offetuses

Fetuses from four bovine recipients were collected for analysis. At the time of tissue collection, samples of fetal and placental tissue were analyzed using fluorescence microscopy. A total of eight fetuses were recovered, six of which were produced through SCNT and two through lentiviral microinjection. Five of the fetuses produced through SCNT were found to be positive for the transgene cassette by qRT-PCR. Placental tissue from these same five fetuses, as well as placental and amnionic tissue from one of the fetuses produced through microinjection, were also positive for the transgene cassette through qRT-PCR (Table 3, Chapter IV). Blood was collected from three SCNT fetuses collected at day 105 of gestation, and blood serum was analyzed by p24 ELISA following amplification on the permissive cell line, C8166. Serum was negative for RCL by p24 analysis for all three fetuses (Table 4). In addition, all fetal and placental samples collected were analyzed by qRT-PCR for the presence of VSV-G and were negative (Table 4).

A total of nine fetuses and one conceptus was recovered from ovine recipients, and all of these were collected for analysis. One of the fetuses collected was a nontransgenic control fetus. The conceptus sample, taken at day 15 of gestation, was positive for GFP expression when visualized for fluorescence by microscopy (Figure 14). In addition, placental samples taken from the other transgenic fetuses were also positive for GFP. However, placental tissues revealed a mosaic pattern of GFP expression, with both transgenic and nontransgenic cells present. Fetal tissue from 
Table 4 Analysis of bovine and ovine recipients and fetuses for RCL using qRT-PCR to detect the VSV-G gene sequence and the p24 ELISA assay

\begin{tabular}{|c|c|c|c|c|}
\multicolumn{1}{c}{} & $\begin{array}{c}\text { \# tested for } \\
\text { VSVG }\end{array}$ & $\begin{array}{c}\text { \# positive } \\
\text { for VSVG }\end{array}$ & $\begin{array}{c}\text { \# tested } \\
\text { for } \mathrm{p} 24\end{array}$ & $\begin{array}{c}\text { \# positive } \\
\text { for } \mathrm{p} 24\end{array}$ \\
\hline $\begin{array}{c}\text { Bovine } \\
\text { Recipients }\end{array}$ & 4 & 0 & 3 & 0 \\
\hline $\begin{array}{c}\text { Bovine } \\
\text { Fetuses }\end{array}$ & 8 & 0 & 3 & 0 \\
\hline $\begin{array}{c}\text { Ovine } \\
\text { Recipients }\end{array}$ & 9 & 0 & 9 & 0 \\
\hline $\begin{array}{c}\text { Ovine } \\
\text { Fetuses }\end{array}$ & 1 & 0 & 0 & 0 \\
\hline
\end{tabular}

A)
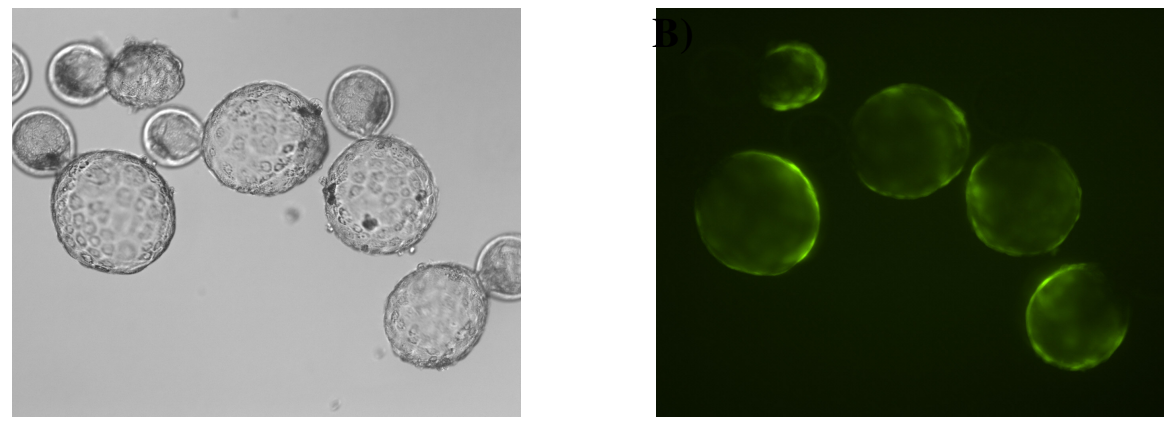

C)

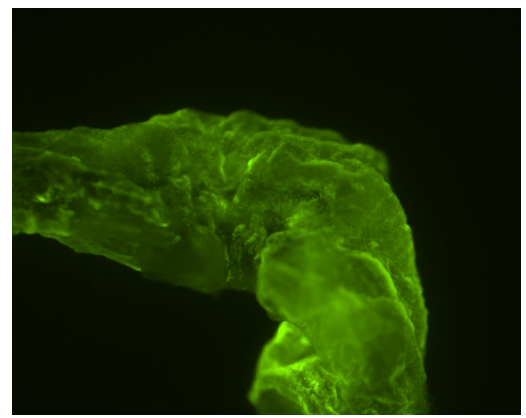

Figure 14 Transgenic ovine blastocysts and conceptus. (A,B) Blastocysts were hatched in vitro and incubated in culture media with recombinant lentivirus for 6 hours prior to transfer. A) brightfield image, B) fluorescent image. C) Ovine conceptus that was recovered at day 15 of gestation, fluorescent image. 
transgenic fetuses were inconclusive for fluorescence by microscopy due to autofluorescence detection. One fetus to date has been analyzed for incorporation of the transgene cassette through qRT-PCR and was negative. However, the placental tissue was positive for the transgene cassette. This same fetus was also analyzed for VSV-G through qRT-PCR and was also negative (Table 4). All fetuses recovered were too small for blood to be collected for p24 ELISA analysis.

\section{Analysis of recipients}

A summary of the recipient data is listed in Tables 4 and 5. Thirteen out of the fourteen recipient animals, including both bovine and ovine, were analyzed using the p24 ELISA assay for presence of p24 antigen in the serum. No positive samples were found (all $<12.5 \mathrm{pg} / \mathrm{mL}$ ). Peripheral blood samples were analyzed using qRT-PCR for presence of VSV-G for all fourteen animals, and no positive samples were found when compared to appropriate positive and negative controls. To date, tissue samples have been analyzed as well for VSV-G for nine of the fourteen recipients, and no positive samples were found. However, one ovine recipient revealed positive incorporation of the transgene cassette in the placentomal tissue (Table 5). This is not unexpected as the placentome consists of both fetal and maternal tissues, and the fetal tissue was also positive for the transgene cassette. In addition, both bovine recipients had positive incorporation in uterine tissue. One of the bovine recipients showed a positive result for both the interplacentomal region as well as caruncular uterine tissue samples, whereas another only showed positive incorporation of the transgene cassette in the caruncular tissue (Table 5). 
Table 5 Analysis of different tissues collected from bovine and ovine recipients for presence of the lentiviral transgene cassette

\begin{tabular}{|c|c|c|c|c|c|c|c|c|c|c|c|}
\hline & $\begin{array}{c}\text { P } \\
\text { B }\end{array}$ & Liver & Lung & Kidney & $\begin{array}{c}\text { Lymph } \\
\text { Node }\end{array}$ & $\begin{array}{c}\text { Skeletal } \\
\text { Muscle }\end{array}$ & $\begin{array}{c}\text { Mammary } \\
\text { Gland }\end{array}$ & Ovary & Uterus & Placentome & Caruncle \\
\hline $\begin{array}{c}\text { Bovine } \\
\text { recipients }\end{array}$ & 4 & 4 & 4 & 4 & 4 & 4 & 4 & 4 & 4 & 0 & 1 \\
\hline $\begin{array}{c}\# \\
\text { positive }\end{array}$ & 0 & 0 & 0 & 0 & 0 & 0 & 0 & 0 & 2 & 0 & 1 \\
\hline $\begin{array}{c}\text { Ovine } \\
\text { recipients }\end{array}$ & 9 & 5 & 5 & 5 & 5 & 5 & 5 & 5 & 5 & 1 & 0 \\
\hline $\begin{array}{c}\# \\
\text { positive }\end{array}$ & 0 & 0 & 0 & 0 & 0 & 0 & 0 & 0 & 0 & 1 & 0 \\
\hline
\end{tabular}

$\mathrm{PB}=$ peripheral blood

Immunohistochemistry analysis was performed for presence of the GFP protein in one bovine sample of uterine tissue. This sample was from the recipient that carried three cloned transgenic fetuses. This tissue sample contained both placental and maternal uterine luminal epithelium and stroma. Staining with an anti-GFP antibody revealed the presence of GFP in the placental tissue as well as the syncitia formed between the placental trophectoderm and maternal luminal epithelial cells (Figure 15). However, no GFP was found in the uterine stroma in this sample. No placentomes were present in the sample, most likely due to the fact that the pregnancy was established with cloned embryos. 


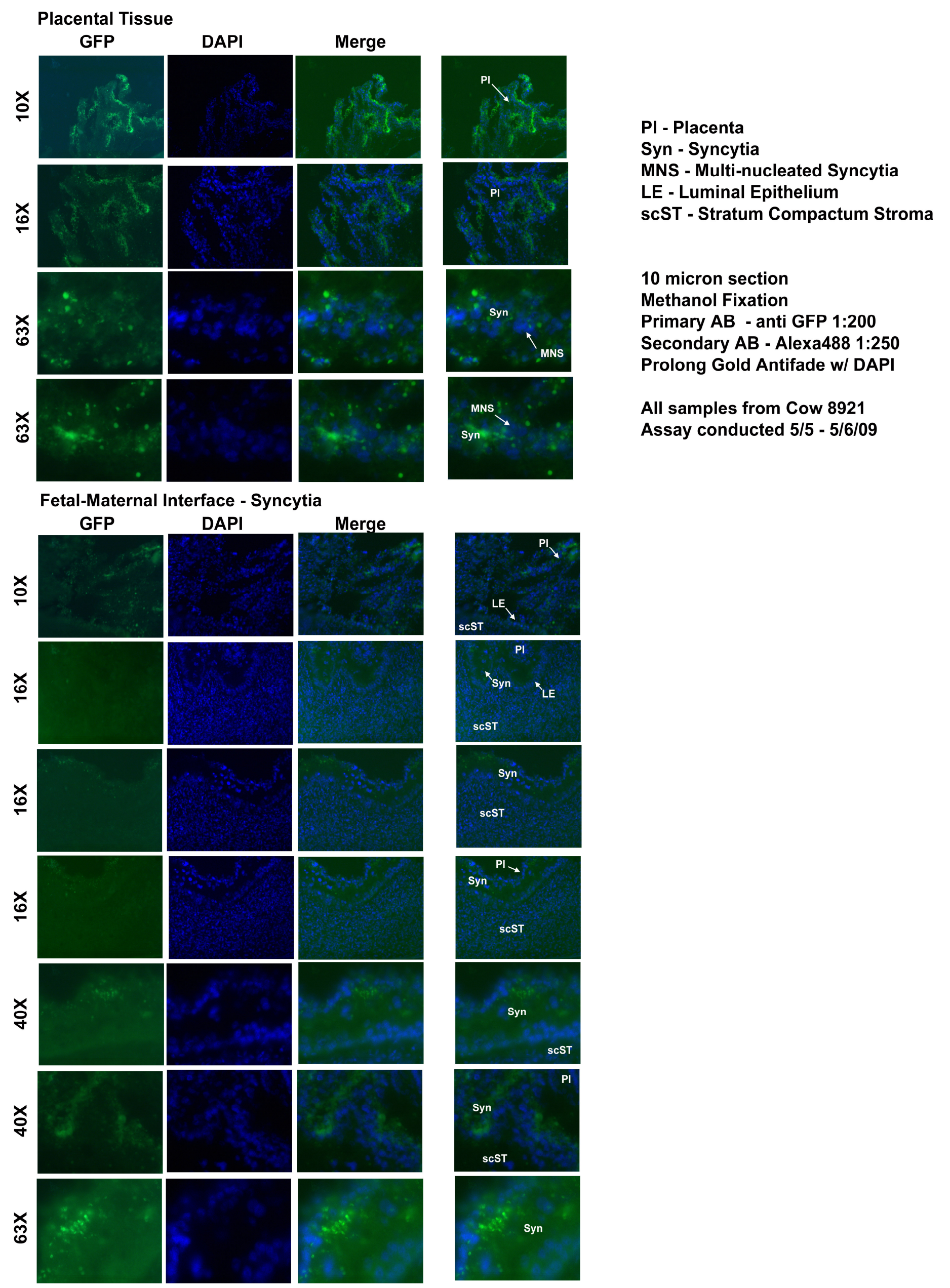

Figure 15 Immunohistochemistry for GFP at the uterine and placental interface. Tissue was recovered from a cloned transgenic pregnancy at day 66 of gestation. Immunohistochemistry was performed using an antibody against the GFP protein green $=$ GFP, blue $=$ DAPI nuclear counterstain. 


\section{Discussion}

Detection of potential RCL is of vital importance for applications involving lentiviral-mediated gene transfer for both transgenic animal production as well as human gene therapies. The establishment of these lentiviral plasmids as being replication incompetent will instill confidence in the safety of using these vectors for therapeutics in human diseases as well as the production of transgenic livestock. This work focused on the detection of RCL both in the developing transgenic fetus as well the recipient female. Detection of RCL in either would indicate that the replication-incompetent viral cassette somehow regained the ability to replicate in vivo, raising concern for use of these vectors in transgenic livestock production.

A total of eight fetuses were recovered from four bovine recipients. These fetuses were produced either by SCNT cloning with a cell line that was transduced with a recombinant lentivirus or through microinjection with recombinant lentivirus. None of the fetal samples were found to be positive for RCL using qRT-PCR for detection of VSV-G incorporation. Analysis of three fetuses recovered at day 105 of gestation using p24 ELISA also was negative. Therefore no RCL was detected in these fetuses.

There were 9 conceptuses recovered from ovine recipients of hatched blastocysts, 8 of which were incubated in culture media containing recombinant lentivirus. All embryos that were treated with the lentivirus were confirmed transgenic by fluorescence microscopy prior to transfer (Figure 14). The conceptus recovered at day 15 of gestation was expressing the transgene (Figure 14), and placental tissue from all of the remaining pregnancies were also expressing the transgene as confirmed by fluorescence 
microscopy . Only one fetus has been analyzed to date using qRT-PCR for VSV-G. This fetus was found to be negative for VSV-G, indicating that no RCL was present in this animal.

Of the four bovine recipients analyzed in this study, three were examined for the RCL using the p24 assay, and all three were negative. This further supports these plasmids as being replication-incompetent. Analysis of all four recipients by qRT-PCR revealed no incorporation of the transgene casssette in any of the tissues analyzed except for the uterine caruncular tissue. Two recipients were positive for the transgene cassette in this tissue; however, since both of the pregnancies carried by these recipients were failing and did not have a tight caruncular-cotylendonary connection, placental tissue remnants on the caruncle may have produced this result. All of the bovine recipients were negative for VSV-G by qRT-PCR, and three have been analyzed for p24 and deemed negative by comparison to positive and negative control samples. This supports the theory that the lentiviral constructs used in these experiments were replicationincompetent.

Ten ovine recipients were analyzed by p24 ELISA, and no positive samples were found. In addition, all of these recipients have been analyzed for VSV-G by qRT-PCR and no positive amplification has been detected. However, one uterine sample was found to be positive for transgene incorporation by qRT-PCR. Again, due to the fact that the placental sample in this animal was positive, residual tissue of any amount on the analyzed uterine tissue would have resulted in a positive amplification. Therefore this is most likely not due to the presence of an RCL in this animal. 
Conclusions

In these experiments, animals that served as surrogates for transgenic embryos produced using a recombinant lentivirus were analyzed for the presence of RCL. In all cases analyzed to date, no evidence of RCL has been detected by both p24 ELISA and qRT-PCR analysis for VSV-G incorporation. Detection of the transgene in uterine tissue from two bovine recipients and one ovine recipient may reflect the sensitivity of qRTPCR based methods in amplifying any residual fetal tissue at the maternal-fetal interface. Although the analyses performed support our lentivirus as being replication incompetent, accumulation of additional samples is needed. Previous issues regarding the production of RCR during construction of retroviral vectors have prompted the FDA to recommend testing for RCL by the methods used in this experiment for any work involving lentivial vectors for transgene delivery. Safety in development of gene therapies as well as transgenic livestock production is imperative for the transition of this technology from the lab to practical applications in human medicine and animal agriculture. Further analyses need to be performed in order to build confidence in the use of these lentiviral vectors in transgenic research and livestock development. 


\section{CHAPTER VI}

\section{SUMMARY}

The goal of this research was to reduce myostatin gene expression in livestock species using RNA interference, thereby demonstrating the usefulness of RNAi as a tool for manipulating gene expression in vivo. The in vitro experiments described effectively demonstrated a reduction of bovine and goat myostatin using siRNAs designed against regions of sequence identity between these two species. The siRNAs were successful in suppressing mRNA expression both when introduced as an siRNA or when expressed from a lentiviral plasmid as an shRNA. The siRNA sequence shown to be the most effective at suppressing myostatin mRNA in vitro, GDF8-1026, was chosen for evaluation in an in vivo setting using a recombinant lentiviral plasmid (PG1026).

The expression of shRNAs in vivo has been previously shown to sometimes cause off-target effects such as organ toxicity and reduced expression of nontarget genes. Therefore, the possibility of tissue-specific expression of shRNAs in vivo utilizing skeletal muscle-specific promoters was investigated. The bovine myogenin and MCK promoter sequences were isolated from genomic DNA and analyzed for their ability to drive GFP expression in both bovine fetal muscle and C2C12 mouse cell lines. Myotube specific expression of GFP was seen in bovine fetal muscle cells induced to differentiate after transduction with a construct containing the myogenin promoter. This same experiment with the MCK promoter also resulted in GFP expression in bovine fetal muscle cells but did not show myotube specific expression of GFP. A significant 
difference in mean intensity of GFP in transduced cells when compared to the nontransgenic control on day 9 post differentiation confirmed the activity of these promoters in vitro. However, further characterization of these promoters needs to be performed prior to their use for in vivo expression of shRNAs in skeletal muscle.

Two methods of transgenic animal production using lentiviral-mediated gene transfer were investigated in this work, SCNT with a transgenic cell line and microinjection of concentrated lentivirus into the perivitelline space of zygotes. Cloning resulted in a total of 43 blastocysts, 37 of which were confirmed to express GFP prior to embryo transfer. Transfer of these embryos into 14 synchronized bovine recipients established seven pregnancies, one of which is still ongoing. Lentiviral microinjection of zygotes produced a total of 181 blastocysts, the majority of were confirmed to be transgenic through expression of GFP fluorescence. Transfer into 21 synchronized recipients resulted in a total of 9 pregnancies, 4 of which are still ongoing. Analysis of fetuses from a cloned pregnancy terminated at 66 days revealed GFP expression in both fetal and placental tissues. Analysis of fetuses produced by lentiviral microinjection were negative for GFP expression by fluorescence microscopy as well as incorporation of the transgene cassette by qRT-PCR. However, placental and amnionic tissue from one of these fetuses was positive for incorporation of the transgene using qRT-PCR.

Therefore this fetus was mosaic for the transgene.

In the experiments outlined above as well as related experiments utilizing ovine recipients, animals that served as surrogates for transgenic embryos produced using a recombinant lentivirus were analyzed for the presence of RCL. In all cases analyzed to 
date, no evidence of RCL has been detected by both p24 ELISA and qRT-PCR analysis for VSV-G incorporation. Detection of the transgene cassette in uterine tissue from two bovine recipients and one ovine recipient may reflect the sensitivity of qRT-PCR based methods in amplifying genomic DNA from any residual fetal tissue at the maternal-fetal interface. These results help confirm that the lentivirus used in these studies as being replication incompetent. However, further accumulation and testing of samples is needed. 


\section{REFERENCES}

1. Mittal V. Improving the efficiency of RNA interference in mammals. Nat Rev Genet 2004; 5: 355-365.

2. Sledz CA, Williams BR. RNA interference in biology and disease. Blood 2005; 106: $787-794$.

3. Fire A, Xu S, Montgomery MK, Kostas SA, Driver SE, Mello CC. Potent and specific genetic interference by double-stranded RNA in Caenorhabditis elegans. Nature 1998; 391: 806-811.

4. Kennerdell JR, Carthew RW. Use of dsRNA-mediated genetic interference to demonstrate that frizzled and frizzled 2 act in the wingless pathway. Cell 1998; 95: 1017-1026.

5. Romano N, Macino G. Quelling: transient inactivation of gene expression in Neurospora crassa by transformation with homologous sequences. Mol Microbiol 1992; 6: 3343-3353.

6. Chuang CF, Meyerowitz EM. Specific and heritable genetic interference by double-stranded RNA in Arabidopsis thaliana. Proc Natl Acad Sci U S A 2000; 97: 4985-4990.

7. Wianny F, Zernicka-Goetz M. Specific interference with gene function by double-stranded RNA in early mouse development. Nat Cell Biol 2000; 2: 70-75.

8. Napoli C, Lemieux C, Jorgensen R. Introduction of a chimeric chalcone synthase gene into petunia results in reversible co-suppression of homologous genes in trans. Plant Cell 1990; 2: 279-289.

9. Meister G, Landthaler M, Patkaniowska A, Dorsett Y, Teng G, Tuschl T. Human Argonaute 2 mediates RNA cleavage targeted by miRNAs and siRNAs. Mol Cell 2004; 15: 185-197. 
10. Valencia-Sanchez MA, Liu J, Hannon GJ, Parker R. Control of translation and mRNA degradation by miRNAs and siRNAs. Genes Dev 2006; 20: 515-524.

11. Yang M, Mattes J. Discovery, biology and therapeutic potential of RNA interference, microRNA and antagomirs. Pharmacol Ther 2008; 117: 94-104.

12. Brennecke J, Stark A, Russell RB, Cohen SM. Principles of microRNA-target recognition. PLoS Biol 2005; 3: e85.

13. Wightman B, Ha I, Ruvkun G. Posttranscriptional regulation of the heterochronic gene lin-14 by lin-4 mediates temporal pattern formation in C. elegans. Cell 1993; 75: 855-862.

14. Nakasa T, Ishikawa M, Shi M, Shibuya H, Adachi N, Ochi M. Acceleration of muscle regeneration by local injection of muscle-specific microRNAs in rat skeletal muscle injury model. J Cell Mol Med 2009.

15. Rao PK, Kumar RM, Farkhondeh M, Baskerville S, Lodish HF. Myogenic factors that regulate expression of muscle-specific microRNAs. Proc Natl Acad Sci U S A 2006; 103: 8721-8726.

16. Wang N, Zhou Z, Liao X, Zhang T. Role of microRNAs in cardiac hypertrophy and heart failure. IUBMB Life 2009; 61: 566-571.

17. Laurent LC. MicroRNAs in embryonic stem cells and early embryonic development. J Cell Mol Med 2008; 12: 2181-2188.

18. Wang Y, Keys DN, Au-Young JK, Chen C. MicroRNAs in embryonic stem cells. J Cell Physiol 2009; 218: 251-255.

19. Ruvkun G. Clarifications on miRNA and cancer. Science 2006; 311: 36-37.

20. Tong AW, Nemunaitis J. Modulation of miRNA activity in human cancer: a new paradigm for cancer gene therapy? Cancer Gene Ther 2008; 15: 341-355. 
21. Grishok A, Pasquinelli AE, Conte D, Li N, Parrish S, Ha I et al. Genes and mechanisms related to RNA interference regulate expression of the small temporal RNAs that control C. elegans developmental timing. Cell 2001; 106: 23-34.

22. Timmons L, Court DL, Fire A. Ingestion of bacterially expressed dsRNAs can produce specific and potent genetic interference in Caenorhabditis elegans. Gene 2001; 263: 103-112.

23. Sledz CA, Holko M, de Veer MJ, Silverman RH, Williams BR. Activation of the interferon system by short-interfering RNAs. Nat Cell Biol 2003; 5: 834-839.

24. Svoboda P. Off-targeting and other non-specific effects of RNAi experiments in mammalian cells. Curr Opin Mol Ther 2007; 9: 248-257.

25. Amarzguioui M, Rossi JJ, Kim D. Approaches for chemically synthesized siRNA and vector-mediated RNAi. FEBS Lett 2005; 579: 5974-5981.

26. Sandy P, Ventura A, Jacks T. Mammalian RNAi: a practical guide. Biotechniques 2005; 39: 215-224.

27. Manjunath N, Wu H, Subramanya S, Shankar P. Lentiviral delivery of short hairpin RNAs. Adv Drug Deliv Rev 2009; 61: 732-745.

28. Patil SD, Rhodes DG, Burgess DJ. DNA-based therapeutics and DNA delivery systems: a comprehensive review. AAPS J 2005; 7: E61-77.

29. Towne C, Aebischer P. Lentiviral and adeno-associated vector-based therapy for motor neuron disease through RNAi. Methods Mol Biol 2009; 555: 87-108.

30. Karnabi E, Qu Y, Mancarella S, Yue Y, Wadgaonkar R, Boutjdir M. Silencing of Cav1.2 gene in neonatal cardiomyocytes by lentiviral delivered shRNA. Biochem Biophys Res Commun 2009; 384: 409-414. 
31. Venugopal SK, Chen J, Zhang Y, Clemens D, Follenzi A, Zern MA. Role of MAPK phosphatase-1 in sustained activation of JNK during ethanol-induced apoptosis in hepatocyte-like VL-17A cells. J Biol Chem 2007; 282: 3190031908.

32. Lois C, Hong EJ, Pease S, Brown EJ, Baltimore D. Germline transmission and tissue-specific expression of transgenes delivered by lentiviral vectors. Science 2002; 295: 868-872.

33. Jahner D, Stuhlmann H, Stewart CL, Harbers K, Lohler J, Simon I et al. De novo methylation and expression of retroviral genomes during mouse embryogenesis. Nature 1982; 298: 623-628.

34. Dull T, Zufferey R, Kelly M, Mandel RJ, Nguyen M, Trono D et al. A thirdgeneration lentivirus vector with a conditional packaging system. J Virol 1998; 72: 8463-8471.

35. Miyoshi H, Blomer U, Takahashi M, Gage FH, Verma IM. Development of a self-inactivating lentivirus vector. $J$ Virol 1998; 72: 8150-8157.

36. Zufferey R, Dull T, Mandel RJ, Bukovsky A, Quiroz D, Naldini L et al. Selfinactivating lentivirus vector for safe and efficient in vivo gene delivery. $J$ Virol 1998; 72: 9873-9880.

37. Chong H, Starkey W, Vile RG. A replication-competent retrovirus arising from a split-function packaging cell line was generated by recombination events between the vector, one of the packaging constructs, and endogenous retroviral sequences. J Virol 1998; 72: 2663-2670.

38. Garrett E, Miller AR, Goldman JM, Apperley JF, Melo JV. Characterization of recombination events leading to the production of an ecotropic replicationcompetent retrovirus in a GP+envAM12-derived producer cell line. Virology 2000; 266: 170-179. 
39. Manilla P, Rebello T, Afable C, Lu X, Slepushkin V, Humeau LM et al. Regulatory considerations for novel gene therapy products: a review of the process leading to the first clinical lentiviral vector. Hum Gene Ther 2005; 16: $17-25$.

40. Escarpe P, Zayek N, Chin P, Borellini F, Zufferey R, Veres G et al. Development of a sensitive assay for detection of replication-competent recombinant lentivirus in large-scale HIV-based vector preparations. Mol Ther 2003; 8: 332-341.

41. Sastry L, Xu Y, Johnson T, Desai K, Rissing D, Marsh J et al. Certification assays for HIV-1-based vectors: frequent passage of gag sequences without evidence of replication-competent viruses. Mol Ther 2003; 8: 830-839.

42. Sastry L, Cornetta K. Detection of replication competent retrovirus and lentivirus. Methods Mol Biol 2009; 506: 243-263.

43. Scacheri PC, Rozenblatt-Rosen O, Caplen NJ, Wolfsberg TG, Umayam L, Lee JC et al. Short interfering RNAs can induce unexpected and divergent changes in the levels of untargeted proteins in mammalian cells. Proc Natl Acad Sci U S A 2004; 101: 1892-1897.

44. Fish RJ, Kruithof EK. Short-term cytotoxic effects and long-term instability of RNAi delivered using lentiviral vectors. BMC Mol Biol 2004; 5: 9.

45. Fedorov Y, Anderson EM, Birmingham A, Reynolds A, Karpilow J, Robinson K et al. Off-target effects by siRNA can induce toxic phenotype. RNA 2006; 12: 1188-1196.

46. Persengiev SP, Zhu X, Green MR. Nonspecific, concentration-dependent stimulation and repression of mammalian gene expression by small interfering RNAs (siRNAs). RNA 2004; 10: 12-18.

47. Tschuch C, Schulz A, Pscherer A, Werft W, Benner A, Hotz-Wagenblatt A et al. Off-target effects of siRNA specific for GFP. BMC Mol Biol 2008; 9: 60. 
48. Yi R, Doehle BP, Qin Y, Macara IG, Cullen BR. Overexpression of exportin 5 enhances RNA interference mediated by short hairpin RNAs and microRNAs. RNA 2005; 11: 220-226.

49. Grimm D, Streetz KL, Jopling CL, Storm TA, Pandey K, Davis CR et al. Fatality in mice due to oversaturation of cellular microRNA/short hairpin RNA pathways. Nature 2006; 441: 537-541.

50. McBride JL, Boudreau RL, Harper SQ, Staber PD, Monteys AM, Martins I et al. Artificial miRNAs mitigate shRNA-mediated toxicity in the brain: implications for the therapeutic development of RNAi. Proc Natl Acad Sci U S A 2008; 105: 5868-5873.

51. Miyata S, Matsuyama T, Kodama T, Nishioka Y, Kuribayashi K, Takeda K et al. STAT6 deficiency in a mouse model of allergen-induced airways inflammation abolishes eosinophilia but induces infiltration of CD8+ T cells. Clin Exp Allergy 1999; 29: 114-123.

52. Braun A, Trigatti BL, Post MJ, Sato K, Simons M, Edelberg JM et al. Loss of SR-BI expression leads to the early onset of occlusive atherosclerotic coronary artery disease, spontaneous myocardial infarctions, severe cardiac dysfunction, and premature death in apolipoprotein E-deficient mice. Circ Res 2002; 90: 270276.

53. Yoshida T, Maulik N, Engelman RM, Ho YS, Das DK. Targeted disruption of the mouse Sod I gene makes the hearts vulnerable to ischemic reperfusion injury. Circ Res 2000; 86: 264-269.

54. Couse JF, Korach KS. Reproductive phenotypes in the estrogen receptor-alpha knockout mouse. Ann Endocrinol (Paris) 1999; 60: 143-148.

55. Conneely OM, Mulac-Jericevic B, DeMayo F, Lydon JP, O'Malley BW. Reproductive functions of progesterone receptors. Recent Prog Horm Res 2002; 57: 339-355.

56. Nandi A, Kitamura Y, Kahn CR, Accili D. Mouse models of insulin resistance. Physiol Rev 2004; 84: 623-647. 
57. Casal M, Haskins M. Large animal models and gene therapy. Eur J Hum Genet 2006; 14: 266-272.

58. Zan Y, Haag JD, Chen KS, Shepel LA, Wigington D, Wang YR et al. Production of knockout rats using ENU mutagenesis and a yeast-based screening assay. Nat Biotechnol 2003; 21: 645-651.

59. Wolfe JH. Gene therapy in large animal models of human genetic diseases. Introduction. ILAR J 2009; 50: 107-111.

60. Tsai KL, Clark LA, Murphy KE. Understanding hereditary diseases using the dog and human as companion model systems. Mamm Genome 2007; 18: 444451 .

61. Nichols TC, Dillow AM, Franck HW, Merricks EP, Raymer RA, Bellinger DA et al. Protein replacement therapy and gene transfer in canine models of hemophilia A, hemophilia B, von Willebrand disease, and factor VII deficiency. ILAR J 2009; 50: 144-167.

62. Stieger K, Lheriteau E, Moullier P, Rolling F. AAV-mediated gene therapy for retinal disorders in large animal models. ILAR J 2009; 50: 206-224.

63. Yuasa K, Nakamura A, Hijikata T, Takeda S. Dystrophin deficiency in canine Xlinked muscular dystrophy in Japan (CXMDJ) alters myosin heavy chain expression profiles in the diaphragm more markedly than in the tibialis cranialis muscle. BMC Musculoskelet Disord 2008; 9: 1.

64. Hughes GC, Post MJ, Simons M, Annex BH. Translational physiology: porcine models of human coronary artery disease: implications for preclinical trials of therapeutic angiogenesis. J Appl Physiol 2003; 94: 1689-1701.

65. Welsh MJ, Rogers CS, Stoltz DA, Meyerholz DK, Prather RS. Development of a porcine model of cystic fibrosis. Trans Am Clin Climatol Assoc 2009; 120: 149162. 
66. Barry JS, Rozance PJ, Anthony RV. An animal model of placental insufficiencyinduced intrauterine growth restriction. Semin Perinatol 2008; 32: 225-230.

67. Salamone D, Baranao L, Santos C, Bussmann L, Artuso J, Werning C et al. High level expression of bioactive recombinant human growth hormone in the milk of a cloned transgenic cow. J Biotechnol 2006; 124: 469-472.

68. Gol'dman IL, Kadulin SG, Razin SV. [Transgenic goats in the world's pharmaceutical industry in the XXI century]. Genetika 2002; 38: 5-21.

69. Echelard Y, Williams JL, Destrempes MM, Koster JA, Overton SA, Pollock DP et al. Production of recombinant albumin by a herd of cloned transgenic cattle. Transgenic Res 2009; 18: 361-376.

70. Carver AS, Dalrymple MA, Wright G, Cottom DS, Reeves DB, Gibson YH et al. Transgenic livestock as bioreactors: stable expression of human alpha-1antitrypsin by a flock of sheep. Biotechnology (N Y) 1993; 11: 1263-1270.

71. Lavine G. FDA approves first biological product derived from transgenic animal. Am J Health Syst Pharm 2009; 66: 518.

72. Ekser B, Rigotti P, Gridelli B, Cooper DK. Xenotransplantation of solid organs in the pig-to-primate model. Transpl Immunol 2009; 21: 87-92.

73. Lai L, Park KW, Cheong HT, Kuhholzer B, Samuel M, Bonk A et al. Transgenic pig expressing the enhanced green fluorescent protein produced by nuclear transfer using colchicine-treated fibroblasts as donor cells. Mol Reprod Dev 2002; 62: 300-306.

74. Richt JA, Kasinathan P, Hamir AN, Castilla J, Sathiyaseelan T, Vargas F et al. Production of cattle lacking prion protein. Nat Biotechnol 2007; 25: 132-138.

75. Golding MC, Long CR, Carmell MA, Hannon GJ, Westhusin ME. Suppression of prion protein in livestock by RNA interference. Proc Natl Acad Sci U S A 2006; 103: 5285-5290. 
76. Wall RJ, Powell AM, Paape MJ, Kerr DE, Bannerman DD, Pursel VG et al. Genetically enhanced cows resist intramammary Staphylococcus aureus infection. Nat Biotechnol 2005; 23: 445-451.

77. Donovan DM, Kerr DE, Wall RJ. Engineering disease resistant cattle. Transgenic Res 2005; 14: 563-567.

78. Melo EO, Canavessi AM, Franco MM, Rumpf R. Animal transgenesis: state of the art and applications. J Appl Genet 2007; 48: 47-61.

79. Wagner TE, Hoppe PC, Jollick JD, Scholl DR, Hodinka RL, Gault JB. Microinjection of a rabbit beta-globin gene into zygotes and its subsequent expression in adult mice and their offspring. Proc Natl Acad Sci U S A 1981; 78: 6376-6380.

80. Denning C, Dickinson P, Burl S, Wylie D, Fletcher J, Clark AJ. Gene targeting in primary fetal fibroblasts from sheep and pig. Cloning Stem Cells 2001; 3: 221231.

81. Ramsoondar J, Vaught T, Ball S, Mendicino M, Monahan J, Jobst P et al. Production of transgenic pigs that express porcine endogenous retrovirus small interfering RNAs. Xenotransplantation 2009; 16: 164-180.

82. Ramsoondar JJ, Machaty Z, Costa C, Williams BL, Fodor WL, Bondioli KR. Production of alpha 1,3-galactosyltransferase-knockout cloned pigs expressing human alpha 1,2-fucosylosyltransferase. Biol Reprod 2003; 69: 437-445.

83. Kurome M, Ishikawa T, Tomii R, Ueno S, Shimada A, Yazawa H et al. Production of transgenic and non-transgenic clones in miniature pigs by somatic cell nuclear transfer. J Reprod Dev 2008; 54: 156-163.

84. Matsunari H, Onodera M, Tada N, Mochizuki H, Karasawa S, Haruyama E et al. Transgenic-cloned pigs systemically expressing red fluorescent protein, Kusabira-Orange. Cloning Stem Cells 2008; 10: 313-323. 
85. Cibelli JB, Stice SL, Golueke PJ, Kane JJ, Jerry J, Blackwell C et al. Cloned transgenic calves produced from nonquiescent fetal fibroblasts. Science 1998; 280: $1256-1258$.

86. Reggio BC, James AN, Green HL, Gavin WG, Behboodi E, Echelard Y et al. Cloned transgenic offspring resulting from somatic cell nuclear transfer in the goat: oocytes derived from both follicle-stimulating hormone-stimulated and nonstimulated abattoir-derived ovaries. Biol Reprod 2001; 65: 1528-1533.

87. Cabot RA, Kuhholzer B, Chan AW, Lai L, Park KW, Chong KY et al. Transgenic pigs produced using in vitro matured oocytes infected with a retroviral vector. Anim Biotechnol 2001; 12: 205-214.

88. Hofmann A, Kessler B, Ewerling S, Weppert M, Vogg B, Ludwig H et al. Efficient transgenesis in farm animals by lentiviral vectors. EMBO Rep 2003; 4: 1054-1060.

89. Ewerling S, Hofmann A, Klose R, Weppert M, Brem G, Rink K et al. Evaluation of laser-assisted lentiviral transgenesis in bovine. Transgenic Res 2006; 15: 447454.

90. Whitelaw CB, Lillico SG, King T. Production of transgenic farm animals by viral vector-mediated gene transfer. Reprod Domest Anim 2008; 43 Suppl 2: 355-358.

91. Hong SG, Kim MK, Jang G, Oh HJ, Park JE, Kang JT et al. Generation of red fluorescent protein transgenic dogs. Genesis 2009; 47: 314-322.

92. Pope CE, Crichton EG, Gomez MC, Dumas C, Dresser BL. Birth of domestic cat kittens of predetermined sex after transfer of embryos produced by in vitro fertilization of oocytes with flow-sorted sperm. Theriogenology 2009; 71: 864871.

93. Yin XJ, Lee HS, Yu XF, Choi E, Koo BC, Kwon MS et al. Generation of cloned transgenic cats expressing red fluorescence protein. Biol Reprod 2008; 78: 425431. 
94. Palmiter RD, Brinster RL, Hammer RE, Trumbauer ME, Rosenfeld MG, Birnberg NC et al. Dramatic growth of mice that develop from eggs microinjected with metallothionein-growth hormone fusion genes. Nature 1982; 300: 611-615.

95. Rubin EM, Barsh GS. Biological insights through genomics: mouse to man. $J$ Clin Invest 1996; 97: 275-280.

96. Roes J. Animal models in biomedical research: transgenesis and gene targeting. Br J Hosp Med 1997; 57: 410-411.

97. Wilmut I, Schnieke AE, McWhir J, Kind AJ, Campbell KH. Viable offspring derived from fetal and adult mammalian cells. Nature 1997; 385: 810-813.

98. Park KW, Kuhholzer B, Lai L, Machaty Z, Sun QY, Day BN et al. Development and expression of the green fluorescent protein in porcine embryos derived from nuclear transfer of transgenic granulosa-derived cells. Anim Reprod Sci 2001; 68: 111-120.

99. Park KW, Lai L, Cheong HT, Cabot R, Sun QY, Wu G et al. Mosaic gene expression in nuclear transfer-derived embryos and the production of cloned transgenic pigs from ear-derived fibroblasts. Biol Reprod 2002; 66: 1001-1005.

100. Hofmann A, Zakhartchenko V, Weppert M, Sebald H, Wenigerkind H, Brem G et al. Generation of transgenic cattle by lentiviral gene transfer into oocytes. Biol Reprod 2004; 71: 405-409.

101. Oback B. Climbing Mount Efficiency--small steps, not giant leaps towards higher cloning success in farm animals. Reprod Domest Anim 2008; 43 Suppl 2: 407-416.

102. Oback B, Wells DN. Cloning cattle: the methods in the madness. Adv Exp Med Biol 2007; 591: 30-57.

103. Farin CE, Farin PW, Piedrahita JA. Development of fetuses from in vitroproduced and cloned bovine embryos. J Anim Sci 2004; 82 E-Suppl: E53-62. 
104. Palmieri C, Loi P, Reynolds LP, Ptak G, Della Salda L. Placental abnormalities in ovine somatic cell clones at term: a light and electron microscopic investigation. Placenta 2007; 28: 577-584.

105. McPherron AC, Lawler AM, Lee SJ. Regulation of skeletal muscle mass in mice by a new TGF-beta superfamily member. Nature 1997; 387: 83-90.

106. McPherron AC, Lee SJ. Double muscling in cattle due to mutations in the myostatin gene. Proc Natl Acad Sci U S A 1997; 94: 12457-12461.

107. Berry C, Thomas M, Langley B, Sharma M, Kambadur R. Single cysteine to tyrosine transition inactivates the growth inhibitory function of Piedmontese myostatin. Am J Physiol Cell Physiol 2002; 283: C135-141.

108. Grobet L, Martin LJ, Poncelet D, Pirottin D, Brouwers B, Riquet J et al. A deletion in the bovine myostatin gene causes the double-muscled phenotype in cattle. Nat Genet 1997; 17: 71-74.

109. Schuelke M, Wagner KR, Stolz LE, Hubner C, Riebel T, Komen W et al. Myostatin mutation associated with gross muscle hypertrophy in a child. $N$ Engl J Med 2004; 350: 2682-2688.

110. Patel K, Amthor H. The function of myostatin and strategies of myostatin blockade-new hope for therapies aimed at promoting growth of skeletal muscle. Neuromuscul Disord 2005; 15: 117-126.

111. Walsh FS, Celeste AJ. Myostatin: a modulator of skeletal-muscle stem cells. Biochem Soc Trans 2005; 33: 1513-1517.

112. Bogdanovich S, Krag TO, Barton ER, Morris LD, Whittemore LA, Ahima RS et al. Functional improvement of dystrophic muscle by myostatin blockade. Nature 2002; 420: 418-421.

113. Rodino-Klapac LR, Haidet AM, Kota J, Handy C, Kaspar BK, Mendell JR. Inhibition of myostatin with emphasis on follistatin as a therapy for muscle disease. Muscle Nerve 2009; 39: 283-296. 
114. Boman IA, Klemetsdal G, Blichfeldt T, Nafstad O, Vage DI. A frameshift mutation in the coding region of the myostatin gene (MSTN) affects carcass conformation and fatness in Norwegian White Sheep (Ovis aries). Anim Genet 2009.

115. Clop A, Marcq F, Takeda H, Pirottin D, Tordoir X, Bibe B et al. A mutation creating a potential illegitimate microRNA target site in the myostatin gene affects muscularity in sheep. Nat Genet 2006; 38: 813-818.

116. Hickford JG, Forrest RH, Zhou H. Association between a g.+6723G-A SNP in the myostatin gene (MSTN) and carcass traits in New Zealand Texel sheep. $J$ Anim Sci 2009; 87: 1853.

117. Mosher DS, Quignon P, Bustamante CD, Sutter NB, Mellersh CS, Parker HG et al. A mutation in the myostatin gene increases muscle mass and enhances racing performance in heterozygote dogs. PLoS Genet 2007; 3: e79.

118. Shelton GD, Engvall E. Gross muscle hypertrophy in whippet dogs is caused by a mutation in the myostatin gene. Neuromuscul Disord 2007; 17: 721-722.

119. Zhu X, Hadhazy M, Wehling M, Tidball JG, McNally EM. Dominant negative myostatin produces hypertrophy without hyperplasia in muscle. FEBS Lett 2000; 474: 71-75.

120. Grobet L, Pirottin D, Farnir F, Poncelet D, Royo LJ, Brouwers B et al. Modulating skeletal muscle mass by postnatal, muscle-specific inactivation of the myostatin gene. Genesis 2003; 35: 227-238.

121. Thomas M, Langley B, Berry C, Sharma M, Kirk S, Bass J et al. Myostatin, a negative regulator of muscle growth, functions by inhibiting myoblast proliferation. J Biol Chem 2000; 275: 40235-40243.

122. Rios R, Carneiro I, Arce VM, Devesa J. Myostatin regulates cell survival during C2C12 myogenesis. Biochem Biophys Res Commun 2001; 280: 561-566. 
123. Joulia D, Bernardi H, Garandel V, Rabenoelina F, Vernus B, Cabello G. Mechanisms involved in the inhibition of myoblast proliferation and differentiation by myostatin. Exp Cell Res 2003; 286: 263-275.

124. Langley B, Thomas M, Bishop A, Sharma M, Gilmour S, Kambadur R. Myostatin inhibits myoblast differentiation by down-regulating MyoD expression. J Biol Chem 2002; 277: 49831-49840.

125. Magee TR, Artaza JN, Ferrini MG, Vernet D, Zuniga FI, Cantini L et al. Myostatin short interfering hairpin RNA gene transfer increases skeletal muscle mass. J Gene Med 2006; 8: 1171-1181.

126. McCroskery S, Thomas M, Maxwell L, Sharma M, Kambadur R. Myostatin negatively regulates satellite cell activation and self-renewal. J Cell Biol 2003; 162: 1135-1147.

127. McFarlane C, Hennebry A, Thomas M, Plummer E, Ling N, Sharma M et al. Myostatin signals through Pax7 to regulate satellite cell self-renewal. Exp Cell Res 2008; 314: 317-329.

128. Wagner KR, Liu X, Chang X, Allen RE. Muscle regeneration in the prolonged absence of myostatin. Proc Natl Acad Sci U S A 2005; 102: 2519-2524.

129. Deveaux V, Picard B, Bouley J, Cassar-Malek I. Location of myostatin expression during bovine myogenesis in vivo and in vitro. Reprod Nutr Dev 2003; 43: 527-542.

130. Cassar-Malek I, Langlois N, Picard B, Geay Y. Regulation of bovine satellite cell proliferation and differentiation by insulin and triiodothyronine. Domest Anim Endocrinol 1999; 17: 373-388.

131. Springer ML, Rando TA, Blau HM. Gene delivery to muscle. Curr Protoc Hum Genet 2002; 31: 13.4.1-13.4.19.

132. Rando TA, Blau HM. Primary mouse myoblast purification, characterization, and transplantation for cell-mediated gene therapy. J Cell Biol 1994; 125: 1275-1287. 
133. Endesfelder S, Bucher S, Kliche A, Reszka R, Speer A. Transfection of normal primary human skeletal myoblasts with p21 and p57 antisense oligonucleotides to improve their proliferation: a first step towards an alternative molecular therapy approach of Duchenne muscular dystrophy. J Mol Med 2003; 81: 355362.

134. Neuhuber B, Huang DI, Daniels MP, Torgan CE. High efficiency transfection of primary skeletal muscle cells with lipid-based reagents. Muscle Nerve 2002; 26: 136-140.

135. Benabdallah BF, Bouchentouf M, Rousseau J, Tremblay JP. Over-expression of follistatin in human myoblasts increases their proliferation and differentiation, and improves the graft success in SCID mice. Cell Transplant 2009.

136. Li S, Kimura E, Fall BM, Reyes M, Angello JC, Welikson R et al. Stable transduction of myogenic cells with lentiviral vectors expressing a minidystrophin. Gene Ther 2005; 12: 1099-1108.

137. Blanton JR, Jr., Bidwell CA, Sanders DA, Sharkey CM, McFarland DC, Gerrard DE et al. Plasmid transfection and retroviral transduction of porcine muscle cells for cell-mediated gene transfer. J Anim Sci 2000; 78: 909-918.

138. Sato F, Kurokawa M, Yamauchi N, Hattori MA. Gene silencing of myostatin in differentiation of chicken embryonic myoblasts by small interfering RNA. Am J Physiol Cell Physiol 2006; 291: C538-545.

139. Dunant P, Larochelle N, Thirion C, Stucka R, Ursu D, Petrof BJ et al. Expression of dystrophin driven by the $1.35-\mathrm{kb}$ MCK promoter ameliorates muscular dystrophy in fast, but not in slow muscles of transgenic mdx mice. Mol Ther 2003; 8: 80-89.

140. Johnson JE, Wold BJ, Hauschka SD. Muscle creatine kinase sequence elements regulating skeletal and cardiac muscle expression in transgenic mice. Mol Cell Biol 1989; 9: 3393-3399. 
141. Jaynes JB, Chamberlain JS, Buskin JN, Johnson JE, Hauschka SD. Transcriptional regulation of the muscle creatine kinase gene and regulated expression in transfected mouse myoblasts. Mol Cell Biol 1986; 6: 2855-2864.

142. Petropoulos CJ, Rosenberg MP, Jenkins NA, Copeland NG, Hughes SH. The chicken skeletal muscle alpha-actin promoter is tissue specific in transgenic mice. Mol Cell Biol 1989; 9: 3785-3792.

143. Wan H, He J, Ju B, Yan T, Lam TJ, Gong Z. Generation of two-color transgenic zebrafish using the green and red fluorescent protein reporter genes gfp and rfp. Mar Biotechnol (NY) 2002; 4: 146-154.

144. Muroya S, Nakajima I, Chikuni K. Sequential expression of myogenic regulatory factors in bovine skeletal muscle and the satellite cell culture. Animal Science Journal 2002; 73: 375-381.

145. Larochelle N, Lochmuller H, Zhao J, Jani A, Hallauer P, Hastings KE et al. Efficient muscle-specific transgene expression after adenovirus-mediated gene transfer in mice using a $1.35 \mathrm{~kb}$ muscle creatine kinase promoter/enhancer. Gene Ther 1997; 4: 465-472.

146. Takeshita F, Takase K, Tozuka M, Saha S, Okuda K, Ishii N et al. Muscle creatine kinase/SV40 hybrid promoter for muscle-targeted long-term transgene expression. Int J Mol Med 2007; 19: 309-315.

147. Jaenisch R, Fan H, Croker B. Infection of preimplantation mouse embryos and of newborn mice with leukemia virus: tissue distribution of viral DNA and RNA and leukemogenesis in the adult animal. Proc Natl Acad Sci U S A 1975; 72: 4008-4012.

148. Fukui Y. Effect of follicle cells on the acrosome reaction, fertilization, and developmental competence of bovine oocytes matured in vitro. Mol Reprod Dev 1990; 26: 40-46.

149. Younis AI, Brackett BG. Importance of cumulus cells and insemination intervals for development of bovine oocytes into morulae and blastocysts in vitro. Theriogenology 1991; 36: 11-21. 
150. Parrish JJ, Susko-Parrish JL, Leibfried-Rutledge ML, Critser ES, Eyestone WH, First NL. Bovine in vitro fertilization with frozen-thawed semen. Theriogenology 1986; 25: 591-600.

151. Karolewski BA, Watson DJ, Parente MK, Wolfe JH. Comparison of transfection conditions for a lentivirus vector produced in large volumes. Hum Gene Ther 2003; 14: 1287-1296.

152. Hasler JF, W.B. Henderson, P.J. Hurtgen, Z.Q. Jin, A.D. McCauley, S.A. Mower, B. Neely, L.S. Shuey, J.E. Stokes, S.A. Trimmer. Production, freezing and transfer of bovine IVF embryos and subsequent calving results.

Theriogenology 1995; 43: 141-152.

153. Keefer CL. Lessons learned from nuclear transfer (cloning). Theriogenology 2008; 69: 48-54.

154. Hofmann A, Kessler B, Ewerling S, Kabermann A, Brem G, Wolf E et al. Epigenetic regulation of lentiviral transgene vectors in a large animal model. $\mathrm{Mol}$ Ther 2006; 13: 59-66. 


\section{APPENDIX A}

Maps of lentiviral plasmids used

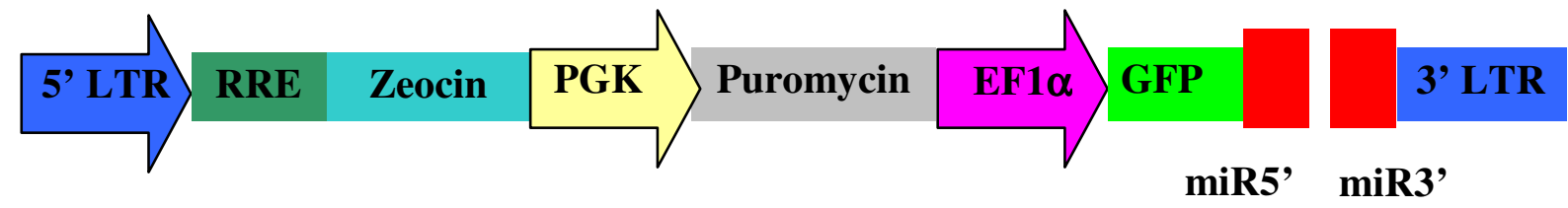

PEF-green lentiviral plasmid. LTR = long terminal repeat, RRE $=$ rev response element, PGK = phosphoglycerate kinase promoter, EF1 $\alpha=$ elongation factor 1 alpha promoter, eGFP = enhanced green fluorescent protein, $\mathrm{miR}=$ microRNA 30.
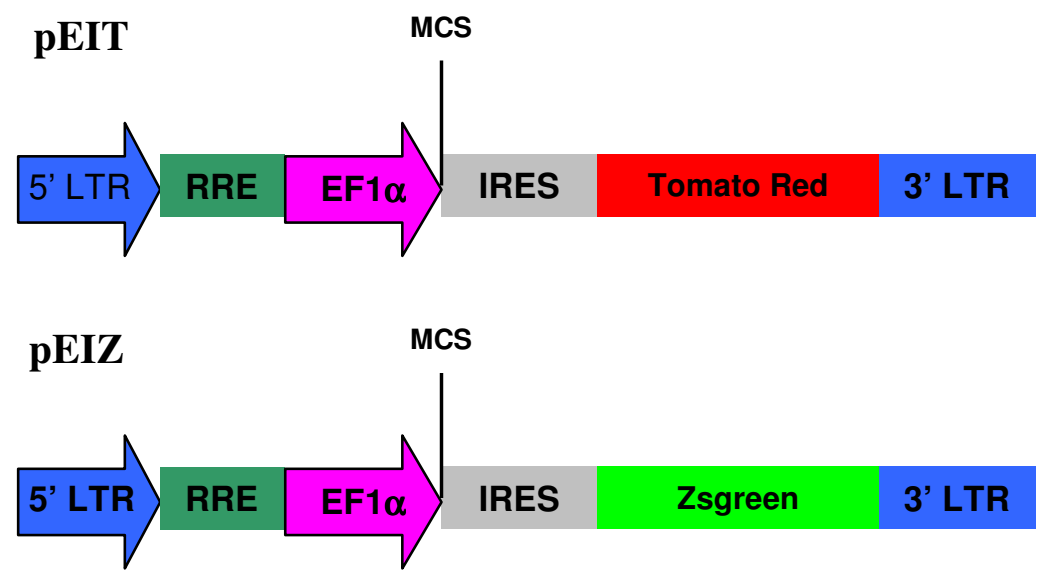

pEIT and pEIZ lentiviral plasmids. $L T R=$ long terminal repeat, $R R E=$ rev response element, EF1 $\alpha=$ elongation factor 1 alpha promoter, IRES = internal ribosomal entry site, Zsgreen and Tomato Red = fluorescent proteins. 


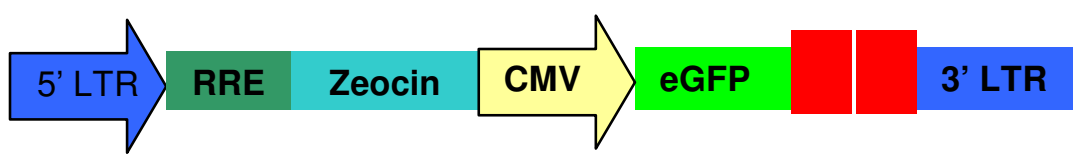

G-zeo lentiviral plasmid. LTR = long terminal repeat, RRE $=$ rev response element, $\mathrm{CMV}=$ cytomegalovirus promoter, $\mathrm{eGFP}=$ enhanced green fluorescent protein, $\mathrm{miR}=$ microRNA 30. 


\section{APPENDIX B}

Primer sequences used

\begin{tabular}{|c|c|c|c|}
\hline Gene/Promoter & Primer Name & Sequence & Size \\
\hline \multirow[t]{2}{*}{ shRNA } & 5'miR30PCRxho1F & cagaaggctcgagaaggtatattgctgttgacagtgagcg & 197bp \\
\hline & 3'miR30PCREcoR1F & ctaaagtagcccettgaattccgaggcagtaggca & \\
\hline \multirow{2}{*}{$\begin{array}{l}\text { goat, bovine } \\
\text { myostatin }\end{array}$} & GDF8_goat_bov_189F & acttcgcctggaaacagctcctaa & $417 b p$ \\
\hline & GDF8_goat_bov_605R & ataccagtgcctgggttcatgtca & \\
\hline \multirow{2}{*}{$\begin{array}{l}\text { goat, bovine } \\
\text { myostatin }\end{array}$} & RT_GDF8_goatboc_605F & tttggcagagcattgatgtga & $121 b p$ \\
\hline & RT_GDF8_goatbov_725R & gggaaggttacagcaagatcatg & \\
\hline \multirow[t]{2}{*}{ bovine myostatin } & RT_GDF8_bov_309F & cggctccttggaagacgat & 64bp \\
\hline & RT_GDF8_bov_372R & ctccgtgggcatggtaatg & \\
\hline \multirow[t]{2}{*}{ bovine GAPDH } & bov_GAPDH_forward & ggcattctaggctacact & $73 b p$ \\
\hline & bov_GAPDH_reverse & cgaaggtagaagagtgagt & \\
\hline \multirow[t]{2}{*}{ human GAPDH } & RT_gapdh_human_837F & ccaggtggtctcctctgacttc & $82 b p$ \\
\hline & RT_gapdh_human_918R & gtggtcgttgagggcaatg & \\
\hline \multirow{2}{*}{$\begin{array}{l}\text { bovine myogenin } \\
\text { promoter }\end{array}$} & bov_myogpr_190F & gtcagcagatgttggacaatggct & $1404 \mathrm{bp}$ \\
\hline & bov_myogprom_372R & ccatggatccagaagagacttgttcctgccacca & \\
\hline \multirow{2}{*}{$\begin{array}{c}\text { bovine MCK } \\
\text { promoter }\end{array}$} & bov_mck_prom_2F & ggacaggggtttgggttatc & $1567 \mathrm{bp}$ \\
\hline & bov_MCKpr_16R & tggaaggggetgtctgttatc & \\
\hline \multirow{2}{*}{$\begin{array}{l}\text { lentiviral } \\
\text { integration }\end{array}$} & Lenti F & acttgaaagcgaaagggaaac & 145bp \\
\hline & Lenti R & cacceatctctctcettctagcc & \\
\hline
\end{tabular}




\section{VITA}

Kimberly Jean Tessanne received her Bachelor of Science degree in agriculture from The Ohio State University in 1999. She entered the animal breeding and genetics program at the University of Wisconsin at Madison in August of 1999 and received her Master of Science degree in animal sciences in 2001. After two years working as a research assistant at the Plant-Microbe Genomics Facility at The Ohio State University (2003-2005), she entered the Department of Veterinary Physiology and Pharmacology at Texas A\&M University in August 2005. Her research interests include the production of large animal transgenics and isolation and use of adult stem cells in the treatment of human disorders.

Ms. Tessanne can be reached at the Reproductive Sciences Laboratory at Texas A\&M University, MS4466, College Station, TX 77843. Her email address is ktessanne@cvm.tamu.edu. 